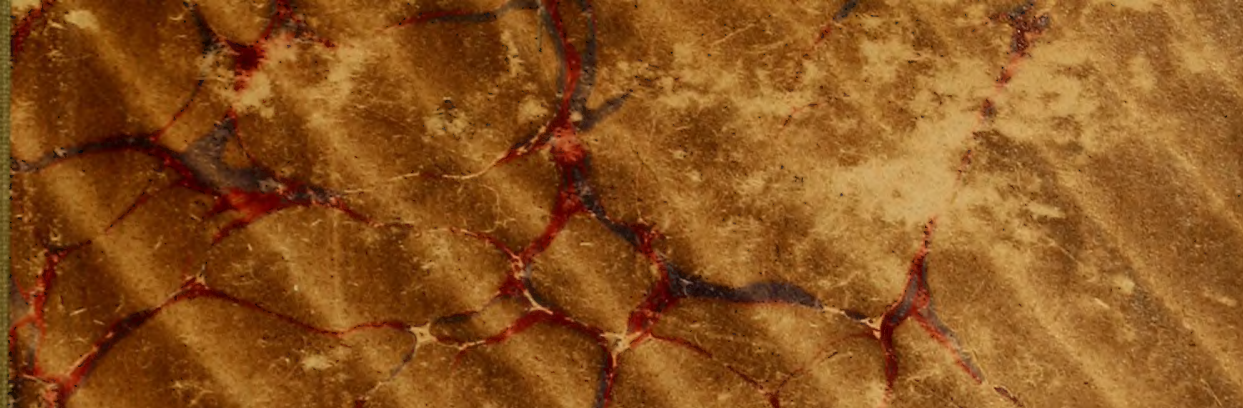

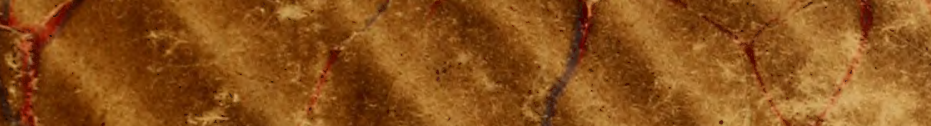

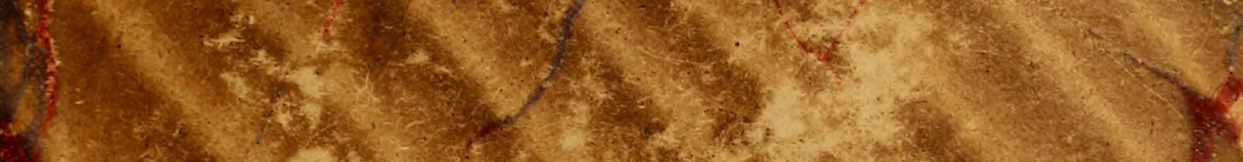

$4.8 \times x^{2}-5^{2}+2^{2}$

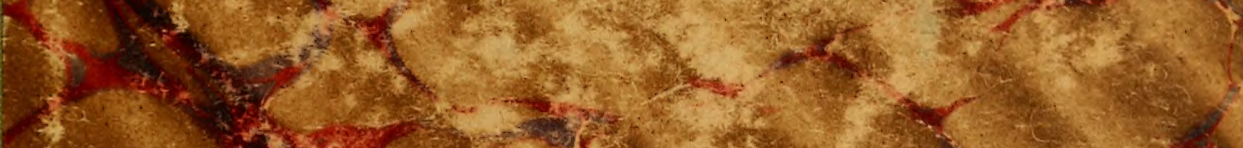

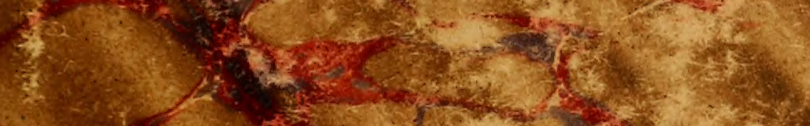

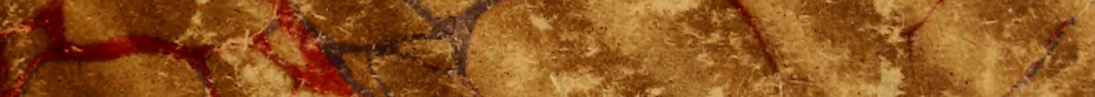

3.t.

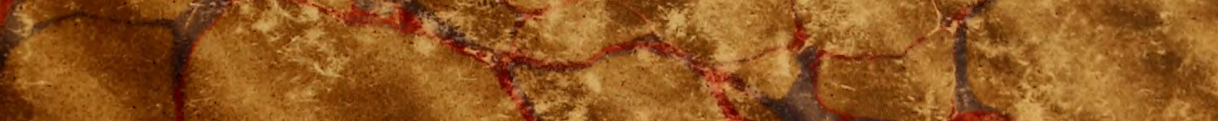

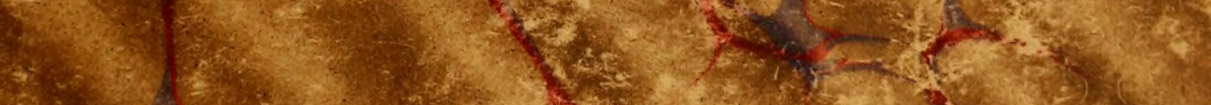

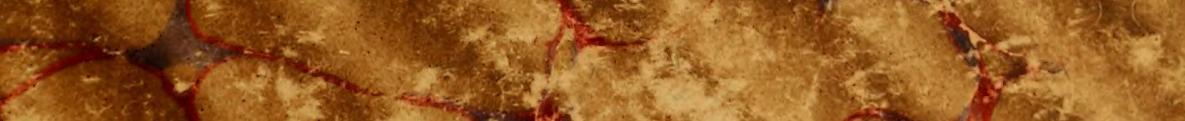

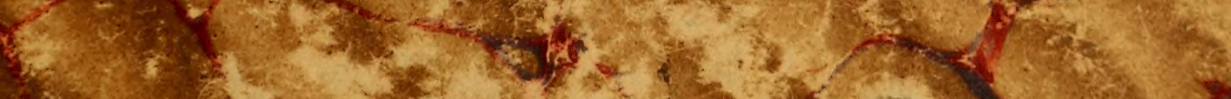

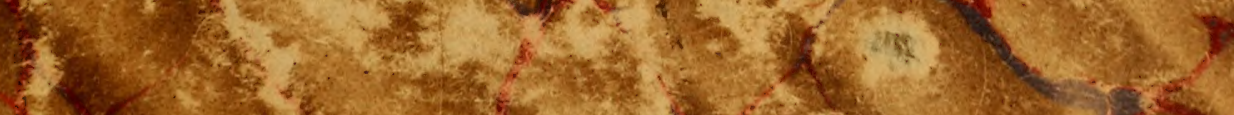

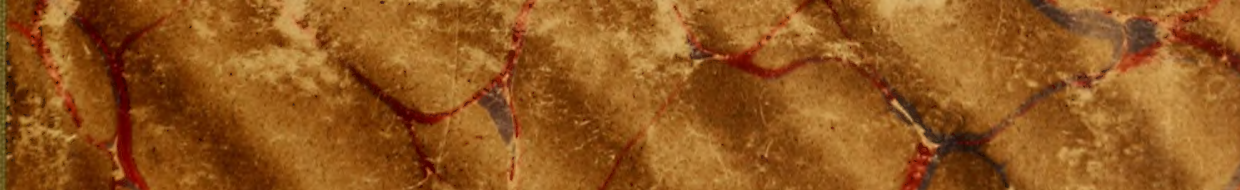

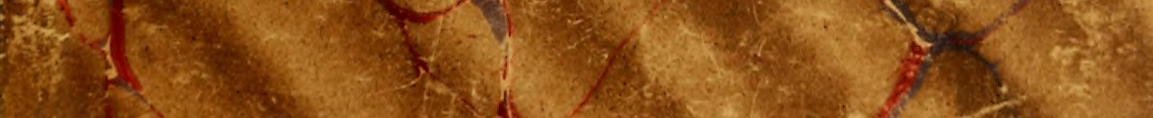

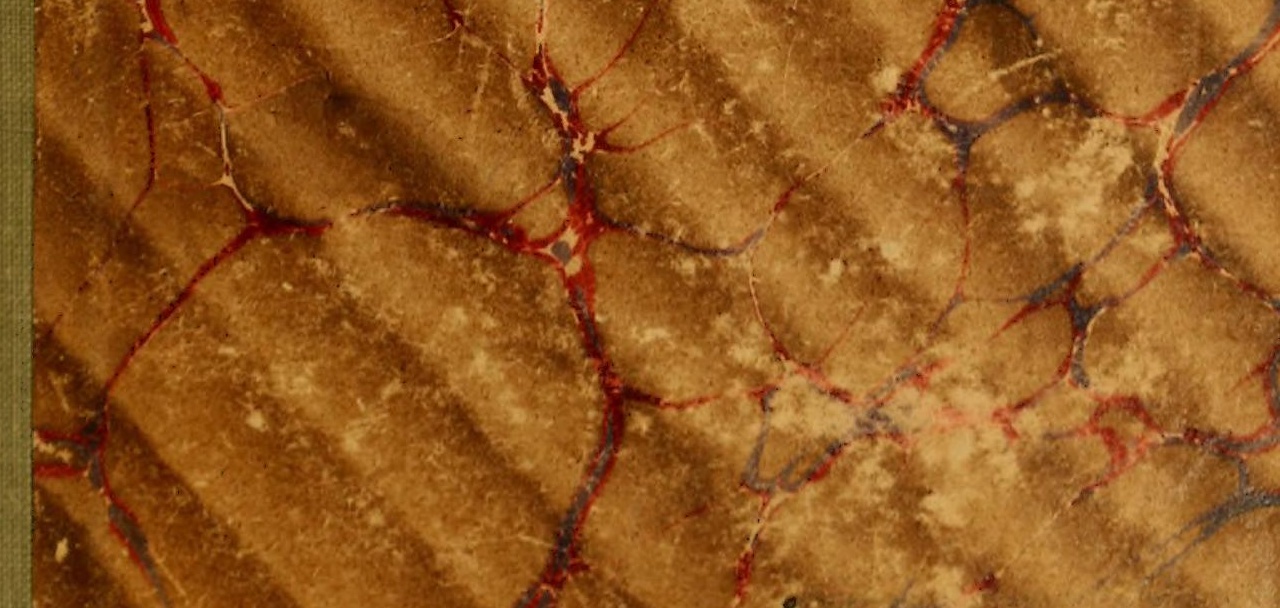





\section{DieSamenreifung beiden Planarien.}

Habilitationsschrift

zur

Erlangung der Venia legendi

der

Hohen philosophischen Fakultät

der

Albert-Ludwigs-Universität zu Freiburg i. Br.

vorgelegt von

Waldemar Schleip,

Dr. med, et phil.,

aus Freiburg i. Br.

Naumburg a. S.

Lippert \& Co. (G. Pätz'sche Buchdr.).

1907. 


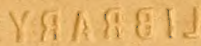

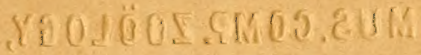

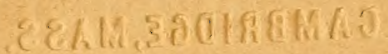




\title{
MAR 301923
}

\section{DieSamenreifung beiden Planarien.}

\section{Habilitationsschrift}

\author{
zur \\ Erlangung der Venia legendi \\ der
}

Hohen philosophischen Fakultät

der

Albert-Ludwigs-Universität zu Freiburg i. Br.

vorgelegt von

\section{Waldemar Schleip,}

Dr. med, et phil.,

aus Freiburg i. Br.

Naumburg a. S.

Lippert \& Co. (G. Pätz'sche Buchdr.).

1907. 


\section{Harvard College Library DEC 111907 \\ From the University \\ by exchance}

\section{2hendio to Mas, of Comp. Zooto}

A b d r u c k

aus den

Zoologischen Jahrbüchern. Bd. 24. Abt. f. Anatomie. 1907.

Herausgegeben von Prof. Dr. J. W. Spenget in Gießen.

Verlag von Gustar Fischer, Jena. 


\section{Die Samenreifung bei den Planarien.}

\section{Dr. Waldemar Schleip,}

Assistent am Zoologischen Institut in Freiburg i. Br.

Mit Tafel 1-2 und 2 Abbildungen im Text.

\section{Einleitung.}

Die fast unübersehbare Menge von Arbeiten über die Reifungsvorgänge in den männlichen und weiblichen Geschlechtszellen, welche sich seit etwa 25 Jahren auf zoologischem und botanischem Gebiet angehäuft haben, verdanken ihre Entstehung in der Hauptsache den beiden Fragen, ob die Reduction der Chromosomenzahl in den Geschlechtszellen auf die Hälfte der in den somatischen Zellen vorhandenen eine allgemeine Erscheinung sei und was für eine Bedeutung die Reduction besitze. Daß eine solche Verminderung der Chromosomenzahl auf die Hälfte bei der Reifung der Geschlechtszellen eintritt, wie es Weismans 1887 als theoretisches Postulat aufstellte, das haben in völliger Übereinstimmung alle bisherigen Beobachtungen ergeben. Darüber aber sind die Meinungen stets geteilt gewesen, ob diese Reduction bloß eine Halbierung der Chromatinmasse bedeutet oder eine Entfernung der halben Zahl dauernd individuell bestehender Einheiten, der Chromosomen. Es galt also zu untersuchen, ob die Chromosomen solche dauernd individuell bestehende Einheiten sind, oder ob sie nur aus einer jedes- 
maligen Neuordnung des Chromatins in gleicher Zahl wieder neu entstehen. Ferner erforderten gewisse theoretische Fragen der Vererbung die Feststellung, wie sich die Chromosomen bei der Reduction im genauern verhalten.

Bekanntlich hat erst vor kurzem Bover (1904) in seiner Zusammenfassung über die Konstitution des Chromatins alle Beweise, welche bisher für die "Theorie der Chromosomen-Individualität" erbracht worden sind, übersichtlich zusammengestellt und die letztere entschieden verteidigt. Und jetzt ist von der Mehrzahl der Autoren die Individualitätstheorie auch wohl anerkannt. Doch hat die Anschauung, daß die Chromosomen dauernd individuell bestehende Einheiten sind, bis auf den heutigen Tag noch viele Gegner, ich verweise nur auf den Aufsatz von Fick (1905). Daher sind, wie ich schon in meiner vorhergehenden Arbeit betonte, neue Untersuchungen zur sichern Feststellung dieser für die Bedeutung des Chromatins fundamentalen Frage sehr wünschenswert.

Die andere Frage, wie sich die Chromosomen im genauern bei den Reifungsteilungen verhalten, hat ebenfalls bis heute eine sehr verschiedene Beantwortung erfahren. Wenn auch Konschelt u. HeIDER (1902) in ihrem Lehrbuch der vergleichenden Entwicklungsgeschichte die verschiedenen Beobachtungen über Reifungsteilungen in 3 Kategorien zusammenfassen konnten, den eumitotischen und den pseudomitotischen Reifungsmodus, welch letzterer wieder in den Prä- und den Postreductionsmodus zerfällt, so zeigen sich doch innerhalb eines und desselben Reifungsmodus noch so beträchtliche Verschiedenheiten, daß von einem Verstehen der ganzen Vorgänge eigentlich noch nicht gesprochen werden kann. Zwei Reihen von Beobachtungen haben sich aber seit der Darstellung von Korschelt u. Heider auffällig gemehrt: Erstens die, daß nach neuern Beobachtungen der Präreductionsmodus anscheinend der häufigste ist und auch da vorkommt, wo man früher keine Reduction im Sinne Weismann's, sondern eine zweimalige Längsspaltung der Chromosomen fand; ich erinnere an die Wirbeltiere und an die Phanerogamen. Und die zweite immer häufiger gemachte Beobachtung ist die paarweise Vereinigung, die sog. „Conjugation“ zweier Chromosomen vor den Reifungsteilungen. Hier erheben sich wieder mehrere Fragen: Zunächst, ist diese paarweise Vereinigung der Chromosomen eine ganz allgemeine Erscheinung und was für eine Rolle spielt sie in dem Reifungsprozeß? Es wäre also zu untersuchen, ob bei der Reduction die Chromosomen sich auch beliebig auf die Tochterzellen verteilen können, ohne 
dab vorher eine mehr oder weniger ausgesprochene „Paarung“ derselben eintritt. Nun sind in neuerer Zeit drei Arbeiten erschienen, in denen der letztere Vorgang beschrieben ist: Mattiesen (1904) gibt etwas derartiges für die Oogenese der Tricladen an, doch bin ich bei meinen eignen Untersuchungen (1906) am gleichen Objekt zu einem andern Resultat gelangt. Ferner gehören hierher die Arbeit von Goldschmmт (1905) über die Eireifung von Zoogonus mirus und die vorläufige Mitteilung von Prandtu (1905) über die Reduction bei einem Infusor. Ich muß aber gestehen, daß mir die Ergebnisse der beiden Autoren noch nicht einwandsfrei bewiesen scheinen. Weiterhin muß man fragen: in welchem Verhältnis stehen die verschiedenen Formen der „Chromosomen-Conjugation“ zueinander? Bei Ophryotrocha findet nach KonscheLt (1895) die Paarung der Chromosomen erst in der Äquatorialplatte der ersten Richtungsspindel statt; bei andern Objekten vereinigen sich die Chromosomen parweise zu einer viel frühern Zeit, und zwar bei gewissen Tieren mit je einem ihrer Enden, indem die Querteilung des Chromatinfadens unterbleibt, bei andern durch Aneinanderlegen der Länge nach. Werden wir diese verschieden intensive "Conjugation“ der Chromosomen in Übereinstimmung bringen können mit den Vererbungserscheinungen? Oder werden spätere Untersuchungen eine größere Einheitlichkeit der Chromosomenpaarung und der Reifungsvorgänge im allgemeinen zutage fördern, als wir nach den bisherigen Ergebnissen zu erwarten berechtigt sind?

Ein neues Interesse haben die angedeuteten Vorgänge bei der Chromatinreduction gewonnen, als von verschiedener Seite, insbesondere von Sutton und Boveri, die wiederentdeckten Mendel'schen Vererbungsregeln in Zusammenhang mit den Vorgängen bei der Chromosomenconjugation und -reduction gebracht wurden. Da die Allgemeingültigkeit der MENDEL'schen Regeln aber nicht von allen Vererbungsforschern anerkannt wurde, so entstand durch die Verknüpfung der Vorgänge am Chromatin mit den MendeL'schen Regeln wieder ein nener Gegensatz: Nach Suttor und Boveri sind die Chromosomen der reifen Geschlechtszellen Träger verschiedener Eigenschaften, also selbst essentiell oder qualitativ verschieden, während sie nach Wersmans nur individuell verschieden sind, Iden oder Idanten darstellen.

Vorliegende Untersuchung bezweckt nun, neues Material zur Entscheidung der angedeuteten Fragen herbeizuschaffen. Es soll ferner versucht werden, durch eine Vergleichung der Entwicklung 
der Chromosomen in den Spermatocyten mit der ron mir (1906) schon beschriebenen in den Oocyten einen tiefern Einblick in die Bedeutung der mannigfachen Veränderungen im Kern während der Ausbildung der Chromosomen zu erlangen.

\section{Literatur.}

Es ist auffallend, daß bisher über die Samenreifung bei den Turbellarien so wenig bekannt geworden ist, während doch die Eireifung derselben vielfach und zum Teil wiederholt an demselben Objekt studiert wurde. Die Samenreifung scheint zwar einer Untersuchung auf den ersten Blick größere Schwierigkeiten entgegenzusetzen wegen der verhältnismäßigen Kleinheit der Kerne, aber sie zeigte sich in vieler Hinsicht besser geeignet als die Eireifung. Was bisher meines Wissens über die Samenreifung bekannt wurde, ist Folgendes :

VAN DER STRIcht (1898) bildet einige Spermatogonien und Spermatocyten von Thysanozoon brocchi ab und findet als Zahl der Chromosomen in den Kernen der erstern 18, in denen der letztern 9; und zwar haben die Chromosomen der Spermatocyten die Form von offenen oder geschlossenen Ringen.

K. C. Schneider (1902) beschreibt in seinem Lehrbuch der vergleichenden Histologie die Hodenbläschen von Dendrocoelum lacteum etwas genauer: peripher sollen nach ihm die Urgenitalzellen liegen, weiter innen die Spermatogonien; letztere sollen eine "Spermogemme" liefern, deren Elemente die Spermatocyten und Spermatiden durch die rasch aufeinander folgenden Reifeteilungen bilden; auf die letztern geht Schneider nicht ein. Wenn Schneider sämtliche Zellen der Wand der Hodenfollikel als Ursamenzellen oder Spermatogonien deutet, so kann ich mich ihm darin deshalb nicht anschließen, weil man in den Kernen der meisten dieser Zellen die reduzierte Zahl von Chromatinschleifen findet (vgl. unten). Auch war es mir nicht möglich, bei den untersuchten Arten normale Zellengruppen in den Hodenbläschen zu finden, welche eine Deutung als "Spermogemmen“ zulassen würden.

Ein wenig eingehender behandelt N. M. Stevens (1904) die Samenreifung und zwar bei der amerikanischen Art Planaria simplicissima. Da Stevens zu ganz andern Resultaten gelangt, als ich in der vorliegenden Arbeit, und da unsere Ergebnisse sich nicht im geringsten in Einklang bringen lassen, so will ich gleich hier die 
Beobachtungen von Stevens genauer besprechen. STEvers fand in den Spermatogonien \& Chromosomen, in den beiden Reifungsspindeln 4. manchmal aber nur 3. Die Chromosomen der letztern sollen Tförmig sein und sich dadurch von den V-oder Uförmigen Chromosomen der Spermatogonien unterscheiden. Das Torhandensein einer Quel- oder Reductionsteilung kann Stevexs nicht feststellen. Aus ihren beigefügten Figuren lassen sich auch keine weitern Einzelheiten entnehmen. Bei allen von mir untersuchten Arten verläuft nun die Samenreifung ganz gleichartig, aber ganz anders als Sterexs für Planaria simplicissima beschreibt, anch ist die Zahl der Chromosomen bei allen von mir untersuchten Arten konstant und gleich. Aus diesen Gründen, und auch weil die Nitteilung von STEvexs sehr kurz ist, muß man vielleicht eine ausführlichere Bestätigung dieser merkwïrdigen Verschiedenheit abtrarten, bevor man aus ihr irgend welche Schlïsse zieht.

\section{Material und Methode.}

In ausführlicher Weise untersuchte ich nur Planaria gonocephala Dug., während Dendrocoelum lacteum Oerst., Polycelis cornuta O. Schм. und nigra EHrBg. nur zum Tergleich herangezogen wurden. Alle Abbildungen sind nach Schnitten durch Planaria yonocephala gemacht. Die Untersuchungsmethode mar dieselbe wie bei meiner Arbeit über die Eireifung des gleichen Objekts: Fixierung entweder mit heißem Sublimatgemisch nach Gusox-Petruxenwisch oder mit Fuemangscher Lösung. Färbung mit BöHuter'schem Hämatoxylin und Pikrokarmin oder mit Eisenhämatoxylin nach Torfärbung mit Bordeauxrot oder mit andern Kernfarbstoffen.

\section{Untersuchungen.}

1. Entwicklung und Bau der Hodenfollikel.

Es duirfte vielleicht angebracht sein, der Beschreibung der samenreifungsteilungen einiges über die Entwicklung und den Ban der Hodenfollikel im ganzen vorauszuschicken, da in den bisherigen Arbeiten über die Anatomie der Planarien dieser Punkt weniger oder nur teilweise berïcksichtigt wurde. Die Entwicklung der Hoden läbt sich leicht an Schnitten durch eine Reihe verschieden alter Planarien verfolgen, doch genïgen auch schon Schnitte clurch 
ein einziges gerade in die Samenproduktion eintretendes Exemplar. da man in solchen neben reifen Follikeln fast immer noch andere in allen Ausbildungsstufen antrifft. Die Hoden liegen bei Planaric gonocephata an der dorsalen Seite des Tiers und zwar fast in seiner ganzen Längenausdehnung; nur das vordere und das hintere Ende enthält keine. Auf dem Querschnitt durch ein Tier sind jederseits von der Mittellinie bis zu 7 oder 8 Follikel zu zählen.

Die erste erkemnbare Anlage eines Hodenfollikels besteht in einer Ansammlung von großen bläschenförmigen Kernen, von deneı jeder von einem dichtern Plasmahof umgeben ist; die genaueve Struktur derselben wird weiter unten behandelt werden. Wir haben es also hier mit jenen Zellen zu tun, von welchen nach den übereinstimmenden Angaben von v. Wagner (1890), Снicкhoff (1892), Keller (1894) und Curtis (1902) außer der Bildung der Geschlechtsorgane auch die Regeneration vor sich geht. Auch in meiner Arbeit iiber die Eireifung bei Planaria gonocephala konnte ich die Entstehung der Ovarien aus einer Zusammenlagerung dieser Zellen verfolgen. Ein näheres Eingehen auf diese theoretisch interessante Tatsache liegt außerhalb meines Themas, es sei nur kurz darauf hingewiesen, daß KeLLER (1894) annimmt, daß die oben gekennzeichneten Parenchymzellen - von ihm "Stammzellen" genannt direkt von den Blastomeren abstammen und mit den gewöhnlichen verästelten Bindegewebszellen nichts zu tun haben. Nach KELLER muß man also annehmen, daß es nicht beliebige Zellen sind, von welchen die Regeneration und damit die ungeschlechtliche Fortpflanzung bei den Planarien ausgeht, sondern gleichsam dafür aufgesparte, und daß ferner die gleichen Zellen anch alle Anlagen in sich tragen, welche sie befähigen zu Keimzellen zu werden. Die andern oben genannten Autoren, namentlich CuRTis, drücken sich über den Ursprung dieser Stammzellen nicht so bestimmt aus und weisen auf Zwischenformen zwischen ihnen und den verästelten Bindegewebszellen hin; immerhin bleibt aber noch festzustellen, ob diese Zwischenformen darauf beruhen, daß die "Stammzellen" aus den verästelten Bindegewebszellen entstehen oder vielleicht umgekehrt. Denn letzteres muß man nach KELLER natürlich bei jeder Teilung und Regeneration der Planarien erwarten.

Die Anlage der Hoden ist erst dann dentlich, wenn die sie zusammensetzenden Zellen sich enger zusammengeschlossen haben, so wie es Fig. 1 zeigt; dieses engere Zusammenschließen beruht wahrscheinlich auf einer Vermehrung der „Stammzellen“, wenn man 
anch Mitosen in den jungen Hodenanlagen ziemlielı selten triftt. Eine Abgrenzung gegen das Parenchym besteht nur insoferin. als das Protoplasma der Hodenzellen dichter strukturielt und stärker färbbar ist als das der Parenchymzellen in der Umgebung. Am Raund der Follikel liegen stets einige Zellen, von welchen es zweifellaaft ist, ob sie zum Hoden oder zum Parenchym zu rechnen sind. Im ïbrigen bilden die Zellen des Hodens selbst ein Syncytim; nur ansmahmsweise sind Zellgrenzen erkennbar in Form ron spaltränmen. mol diese sind damn wohl eher als schrumpfungserscheinungen anznsehen. Wem die Follikel heranreifen (Fig. 2), dann treten, wie auch iibereinstimmend ron allen Autoren angegeben wird, zuerst die in der Mitte liegenden Kerne in die Reifeteilungen ein, während ulie thie Aubenzone bildenden Kerne sich noch fortgesetzt vermehren. Durch letztern Prozeb und durch die Anlagerung neuer ..Stammzellen" nehmen die Follikel an Gröbe zu. Schließlich treten zwischen den in der Mitte liegenden Spermatocyten Spalträume auf. so dab zuletzt ein Follikellumen entsteht. in welchem die Zellen einzeln liegen. Fig. 2 zeigt einen Schnitt mitten durch ein Hodenbläschen dieses stadiums: die $W_{\text {and }}$ des Bläschens ist von einer vielschichtigen Lage ron Zellen gebildet, im Lumen sind einige Reifeteilungen und anch schon spermatiden zu sehen. Nit der zunelımenden Reife der Fullikel nelmen diese noch weiter beträchtlich an Größje zu, so dab sie auf dem Schnitt dicht gedrängt nebeneinander liegen. Ihr Lumen wird grülier: und gleichzeitig nimmt die Dicke der Wand, wenigstens stellenweise. ab. da die Teubildung ron Kernen durch 'Teilung der' ..stammzellen" nicht gleichen Schritt hält mit dem Terbranch an solehen \%ur Bildung ron spermatiden. In Fig. 3 ist ein 'Teil eines solnhitts durch ein ganz reifes Hodenblïschen abgebildet: an einer Stelle dessellen fehlt die Wand vollkommen. Reifungsteilmngen sind darin nicht meln zu sehen, sondern nur noch Spermatiden anf verschiedenen stadien der Lmbildung zu spermatozoen. Anf ilne anffallende biischelförmige Anordnung werde ich miten noch \%n sprechen kommen. Tentliche Ausführungsgänge der Hodenbläschen habe ich ebmisowenig wie die meisten der Autoren. welche sich mit der I'lantrien-Anatomif: beschaftigt haben. erkennen kïmen. Dagegen fand ish öfters ein Bündel sprermatoroen in gangtörmigen, einn. besondern Wand enthehrenden Hohloümmen des Pandnchroms. Welche mit den Lumina der Hodenblïschen kommunizierten.

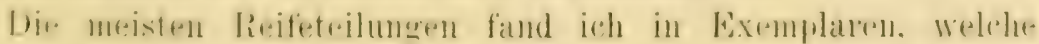


gegen Ende des Winters fixiert waren; während der übrigen Jahreszeiten herrschten die Follikel von dem Ausselıen der Fig. 3 ror.

2. Spermatogonien.

Ein 'Teil der' sogenamnten „Stammzellen", welche durch ihr Zusammentreten die erste Anlage eines Hodenfollikels bilden, scheinen unmittelbar zu Spermatocyten 1. Ordnung zu werden, ohne vorher eine oder mehrere Generationen von Spermatogonien zu liefern; demn wenn die Kierne einer Hodenanlage noch ganz locker liegen, befinden sich einige von ihnen schon in dem Synapsisstadium. Ein anderer Teil der "Stammzellen“ durchläuft entweder eine oder vielleicht auch melrere Teilungen, bevor schließlich die aus ihnen entstandenen Tochterkerne die Spermatocyten darstellen; dies wird durch das Torkommen typischer mitotischer Teilungen in der Wand der Hodenfollikel bewiesen. In letzterm Fall sind die .Stammzellen" also als Spermatogonien zu bezeichnen, und deren Vermehrung bedingt das Wachstum der Hodenbläschen. Auch für die Entstehung der Oocyten 1. Ordnung der Planarien mußte ich (1906) die beiden Möglichkeiten annehmen. Für die richtige Beurteilung der Reifungsvorgänge ist hinsichtlich der Spermatogonien die Beantwortung folgender Fragen wichtig: 1. Sind in den ruhenden Spermatogonien die Chromosomen irgendwie an der Anordnung des Chromatins erkennbar? 2. Wieviel Chromosomen sind in den Spermatogonien vorhanden, zeigen sie Größenverschiedenheiten und welcher Art sind die letztern? 3. Wie verhalten sich die Tochterchromosomen während der Auaphase?

a) Spermatogonien im Rulhestadium (Fig. 5). Der Kern ist von rundlicher bis langgestreckter Gestalt und besiłzt eine Membran, welche sich mit allen Kernfarbstoffen stark färbt. Das Chromatin ist in Form von Körnchen verteilt, welche teils der Kernmembran anliegen, teils im hell erscheinenden Kernraum ohne erkennbare Anordnung liegen. Die Körnchen sind meistens annähernd gleich groß, manchmal findet man unter ilınen auch größere Brocken. Ihre Form ist kuglig oder unregelmäßig polyedrisch. Die Zahl der Körnchen scheint nicht konstant zu sein, doch läßt sich das kaum mit Sicherheit feststellen. Ein Liningerüst konnte ich nicht erkennen. Stets ist ein sphärischer Nucleolus vorhanden, welcher ron einem chromatinfreien Hof umgeben ist und meistens der Kernmembran genähert liegt; er färbt sich mit BöHnER'schem Hämatoxylin blaßblau, mit Eisenhämatoxylin intensiv schwarz. Das Kernkörperchen zeigt meistens eine homogene Beschaffenheit, oft aber enthält 
- eine Tactule. In dem Protoplasma des rerhältnismäbio sehr kleinen \%ellkürper's sind keine weitern Difterenzierungen zu erhement. Diese ruhenden spermatogonien sind nur in den jüngsten Fullikelı häufig. in ältern findet man sie nur noch am Rand. -ir wleichen ïbrigens rollkommen den wben besprochenen groben Parenchymzellen oder ".Stammzellen".

b) Teilung der Spermatogonien (Fig: 6-8). 'T'eilungshilder der spermatogonien findet man riel seltner als solche der heiden Gentrationen von spermatocyten. da aber die starke Gröbenzmalme der Hodenfollikel sich nur durch eine beträchtliche Termehrung der sjermatugonien erklären läßt. su mulb man schließen, dab die Teilung derselben sehr rasch verläuft. Die C'mbildung der when beschriebenen Chromatinkürnchen zu den Chromosomen lieb

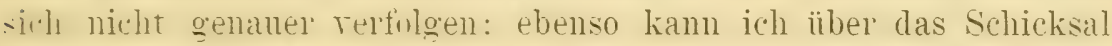
hes Vucleolus währenr der Ausbildung der 'Teilungswindel nichts -iirlier angeben. In dem stadinm des Monasters kamn man bei Pmansicht mit sicherheit 16 winklig gebogene Chromosomen zählen Fig: b!: da dieselhen nahe beisammen liegen und sich infolgedessen meistenteils decken. sind die thbildungen weniger dentlich als die T'äjalrate selbst. In Eisenhämatoxylinpräparaten sind die ('hromosmen. wie Fig. ti zeigt. häufig keulenförmig rerdickt. doch tritt das

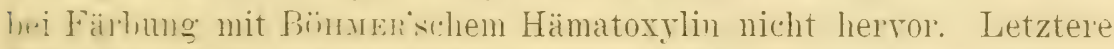
I'läjarate lassen aber meistenteils eine Längsspaltung der (hromosomen erkennen. Es sind unter den Chromosomen eines Kerns imalich. Giöbenunterschiede rorhanden. für welche perspektivische Tolkibzung oder die Ammahme einer Kontraktion der einzelnen ("lnonusmmen nicht zur Erklärung ansreicht. Ich habe abel weder las lorkmmen einer konstanten zahl gröberer mol kleinerer Ele-

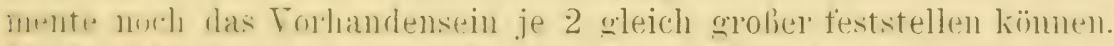

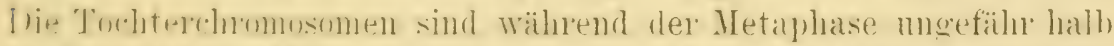

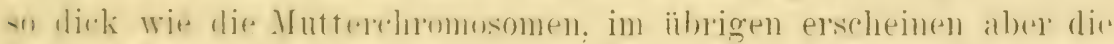

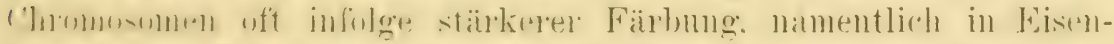

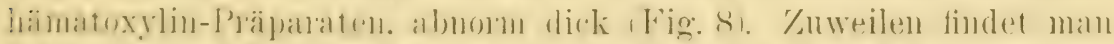

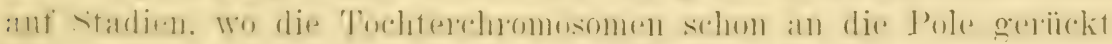

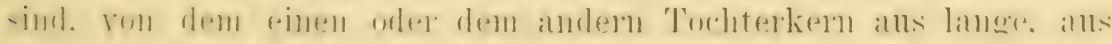

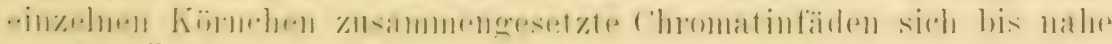
an den Ïguator der Spindel hin erstrecken; das scheint fiur eine

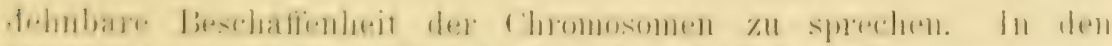

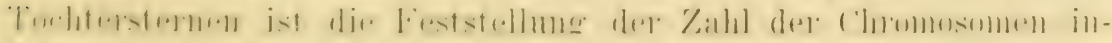

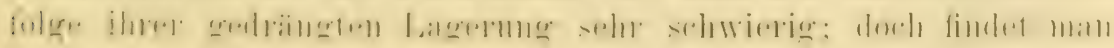


stets wenigstens annähernd die zu erwartende Zahl 16. Die anch nicht seltner zu beobachtende Teilung der großen Kerne des Parenchyms verläuft ebenso wie die der Spermatogonien; namentlich ist die Chromosomenzahl dieselbe.

c) An a phase. An den Spindelpolen drängen sich die Chromosomen zu einer kalottenförmigen Masse zusammen, welche ihre Zusammensetzung aus einzelnen Chromosomen oft nur noch durch die frei hervorstehenden Enden der Schleifenschenkel erkennen läßt. Dann werden die Konturen der letztern zackig, und die Chromosomen verlängern sich zu Fäden, welche aus einzelnen Körnchen zusammengesetzt erscheinen. Es tritt nun um den Tochterkern herum ein heller Raum auf; in diesem liegen also die Schleifen derart, daß die Umbiegungsstellen nach einer Seite des Kerns, die freien Enden nach der andern sehen (Fig. 9). Die Anaphase ist beendet, wem der ganze Kernraum von einem dichten Chromatingerüst ausgefült ist, welches die fädige Anordnung nur noch undeutlich zeigt, so daß das Chromatin wieder in Form von Körnchen verteilt erscheint. In diesen Kernen sind natürlich die 16 Chromosomen nicht mehr zu erkennen. Der Nucleolus ist anf diesem Stadium schon wieder neu anfgetreten (vgl. unten).

Es bleibt noch zu erwähnen, daß die Centrosomen der eben geeschilderten Teilungsspindel während der dicentrischen Wanderung der Chromosomen eine Teilung erfahren (Fig. 7); später vereinigen sich aber beide Hälften anscheinend wieder, denn im Stadium der Fig. 8 findet man an jedem Pol nur ein Centrosom, welches aber durch seine längliche Gestalt mehr oder weniger deutlich seinen Doppelcharakter anzeigt. Woher die Centrosomen der Spermatogonien stammen, konnte ich ebensowenig feststellen wie ihr Schicksal, wem die Tochterkerne sich in ein Chromatingerüst umbilden. Im Zellkörper sind sie nicht mehr nachweisbar.

\section{Erste Reifungsteilung:}

Die Hauptmasse der Kerne, welche in der Wand eines heranreifenden Hodenbläschens liegen, sind Spermatocyten 1. Ordnung: Thr Chromatin befindet sich auf den verschiedenen durch alle wïnschenswerten Zwischenstufen verbundenen Umwandlungsstadien zu den Chromosomen der 1. Reifungsspindel. Den Vorgang dieser Umwandlung kann man in folgende Stadien einteilen:

a) Jüngste Spermatocyten 1. Ordnung (Fig. 10). Thre Kerne sind hervorgegangen aus den Tochterchromosomen der letzten 
Teilung einer spermatogonie, welche, wie oben angegeben. durch Terlängerung und dadurch. daß sie das Aussehen einer Zusammensetzung aus einzelnen hintereinander gereilhten Körnchen oder Microsomen angenommen haben, in ein Ferngerïst übergegangen sind. welches folgende Eigenschaften hat: Das Chromatin erscheint zunüchıst in Form von einzeln liegenden, ungefähr gleichgroßen Körnchen angeordnet. welche dicht gedrängt den ganzen Kernraum erfüllen. Eine Kernmembran ist nicht rorhanden. Zuweilen ist der Kermraum nicht rollstïndig mit Chromatin erfüllt. sondern es bleibt ein heller Randbezirk chromatinfrei. der meistens nur auf einer Kernseite aus. gebildet ist: duch diurfte das wohl nur auf einer Schrumpfung des Chromatingerüsts oder des Zellplasmas ber'uhen. Tenn man num das Chromatin genauer betrachtet, erkennt man, daß die Körnchen nicht einzeln liegen. sondern daß sie mit Nachbarkörnchen zu kurzen Fädchen aneinander gereiht sind. Auf längere Strecken lassen sich diest Fädchen aber nicht rerfolgen. In Fig. 10 ist die Tereinigung. (ler Körnchen zu Fädchen angedentet durch hellere Partien, welche also die nicht in der Einstellungsebene liegenden und daher unschart erscheinenden Körnchen bedeuten sollen. Ein achromatisches Kernger'üst habe ich nicht mit Sicherheit erkennen können. Der Nucleolus ist wieder, wenigstens in Eisenhämatoxylin-Präparaten, deutlich sichtbar, unl auch hier meistens von einem chromatinfreien Hof umgeben. in den mit B̈̈нмеR'schem Hämatoxylin gefärbten Schnitten wird das blasse Kernkürperchen fast immer durch das Chromatin verdeckt. Wie es sich in diesen Fermen wieder gebildet hat, konnte ich trotz aller darauf verwandten Mühe nicht herausbringen.

b) Umwandlung in das Stadium der dünen Chromatinfäden (Fig. 11-13). In andern Kernen finden wir in der Hanptsache dieselle Anordnumg des ('homatins, mit der cinzigen Ausmahme, dali die Mehrzahl der geschilderten Fiadchen nach einem l'unkt der Kernmembran hin gerichtet sind; in der Nähe dieses Punkts liegt das Kernkörperchen. Solange die Fädchen noch so dicht genlränt liegen wie in Fig. 11, ist diese Anordnung nur wenig anffallend: je mehr aber die Fadenstruktur des Chromatins sich ansbildet. desto dentlicher sieht man die eimzehnen Fallenilscinitte. wenigstens die meisten derselhen, nach dem Nucleolus hin gerichter (Fig. 12). Ind sulche Zwischenstufen führen schlieblich zul lermen. we einer in roig. 1:3 dargestellt ist: das ganze ('lnomatin ist in Form einer. Anzahl won Fiden rereinigt, deren Zahl sich mit richer-

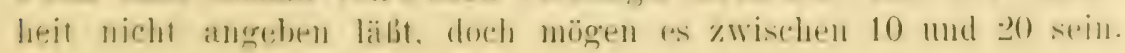


Nur davon konnte ich mich überzengen, daß die einzelnen Fäden sich nicht zu einem zusammenhängenden Spirem vereinigen, sondern es sind freie Endigungen vorhanden; und zwar bestehen die Fäden mindestens in sehr vielen Fällen aus einer Schleife, deren freie schenkel nach dem Nucleolus hin gerichtet sind, während die Umbiegungsstelle nach der entgegengesetzten Seite sieht. Die einzelnen, kleinern, scheinbar nicht zu einem Faden gehörenden Chromatinpartikel, welche man in Fig. 13 sieht, gehören dennoch zu solchen, nul waren sie in dem Gewirr von Fäden nicht weiter zu verfolgen; ïberhaupt komnten in keiner der Figuren dieses Stadiums alle Fadenschleifen eingezeichnet werden. Fig. 14 stellt einen optischen Querschnitt durch eine ähnliche Spermatocyte dar, wobei die Schnittebene so gelegt zu denken ist, daß sie die Schleifenschenkel senkrecht trifft. Die Punkte der Fig. 14 sind also die Querschnitte der' einzelnen Schleifenschenkel. Im Präparat ist das Bild nicht so dentlich, da die meisten Schenkel in Wirklichkeit mehr oder weniger' schräg zur Schnittebene verlaufen und daher die nicht in der Einstellungsebene befindlichen Fadenteile ebenfalls noch, aber unscharf, sichtbar sind. Man sieht in Fig. 14 nun 32 Punkte, bei anderer Einstellung ist die Zahl etwas größer oder kleiner, immer aber etwa 30. Nehmen wir an, daß in einem Kern dieses Stadiums 16 Schleifen vorhanden sind, so müßten wir auf einem Schnitt durch ihn. welcher die Schenkel aller Streifen einmal trifft, gerade 32 Punkte zählen können; würde eine Schleife mehrmals getroffen sein oder eine gar nicht, so würden wir natürlich entweder mehr oder weniger Pinkte finden.

c) Umwandlung in das Stadium der dicken längsgespaltenen Chromatinfäden. - Synapsis (Fig. 15-22). Zwischen den oben beschriebenen Kernen finden sich zahlreiche andere, welche sofort dadurch auffallen, daß ihre Chromatinschleifen nicht dïnn und einfach, ferner in so großer Zahl vorhanden sind, sondern dicker, ungefähr doppelt so dick wie die oben beschriebenen, ferner längsgespalten und in viel geringerer Anzahl vorhanden. Diese sind nun deshalb als die Kerne weiter entwickelter Spermatocyten aufzufassen, weil die allmähliche Umwandlung ihrer Chromatinschleifen in die definitiven Chromosomen der 1. Reifungsspindel in allen Zwischenstufen verfolgt werden kann. Es handelt sich nun dar'um, festzustellen, wie aus den dünnen Schleifen die dicken längsgespaltenen herrorgehen, und das läßt sich, obwohl die Zwischenstufen nicht häufig und daher mir lange Zeit entgangen sind, mit 
Sicherheit erreichen. \%unächst kam man konstatieren, dab sich keine Ferne tinden. deren Chromatinfïden himsichtlich ihrer Iricke zwishen den dünnen ungespaltenen und den dicken längsgespaltenen Fäden stelent. sondern es sind immer nur entreder die einen uder die andern rorhanden. Man sieht aber nicht selten Ferme. Welche suwhl die dicken längsospaltenen wie die dünnen ungespaltenen aufweisen. und häutig rerlauten in solchen Kermen je 2 dümme Fïlen einander parallel oder setzen sich gemeinsam in einen dicken längsgespaltenen Faden fort. Fig. 15 zeigt 2 nebeneinander liegende lerartige Fierne, in denen ich aber die Fäden nicht ganz verfolgen komnte. da es deren immer nuch sehr viele sind und sie nuch ziemlich wiry durcheinander liegen. Ans diesen Beobachtungen scheint mir num hervorzugehen. dals die dimmen Fadenschleifen sich nicht alhmählich rerdicken und damn der Länge nach teilen. sondern die dicken längsgespaltenen Chromatinfäden sind entstanden durch Zusammenlegen von je 2 dïnnen schleifen. Noch andere Beobachtungen surechen füi diese Auffassung: Fig: 17 stellt einen Fern dar. welcher mur die dicken chromatinschleifen enthält; da der Kern nur etwa b-7!l dick ist. so ist er. wie sehr viele andere. in jedem Präparat durch las Mikrotommesser nicht verletzt. da die Schnittdicke 7.5 ma 10 " betrug. Da nun die dicken Schleifen lange nicht mehr s) dicht nedraingt liegen wie die dümen. so kann man in solchen Fermen ihne Zahl mit sicherheit feststellen dadurch, dab man einen derartigen Kern mit dem Zeichenapparat genau kopiert. Man kam sich num iiberzengen. daß es gerade \& Schleifen sind. T'm diese Zahl bester übersehen zu kïmnen. sind ron den 8 schleiten einer Kerns + in Fig. 18 und die andern + in Fig. 19 abgebildet. Sin flentlich ist natürlich die Zahl der sichleifen nicht immer festzustellen: infolge Durchschneidens eines Kerns oder mö̈ustiger Jage descellen , Fig. 16, ist es in den meisten Fällen ummöglich, sit. testzustellen. Auch die dicken längsgespaltenen Fäden stellen also. wie dit dimnen des vorhergehenden stadiuns, Schleifen ding. deren sihenkel narde einer stelle des Kierns konvergieren. Währemel die

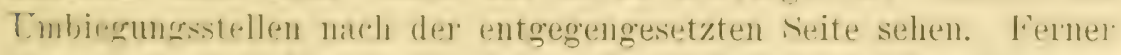
kamm man sich hier noch besser wie auf dem vorher geschilderten Stadium über\%engen. dali die schleifen kein zusinmmenhängendes syirem bilden. sondern iselierte Fadenstücke sind. In Fig. 200 is

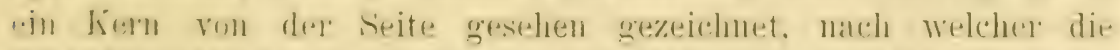

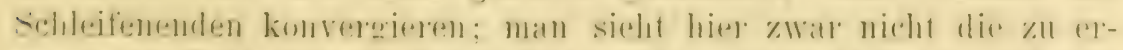

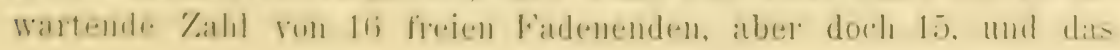


läßt sich ja dadurch erklären, daß ein freies Ende nicht so weit reicht wie die andern oder zufällig verdeckt wird. Fig. 21 1. 22 zeigen 2 Kerne des gleichen Stadiums, die Abbildungen sind zu verstehen wie die oben erklärte Fig. 14. Man findet hier aber nicht ungefähr 32 Fadenquerschnitte, sondern nur ungefähr die Hälfte, nämlich 16 oder 17 . Die eben angeführten Beobachtungen sprechen natürlich sehr dafïr, daß sich die Zahl der Schleifen reduziert hat, und zwar von 16 auf 8 , und das muß ja eintreten, wenn die Chromatinfäden sich paarweise aneinander legen. In meiner Untersuchung über die Entwicklung der Chromosomen in den Oocyten von Planaria habe ich die Möglichkeiten, wie die Verminderung der Chromatinfäden von 16 auf 8 zustande kommen kann und wie daher die dicken längsgespaltenen Chromatinschleifen sich bilden können, ausfiihrlich erörtert. Und die dort angeführten Überlegungen haben meines Erachtens anch für die Entstehung der Doppelfäden in den Spermatocyten vollständige Gültigkeit. Wir können daher zusammenfassend sagen, daß sich auch in den Spermatocyten der Planarien je 2 dünne Fadenschleifen der Länge nach zu einem dicken Doppelfaden aneinander legen, sodaß aus 16 Einzelfäden 8 Doppelfäden entstanden sind. Diese paarweise Vereinigung zweier Chromosomen, denn als solche müssen wir die Einzelfäden auffassen, stellt das Synapsisstadium dar.

Die Längsspalte der Chromosomen ist in einigen der Kerne recht deutlich zu sehen, z. B. in Fig. 18 und 19; die Fäden sehen oft aus, als ob sie aus einer großen Zahl sehr kleiner Kettenglieder zusammengesetzt seien, so wie sie z. B. auch Scнockaent (1902) für die Oocyten von Thysanozoon brocchii beschrieben hat. In andern Kernen, z. B. in Fig. 17, ist die Längsspalte fast oder gar nicht zu sehen. Obwohl dies in den meisten Fällen auf etwas zu intensiver Färbung beruhen dürfte, möchte ich doch annelımen, daß die Einzelfäden sich zu einer gewissen Zeit dichter aneinander legen als später; denn mit der weitern Ausbildung der Doppelchromosomen wird, wie unten zu zeigen ist, diese innigere Vereinigung wieder rückgängig gemacht. Es ist noch nachzutragen, daß man eigentlich erwarten sollte, in den quergetroffenen Doppelfäden der Fig. 21 u. 22 eine Spalte zu finden; bei genauer Betrachtung der Präparate glaubt man anch tatsächlich eine solche zu sehen, aber sie läßt sich in der Zeichnung schwer ohne Übertreibung wiedergeben.

Endlich sind an den Figg. 17-19 noch die auffallenden Unterschiede in der Länge der Doppelfäden eines Kerns zu bemerken; 
besonder's anffallend ist das in Fig. 18 u. 19 zu sehen. Die kiu'zer'n Fadenschlingen sind ebenso dick wie die längern, und wemn man daher eine rerschieden starke Kontraktion als Irsache der Längenunterschiede ansehen wollte. so mïbte diese Kontraktion ohne Dickenzunahme der Fäden ror sich gehen. Tergleicht man Fig. 18 u: 19 mit Fig. 17. so kann man aber auch keinen Anhaltspunkt für die Ammahme finden. daß die Größenunterschiede zwischen den schleifen in jedem Kern gleich und konstant sind: allerdings lassen sich diese nicht messen, sondern nur schätzen.

d) Das Schicksal des Xucleolus (Fig. 23-25). Das Kemkörperchen ist. wie schon erwähnt, in allen mit BöHsterschem Hämatoxylin (und auch mit andern Kernfarbstoffen) behandelten schnitten infolge seiner blassen Färbung durch das dicht gedrängte ('hromatin meistens verdeckt, namentlich dam, wenn das Chromatin in Fadenform angeordnet ist; nur in Eisenhämatoxylin-Präparaten ist es noch im Stadium der Synapsis dentlich erkembar. Bei sehr starker schwärzung des Chromatins tritt der Nucleolus aber auch lier nicht herror, teils weil er rom Chromatin verdeckt wird. teils weil er ron einem optischen Fadenquerschnitt nicht mit Sicherheit unterschieden werden kann. Er hat nun die bemerkenswerte Eigenschaft, die tiefschwarze Fürbung auch dann noch beizubehalten. wenn durch die Differenzierung mit der Eisensalzlösung das ('hromatin rollkommen entfärbt ist. Seine Veränderungen lassen sich daher. an solchen Präparaten gut verfolgen, in denen alles nur noch die Bordeauxfarbe hat mit Ausnahme des tiefschwarzen Nucleolus (Fig: .23-205. In dem Stadium der Spermatocyten, wo das Chromatin noch nicht die oben beschriebenen dünnen Schleifen bildet, ist der Vucleolus stets einheitlich (Fig. 23). Tm Stadium der dünnen Chromatinschleifen liegt er immer in der Tähe der freien Schleifenenden und zeigt hier häufig eine Finsclun̈rung, also den Begimn einer '/weiteilung Fig. 24). Haben sich die dïmen Schleifen paarweise zu den dicken vereinigt. so ist das Kernkörperchen fast immer in 2 nelseneinander liegende kuglige Körnchen zerfallen (Fig. 25). Die Teilung kamn aber auch schon auf viel frïhern Stadien eintreten. If as weiter mit dem Nurleolus geschieht, ließ sich nicht feststellen. vielle-hot leitet sich das im Zellulasma der Fig. 18 liegende Kïm hen von einem der Teilstiucke ab. Diese scheinen also ans dem Kinn entfernt $\%$ werden.

e) Ausbildung der Chromosomen (Fig. 26-41.). Die

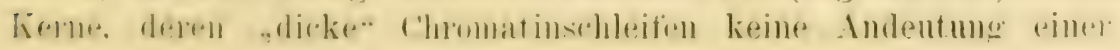


Längsspaltung zeigen, wie Fig. 17, sind verhältnismäßig selten. In den meisten ist die Längsspalte sehr deutlich, und solche Kerne leiten vermittelst aller erdenklichen Übergangsstufen zu jenen über; in welchen 8 je ein Fadenpaar darstellende Chromosomen zu finden sind. Die Längsspalte wird dadurch deutlicher, daß sich die Einzelfäden auf längere Strecken voneinander trennen. In Fig. 28 sind einige der Fäden eines solchen Stadiums abgebildet, ebenso in Fig. 27. TVährend also die Doppelfäden vorher aus zahlreichen, ziemlich gleich großen, aber sehr kleinen Kettengliedern zusammengesetzt erschienen, haben sie jetzt die Form einer Kette mit größern, unregelmäßigen und ungleich großen Gliedern. Noch auf dem Stadium der Fig. 17-19 waren die Schleifen deutlich aus Microsomen zusammengesetzt; dieses Aussehen verlieren sie ,etzt und gehen gleichzeitig eine Reihe anderer Veränderungen ein: Erstens werden ihre Konturen glatt, zweitens nehmen sie beträct lich an Dicke zu und drittens geht damit Hand in Hand eine Verkinzung der Schleifen; man hat dabei oft den Eindruck, als of ie freien Enden der Schleifen an der Stelle, nach welcher sie kol vergieren, festgehalten werden, so dab sich das gesamte Chromatin nach 7 ieser Seite des Kerns zusammendrängen muß. Diese Konzentrierung des Chromatins ist zuweilen so stark, daß ein unentwirrbarer Knäuel entsteht, in welchem die einzelnen Doppelfäden nicht mehr zu erkemnen sind. Es muß zweifelhaft bleiben, ob diese Zusammendrängung zu den normalen Entwicklungsvorgängen des Chromatins gehört oder ob es nicht entweder ein pathologisches Vorkommnis (Degenerationserscheinung) oder ein Kunstprodukt ist. Aus der Beobachtung, daß diese dichten Kinänel in manchen Präparaten gehäuft vorkommen, möchte ich auf letzteres schließen. Auch Janssens (1905) ist der Ansicht, daß die Zusammenballung des Chromatins in den Kernen, das Synapsisstadium verschiedener Autoren, auf einer ungenügenden Finwirkung der Fixierungsflïssigkeit beruht.

Bisher hatten die Doppelchromosomen noch dieselbe Anordnung wie früher, die Enden nach einem Punkt gerichtet, die Umbiegungsstellen nach der entgegengesetzten Seite. Diese Anordnung geht nun verloren. In Fig. 30 kann man annähernd 8 Doppelfäden unterscheiden, welche ziemlich regellos im Kernraum verteilt sind. In den Spermatocyten dieses Stadiums beginnt aber auch die belle Kernvacuole, in welcher das Chromatin bisher alle seine Veränderungen durchgemacht hat, zu schwinden, und dadurch kommen die Doppelfäden in das Zellplasma selbst zu liegen. Eine Kernmembran war. 
wie oben schon erwälmt. in den Spermatocrten zu keiner Zeit zu sehen.

Trenn die Chromatinelemente sich auf diese Treise in der Spermatocrte unregelmäbig rerteilen, stellen sie Doppelfäden dar, deren beide Einzelfäden 1, 2 oder 3mal umeinander herumgetrickelt sind: die Enden der beiden Einzelfäden sind meistens nicht miteinander verklebt. Ton einer Längsspaltung innerhalb der Einzeltäden ist (wenigstens bei Planaria gonocephala) nichts zu erkennen.

Nun begimnen eine Reihe von Umformungen, wie sie anch schon von andern Objekten mit heterotypischen Teilungsfiguren beschrieben wurden. Der Ausgangspunkt ist die Form der eben beschriebenen Fadenparre. das Endstadium wird von den Chromatinelementen der Äquatorialplatte der 1. Reifungsteilung dargestellt. Dazwischen liegen eine Menge von Übergangsformen, von relchen die charakteristischsten in der Textfigur a zusammenyestell' sind. Es kommen zunächst die schon geschilderten umeinander, gewickelten Fadenpaare mit freien oder rerklebten Enden ror ( and b). Weiter finden sich Fadenpare, welche sich mit ihren Ende: nur noch überkieuzen (c) oder sich ïberhaupt nur noch an einer scelle anliegen id).

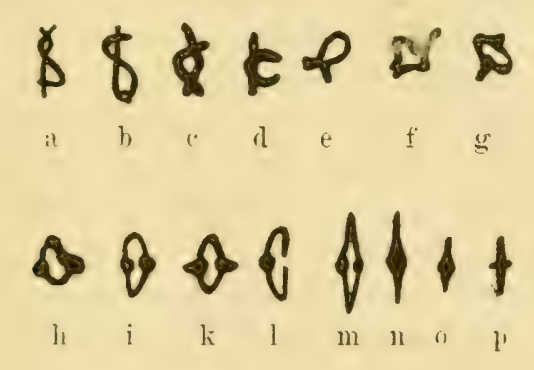

Fig. A.

Damn kommen die bekannten Ringfiguren ror, entstanden dadurch. lali dir Einzelfäden mit ihren Enden rerkleben: die Terklebungsstelle zeigt entweder noch deutlich die Zusammensetzung aus zwei Enden. oder sie stellt nur eine knopfö̈mige Terdickung des Rings dar: J)iese Ringfigmen sind entweder unregelmäig (e bis h), oder. wem sich die spermatocyte der Ausbildmg der Äruatorialplatte nähert. regelmällig geformt (i und k). Der Längsdurchmesser dieser Figuren shoheidet die Witten zwischen den Verklebungstellen, derjenige der frühern figuren (c bis f) die Terklebungsstellen selbst. In der Äquatorialplatre findet man die chromosomen meistens als 
sehr lang'estreckte und spitzausgezogene Gebilde, welche nur manchmal noch ein Lumen erkennen lassen ( $m$ bis $p$ ). Zuweilen ist die eine Verklebungsstelle vorzeitig aufgerissen (l). Etwas anders erscheinen die Chromosomen in den mit Eisenhämatoxylin überfärbten Schnitten (Fig. 33); sie sind viel dicker und plumper als die normal gefärbten; je zarter gefärbt wird, desto graziler erscheinen sie. Komplizierter sehen die Chromosomen natïrlich dann aus, wenn man sie in Polansicht zu sehen bekommt.

Es frägt sich nun, ob alle im Vorstehenden beschriebenen Chromatinfiguren Etappen eines Umbildungsprozesses der umeinander gewickelten Fadenpaare in die spitz ausgezogenen Ringe der Äquatorialplatte sind, welches die Reihenfolge der Stadien ist, ferner ob nicht vielleicht einige der Figuren Kunstprodukte sind. Im allgemeinen ist letzteres wohl nicht der Fall, und es werden in der Hauptsache, wie von Schockaert (1902) und andern Autoren angegeben wurde, zwei Faktoren sein, welche ihre Form bestimmen: erstens die Adhäsion der Einzelfäden an ihren Enden und zweitens der Zug der Spindelfasern. Es scheint mir aber zweifelhaft, ob die beiden Faktoren allein zur Erklärung genügen, denn schon das Vorkommen der umeinander gewickelten Fadenpaare und ihr Umbildungsprozeß, bevor sie sich in der Äquatorialebene anordnen, machen es wahrscheinlich, daß auch innerhalb der Chromosomen selbst irgend welche formbestimmende Eigenschaften vorhanden sind. Die Reihenfolge der Chromatinfiguren in dem Umbildungsprozeß ist wahrscheinlich die in der Textfig. A eingehaltene; denn je zerstreuter die Chromosomen noch in der Spermatocyte liegen, desto häufiger finden sich die am Anfang der Reihe stehenden Formen, und je mehr sich die Spermatocyte der Ausbildung der Äquatorialplatte nähert, desto zahlreicher sind die langgestreckten Ringe vorhanden. In der fertigen 1. Reifungsspindel sind endlich nur solche zu sehen (Fig. 34 เ1. 35$)$.

Ein eigenartiges Verhalten der Chromosomen zeigt Fig. 36, welches nicht so ganz selten ist und ein Licht auf die Zusammensetzung der Chromosomen wirft; Fig. 36 stellt eine Spermatocyte im Stadium der Äquatorialplatte dar; es sind nur 6 Chromosomen eingezeichnet, da die andern das Bild undeutlich machen würden. 4 dieser Ringe sind sehr stark verlängert, zugleich sind sie schwächer gefärbt und sehen aus, als ob sie aus einzelnen Körnchen zusammengesetzt seien. Ich glaube, man darf annehmen, daß sie durch Zug der Spindelfasern oder sonst irgendwie gedehn't sind und infolge dieser Dehnung 
wieder die Znsammensetzung aus Microsomen zeigen, welche die Chromatinschleifen vor ihrer Terkïrung aufwiesen. Etwas ähnliches komnte man anch bei der Teilung der Spermatogonien beobachten (s. 0.), und man darf daher vielleicht aus dieser Dehmung und ans ler Kürze, welche die Tochterchromosomen später nach der Teilung. ler Ringe zeigen, auf eine elastische Beschaffenheit der Chromosomen schlieben, welche ihnen gestattet, sich nach einer erlittenen Dehnung wieder zu verkïrzen. Eine gleiche Termutung äubert auch SCHOCKAERT (1902).

f) Gröbenunterschiede der Chromosomen. In Fig. 30 bís 3ó sind entweder alle oder einige der Chromosomen einer Spermatocyte 1. Ordnung in ihrer natürlichen Lage gezeichnet, und in Fig. $3 \overline{7}-41$ sind alle Chromosomen einiger anderer Spermatocyten der bessern $̈$ Übersicht halber nebeneinander abgebildet. Ein Blick auf diese Figuren zeigt nun olıne weiteres die auffallenden Größenunterschiede zwischen den Chromosomen eines und desselben Kerns. / $/$ mm Teil beruhen dieselben, wie besonders aus der Fig. 36 zu ersehen war: rielleicht auf einer rerschieden starken Kontraktion. Diese allein kamn aber die Größenmterschiede schwerlich bewirken. wie z. B. ans einer Tergleichung des größten Chromosoms der Fig. 37 mit dem kleinsten hervorgeht. Ferner spielt dabei anch die scheinbare Terkürzung der Chromosomen infolge ihrer verschiedenen Orientierung zur Schnittebene eine Rolle; um diesen Faktor soweit als müglich auszuschließen, habe ich vermieden, die Chromosomen solcher spermatocyten abzubilden, die in Polansicht gesehen sind. Die Gribenunterschiede sind nun so stark, dah nicht ron der Hand gewiesen werden kann, daf sie wirkliche, nicht nur schembare sind. l)amit stimmt auch das iiberein, was iiber die Chromosomen der sjermatrgonien und über die dicken längsgespaltenen ('hromatinschleifen der spermatocrten in symapsisstadium gesagt wude. Eine andere Frage ist aber die. ob bei unserm Objekt in jeder relle wleichstalke, also konstante Gröbenunterschiede zu erkemen sind. und meines Erachtens sind solche bei den Planarien anch nur mit einiger Wahrscheinlichkeit nicht zu berbachten. Wohl kam man iiberall ein. Gruppe gröberer Chromosomen und eine kleinerer anseinanderhalten; aber 1. sind immer C̈herginge zwischen beiden irmplen vorlanden, mol 2 . ist in der einen Spermatocyte die eine

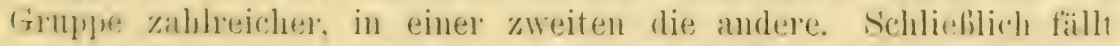
noch anf, wem man die Figgr. 37 n. 38 hinsichtlich der Giölue des. chromosmen vergleicht. dab in der ersten figur die chomatin. 
elemente durchschnittlich kleiner sind als in der zweiten; selbstverständlich sind alle Figuren genau bei derselben Vergrößerung gezeichnet. Die abnorme Massigkeit der Chromosomen der Fig. 33 ist, wie ich schon erwähnt habe, auf Rechnung der Überfärbung mit Eisenhämatoxylin zu setzen.

g) Teilung der Chromatinringe (Fig. 42). Die Teilungsbilder der Ringe trifft man relativ sehr selten, daher dürfte diese Phase sehr schnell vor sich gehen, da die Tochtersterne wieder beinahe ebenso massenhaft in den Präparaten zu sehen sind wie das Stadium der Äquatorialplatte. Die Ringe teilen sich, indem sich ihre Hälften an den Verklebungsstellen, welche stets noch zu erkennen sind, voneinander lösen. Oft ist die eine Verklebungsstelle schon gelöst, während die andere noch festhält (Fig. 34). Fig. 42 zeigt eine sich teilende Spermatocyte 1. Ordnung, in welcher alle Ringhälften sich schon voneinander gelöst haben und etwa Vförmige Gebilde darstellen, die sich während der Polwanderung verkürzen. Leider sind diese Stadien sehr unïbersichtlich, so daß ich keine vollkommenen Bilder geben kann. In Fig. 42 sind auf der einen Seite 8, auf der andern 7 Chromosomen sichtbar. Stets findet man schon während der dicentrischen Wanderung eine Andeutung einer Längsspaltung der Ringhälften, daran kenntlich, daß die Vförmigen Chromosomen nicht 2 freie Enden zeigen, sondern deren 4 oder wenigstens 3. In Fig. 42 ist das bei 4 der Chromosomen deutlich der Fall und kann daher nicht darauf beruhen, daß 2 zufällig nebeneinander liegende Chromosomen ein einziges längsgespaltenes Element vortäuschen. Einmal sah ich auch die Längshälften der Chromosomen schon während der Metaphase vollkommen getrennt; leider aber habe ich versäumt, die betreffende Stelle im Präparat aufzuschreiben, und später konnte ich sie nicht wieder finden. Weder an den Einzelfäden der spätern Synapsisstadien noch an den Ringen war mit Sicherheit eine Längsspaltung zu bemerken, während ich dies in den Oocyten des gleichen Objekts sehr deutlich konstatieren konnte.

h) Die Centrosomen. Auf die achromatische Figur näher einzugehen, liegt nicht im Thema dieser Arbeit. Es gelang mir auch nicht, die Centrosomen mit Sicherheit zu erkennen, bis die Chromosomen in der Äquatorialebene angeordnet waren. Auf frühern Stadien konnte ich nur in einzelnen Fällen im Plasma Körnchen finden, welche man als Centrosomen ansprechen könnte, ohne daß ich aber dafür sichere Beweise anzufïhren imstande bin. An den 
Fpindelpolen sind die Centrosomen sichtbar als ein kleines, etras längliches Gebilde, ron dem die nur undentlich erkennbaren Spindeltasel'n ausgehen. In spätern Stadien der 1. Reifungsteilung hat sich jedes Centrosom in 2 Körnchen geteilt.

\section{Zweite Reifungsteilung:}

Am Ende der Metaphase der 1. Reifungsteilung sind die Tfürmig westalteten Ringhälften dicht an den Spindelpolen zusammengedrängt und lassen wenigstens bei der Ansicht von der Seite weder die Zahl noch die Lüngsspaltung der Chromosomen erkennen, so daß ein ganz ähnliches Bild entsteht wie am Schluß der 'T'eilung' einer Spermatogonie. Ein Ruhestadium schließt sich an die 1. Reifungsteilung nicht an. sondern die Chromosomen rerkürzen sich und bilden dann sofort die Äquatorialplatte der 2. Reifungsteilung. Dabei rüicken die Chromosomen wieder etwas auseinander, so daß man in Polansicht meist recht gute Bilder erhält; man findet damn 8 iloppelte ('lromatimelemente Fig. 43 i. 44), welche recht komplizierte und mamnigfache Figuren bilden, so dab ihre Deutung ohne die Kenntnis der schon während der vorhergegangenen Metaphase aufgetretenen Längsspaltung der Ringhälften sehr schwierig sein würde. Häufig sind ? liurze. nebeneinander liegende Stäbchen rorhanden (2 der ('hromosomen in Fig. 43 und Textfig. B a). Man künnte sich diese

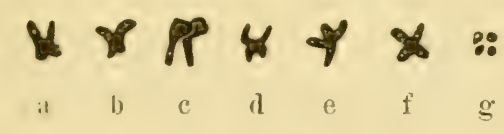

Fig. B.

leicht dadurch entstanden denken, dab das Tfürmige Chromosom an

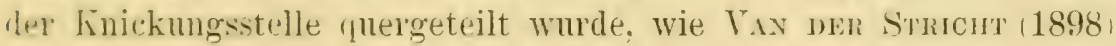
« \%. B. bei der Eireifung von Thysanozoon broceli amnahm. Eine genantere Prüiung zeigt aber fast stets, dab die Form der geraden Stäbchen nur vorgetaiuscht wird und dak es sich um zwei nebencinander lisgende, gebogene oder. Tförmige Gebilde handelt: sie erwheinen deshall, stibchenfïrmig. Weil sie sehr kn\% sind und ungiinstig liegen. In andern fällen sieht man die beiden nebeneinander liegenden gebogenen stäbrhen dentlicher. Wemn man sie nämlich

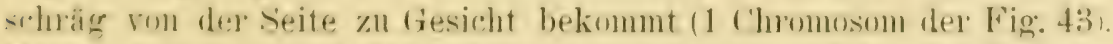

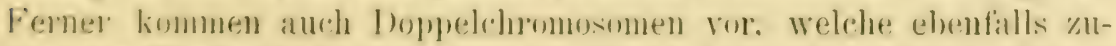

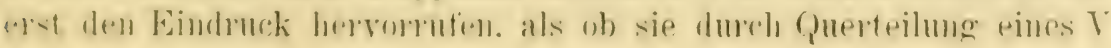


entstanden seien (Textfig. Bb); es sind aber auch lier die durch Längsspaltung entstandenen Hälften derselben, also wieder Vförmige Chromosomen, deren Schenkel einen größern Winkel bilden und die sich mit nur einem ihrer' Schenkel noch anliegen. Noch schwieriger sind auf den ersten Blick solche Gebilde zu deuten, welche aus 4 im Quadrat nebeneinander liegenden Körnchen zu bestehen scheinen und so ganz den Eindruck einer Vierergruppe machen (Textfig. Bg). Durch Heben oder Senken des Tubus kann man aber stets feststellen, daß die 4 Körnchen paarweise zusammenhängen und daß es sich auch hier nur um 2 nebeneinander liegende Vförmige Tochterchromosomen handelt, deren Enden die 4 Körnchen der scheinbaren Tetrade vortäuschen, wenn nur sie eingestellt sind. Sehr häufig sind ferner mehr oder weniger regelmäßige Krenze (Textfig. Bf): Sie wuirden die Deutung zulassen, daß sie durch paarweises Aneinanderlegen der Vförmigen Ringhälften an ihren Knickungsstellen nach der 1. Reifungsteilung entstanden seien. Nimmt man aber das an, so würde man z. B. in Fig. 43 zu viel Chromosomen zählen, mehr als 8. Daher muß man sie so deuten, daß sie die 2 durch Längsspaltung entstandenen Tochterchromosomen der 2. Reifungsteilung darstellen, welche an der ursprünglichen Knickungsstelle ihres Mutterchromosoms noch eine Zeitlang zusammenhängen. In andern Fällen haben sich die Tochterchromosomen schon ganz getremnt und bilden ebenfalls Kreuze, aber dadurch, daß sie schräg. ïbereinander liegen (Textfig. Be). Außer diesen sehr häufigen und charakteristischen Chromatinfiguren kommen noch viele andere und sehr mannigfache vor, welche sich aber immer auf die eine oder andere Weise als durch Längsspaltung entstanden erklären lassen. Um zusammenzufassen, sind also die 16 Einzelchromosomen der Äquatorialplatte der 2. Reifungsteilung als die Tochterchromosomen der 8 Ringhälften aufzufassen, und zwar sind sie aus diesen durch eine Längsspaltung entstanden, wie dadurch bewiesen wird, daß 1. schon während der Metaphase der vorhergehenden Teilung eine Längsspaltung mehr oder weniger deutlich auftritt und 2. in der Äquatorialplatte wenigstens ein großer Teil der 16 Tochterchromosomen die Vförmige Gestalt noch zeigt, welche sie infolge ihrer Entstehung durch eine Längsspaltung haben müssen. Es fällt bei der Betrachtung dieser 16 Tochterchromosomen auf, daß sie so dick sind; dies ist aber erklärlich aus der beträchtlichen Verkürzung; welche die Ringhälften, ihre Mutterchromosomen, erfahren. Ton der 
Seite bekommt man keine ïbersichtlichen Bilder der 2. Reifungsteilung. da hierzu die Chromosomen doch zu dicht liegen.

Die schon an den Schleifen des Synapsisstadiums und an den limgen deutlich erkennbaren Größenunterschiede der Chromosomen eines und desselben Kerns sind auch hier noch im gleichen Mraßstabe zu sehen. Auch die Terschiedenheit in der Größe der Chromısomen rerschiedener Kerne, die oben erwähnt wurde. ist hier zuweilen recht auffallénd (Fig. 43 u. 44).

Tachdem die Tochterchromosomen sich roneinander getremnt haben. Wandern sie nach den Spindelpolen: ilıre Tfürmige Gestalt. ist dort noch bald mehr bald weniger deutlich erkennbar (Fig. 45 n. 46). Schlieblich drängen sich anch hier wieder die Chromosomen zu einer halbkugligen Masse zusammen, welche sich vou den ühnlichen Stadien am Ende der Teilung einer Spermatogonie oder sirermatocyte 1. Ordnung leicht durch ihre geringere Größe unterscheidet. Die 'Teilungsbilder der Spermatocyten 2. Ordnung sind weitalls die häufigsten. welche man in den heranreifenden Follikeln antrifit.

Trie sich die C'entrosomen der 2. Reifungsteilung ron denen der 1. ableiten. komnte ich nicht mit Sicherheit feststellen. Wahrscheinlich werden durch die oben erwähnte Teilung der c'entrosomen an den Spindelpolen die beiden Centrosomen der Spermatocyte 2. Ordnung gebildet.

5. Spermatiden und A usbildung der Spermatozoen.

Auf die histogenetische Ausbildung der reifen Spermatozoen bin ich nicht näher eingegangen, da das Objekt für diesen Zweck zu ungünstig ist. Daher will ich nur das wenige anführen, was inh nebenbei fand und was in der literatur nicht erwähnt ist. Dagegen diirfte es nicht uninteressant sein, ïber die Terändermgen des Zulleibs der spermatiden etwas zu berichten. da diese die Frnährung der Spermatiden zum Zweck zu haben scheinen und ahnlichen Vorgängen bei andern 'Tieren analog sind.

a) Ernährung der S'permat iden. Nach Durchschniurung der: spermatoryte 2. Ordnumg hat die spermatidenzelle eine rundliche oder ovale Gestalt und liogt frei in dem Lumen des Hodenfollikels. Dann streckt sich die \%olle, 1 m zuerst lang oval und shlileblich sehr lang und schmal zu werden. Wenn sie diese Form erreicht hat. befindet sich der kern ganz an dem einen binde der Yelle. und dieste selbat liegt nicht mehr free im Follikellumen. 
sondern mehrere Zellen, bis zu 30 und mehr, sind zu einem Büschel vereinigt. Thre kernfreien, konvergierenden Enden sitzen einer Stelle der Follikelwandung auf, während die kernhaltigen Enden, frei in das Lumen hineinragend, strahlenförmig divergieren (Fig..4). Dabei sitzt ein solches Spermatidenbüschel nicht einer sogenannten Fußzelle auf. sondern steht nur in Berührung mit dem Plasma der die Follikelwand bildenden Spermatocyten. In dem Übersichtsbild (Fig. 3) sind die Spermatidenbüschel teils längs, teils quer oder schräg getroffen, daher das verschiedene Aussehen. Es ist einleuchtend, daß durch die Anlagerung der Spermatiden an die Wand die 'Zufuhr von Nährmaterial zu ihnen ermöglicht wird, und man kann als Beweis für diese Auffassung geltend machen, daß die Verlängerung der der Wand angehefteten Spermatiden zugleich eine Vergrößerung der Zellen darstellt. In seltnen Fällen aber scheinen die Spermatiden keine solche Lagerung einzunehmen, denn man findet $a b$ und $z u$ im Follikellumen eine größere kuglige Plasmamasse, um welche, teilweise noch in ihr steckend, zahlreiche halb oder ganz reife Spermatozoen herumgewickelt sind. Es scheint sich hier also um eine Anzahl von Spermatiden zu handeln, die sich zu einem Klumpen vereinigt haben. -- Von diesen Plasmakugeln sind andere zu unterscheiden, welche mehrere, ungefähr 2-8 Kerne in allen Stadien der Degeneration mit Auflösung des Chromatins im Plasma enthalten. Diese Kerne gleichen, wenn sie noch nicht zu stark degeneriert sind, den Spermatocyten oder den Spermatiden. Eine ernährende Bedeutung haben diese degenerierenden Zellen wohl nicht, denn es wäre schwer zu erklären, wie ihr Material von den Spermatiden aufgenommen werden könnte. In den Ovarien des gleichen Tiers fand ich aber Zellen, für welche eine Bedeutung als Nährmaterial wahrscheinlich ist.

b) Bemerkungen über die A usbildung der Spermatozoen. Die halbkuglige, dichte und dunkel gefärbte Chromatinmasse, welche von den Tochterchromosomen der 2. Reifungsteilung gebildet wird, geht unter den gleichen Vorgängen, welche für die Anaphase der Spermatogonien geschildert wurden, in einen sphärischen Kern mit lockerm, fädig angeordnetem Chromatin über (Fig. 47 u. 48). Durch Verkleinerung des Kerns und Verdichtung des Chromatingerïsts entsteht eine kuglige, intensiv und homogen sich färbende Chromatinmasse, welche in einem hellen Hof liegt. Weiterhin wird der Kern birnförmig; sein spitzes Ende liegt dicht an der Oberfläche der Zelle. Solange das Chromatin noch locker angeordnet war, 
komnte man bei Eisenhämatoxylin-Färbung in den meisten Fällen 2 kleine Kïrnchen erkennen, welche fast immer auf entgegengesetzten Seiten des Kerns liegen. Wenn der Kern birnförmig geworden ist, liegt an seinem spitzen Ende ein Förnchen. welches die schwarze Farbe länger beibehält als das Chromatin (Fig. 49). Manchmal *chien es. als ob an dieser stelle nicht 1, sondern 2 Körnchen lägen, ein dem Kern unmittelbar angelagertes und ein mehr peripher gelegenes: von letzterm schien dam oft ein kurzes blasses Fädchen auszugehen. Weiter habe ich die beiden Centrosomen, welche in diesen Kürnchen wohl zu suchen sind, nicht verfolgen künnen. ...ebenkörper." (Thloderer, 1903) fand ich bei den angewandten Methoden nicht. Der Yorgang, wie sich die birnförmigen Spermatidenkerne in die sehr langen. gleichmäßig dümnen Spermatozoen mmandehn. ist schon mehrfach beschrieben worden, z. B. von IrJmi 1884, und Sterexs (1903); Teues kamn ich nicht hinzufügen, auch liabe ich immerhalb der fertigen spermatozoen keine feinere Differenzierumg gefunden.

\section{Die Samenreifung anderer Planarienarten.}

Fon der im Torstehenden geschilderten Samenreifung bei Plamavia ymocepluta Drox. weicht jene bei den andern vergleichsweise herangezogenen Tricladen (Polycelis migra Енвв., P. cormita O. Sснм. und Dendincoelum larteum OERst.) so gut wie nicht ab, so dab einige wenige Bemerkungen über die gemachten Beobachtungen genügen. Die Starlien der Doppelfäden (Synapsis) sind auch hier die hänfigsten, welche man in der Follikelwand antrifft. Die Symapsis rollzieht sich auf die gleiche Art und Weise. Die Zahl der Doppelchromosomen, welche in den Spermatocyten von Dendrocoelum lacteum und Prolyctis nigm bestimmt werden konnte, betrug wie bei Plan. gonocophale 8; in den Follikeln von Polyc. cormuta fanden sich zufällig nur wenigr 'Teilungsstadien, so daß ich hier die Chromosomenzahl nicht feststellte. GröBenunterschiede der Chromosomen waren auch hin in gleichem Malistabe zu rkemen. Die 1. Reifungsteilung trem iiberall die beiden Ringhälften. Der Wert der 2. Teifungsreilung war besonder's bei Dendorodum gut zu erkenmen, dal die Ringhalften sohon vor Beginn der Metaphase die Laingsspaltung dentlich zeigen. Abwoichend von den spermatoryten 1. Ordnmer W.1. andern Arten, finden sich in denen von Polyc. cormutu anber dem

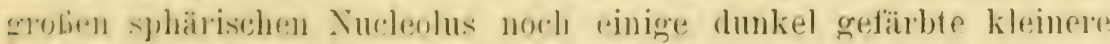

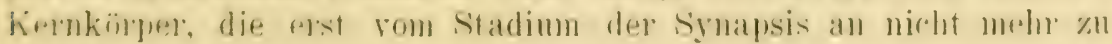


sehen sind. Sie färben sich ebenso wie der sphärische Kernkörper nach der Eisenhämatoxylin-Methode intensiv schwarz; sie liegen an der Kernperipherie. Über ihre Entstehung und ihr Schicksal habe ich nichts herausbringen können.

\section{Zusammenfassung.}

Die Spermatogonien enthalten im Monasterstadium 16 schleifenförmige Chromosomen, welche deutliche Größenunterschiede erkennen lassen. Die durch Längsspaltung entstandenen 16 Chromosomen jeder der beiden Tochterzellen der letzten Spermatogoniengeneration, also die Chromosomen der jüngsten Spermatocyten 1. Ordnung, wandeln sich während der Anaphase in ein Kerngerüst um, in welchem die einzelnen Chromosomen nicht mehr zu erkennen sind. Die Zahl der Spermatogoniengenerationen scheint nicht konstant zu sein, möglicherweise können auch die großen Parenchymzellen („Stammzellen") sich direkt in Spermatocyten umwandeln.

In den jüngsten Spermatocyten 1. Ordnung sind die einzelnen Chromosomen nicht zu erkennen. Durch Aneinanderreihen der im Kernraum (wirklich oder nur scheinbar?) ohne besondere Anordnung verteilten Chromatinkörnchen entstehen wahrscheinlich 16 dünne, ungefähr Vförmige Chromatinschleifen, deren freie Enden nach einer Seite des Kerns und deren Umbiegungsstellen nach der entgegengesetzten Seite gerichtet sind. Diese 16 Chromatinschleifen sind also ganz ähnlich gelagert wie die 16 Tochterchromosomen einer Spermatogonie, bevor sie während der Anaphase unkenntlich werden.

Im Synapsisstadium legen sich je 2 Fäden der Länge nach aneinander, so daß 8 Doppelfäden entstehen. Die Lagerung der letztern im Kern ist dieselbe; sie zeigen deutliche Größenunterschiede, ferner sind sie, auf frühern Stadien wenigstens, ebenso wie die dünnen Schleifen aus einzelnen Körnchen zusammengesetzt. Durch die Synapsis wird also eine sog. Pseudoreduction der Chromosomenzahl bewirkt. Ein parweises Aneinanderlegen der einzelnen Mikrosomen ließ sich nicht erkennen.

Die definitiven Chromosomen der 1. Reifungsteilung entstehen dadurch, daß sich die Doppelfäden verkürzen; dabei trennen sich die Einzelfäden wieder voneinander und hängen nur noch an ihrelı Enden miteinander zusammen, welche so die Verklebungsstellen der ringähnlichen Doppelchromosomen darstellen.

Bei der Teilung der Spermatocyten 1. Ordnung tremen sich die Ringhälften voneinander. Da jede Ringhälfte aus einer der 16 Schleifen 
hervorgegangen ist. stellt also die 1 . Reifungsteilung eine Reductionsteilung im sinne IVEIsunaxy's dar.

Während der folgenden Metaphase und namentlich daum. Wem die 8 Chromosomen der Spermatocyte 2. Ordnung sich in der $\ddot{A} q u$ torialplatte angeordnet haben, zeigen sie dentlich eine Längsspaltung. Ein Ruhestadium tritt zwischen der 1. und 2. Reifungsteilung nicht ein. Bei der letztern werden die Längshälften der 8 Chromosomen auf die spermatiden rerteilt. Die 2. Reifungsteilung ist also eine Äquationsteilung: Die Reifung der mämnlichen Geschlechtszellen bei den Planarien folgt also dem Präreductionsmodus.

Wie der Nucleolus in den jüngsten Spermatocyten entsteht. läßt sich nicht erkennen. Tährend des Synapsisstadiums, manchmal anch etras früher. geht er eine Zweiteilung ein. Während der' Ausbildung der Chromosomen entziehen sich seine Teilprodukte der Beubachtumg und sind auch später nicht wieder aufzufinden. Der Nucleolus steht in keiner erkennbaren Beziehung zum Chromatin.

Es ist nicht nachweisbar. ob die Centrosomen in den ruhenden suermatocyten inuerhalb orler auBerhalb des Kerns liegen. Zuerst sind sie mit Sicherheit erkennbar als 2 Körnchen an den Spindelpolen und teilen sich daselhst während der Metaphase. Tie sich ilne Teilprodukte in den Spermatocyten 2. Ordnung rerhalten. bis sir wieder an den spindelpolen erscheinen, blieb mir unbekannt.

Die spermatiden heften sich büschelweise an die Wand der Hodenfollikel an; dadurch ist eine Nahrungszufuhr zu den zuerst isoliert im Lumen liegenden spermatiden ermöglicht.

\section{YJ. Vergleichung der Ei- und Samenreifung bei den Plannien.}

In meiner Arbeit ïber die Oogenese bei Planariu gonocenludu 19015, habe ich diese zwar nu bis zur Ausbildung der ('hromosomen der 1. Reifungsteilung verfolgt. Es zeigen sich aber schon bis zu diesen rtadium teils su wrobe Öbereinstimmungen, teils so auffallende Verschiedenheiten in dem Verhalten des ('homatins in den spermatu. und oocyten, dab eine Vergleichumg der ki- und simenreifung hinsichtlich der feinsten am chromatin zu beobachotenden Vorgänge lohnend erscheinen diirfe. Voransuschicken ist dir.

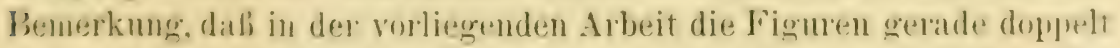
s) stark rergröbert sind wie in der erstgenannten: um dit Ver-

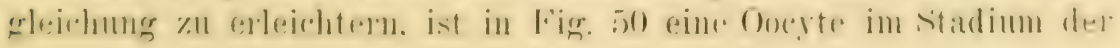


Synapsis bei der gleichen Vergrößerung wie die Spermatocyten dargestellt.

Die Grundlage unserer vergleichenden Betrachtung bildet die Erkenntnis, welche wir den Arbeiten von Platner (1889), Boveri (1887-1890) und besonders von O. Hertwig (1890) verdanken, daß Ei- und Samenreifung zwei vollkommen homologe Prozesse sind. Daher kann die Ähnlichkeit oder teilweise vollkommene Gleichheit in dem Verhalten der Spermato- und Oocyten nichts Überraschendes bieten, wohl aber erfordern die beobachteten Verschiedenheiten eine Erklärung.

Um es kurz zusammenzufassen, stimmen die Vorgänge bei der Ei- und Samenreifung der Planarien in folgenden Punkten miteinander überein. Spermatogonien und Oogonien enthalten beide im IIonasterstadium 16 schleifenförmige Chromosomen mit deutlichen Größenunterschieden. In den Tochterkernen beider Zellarten sind die Chromosomen von der Anaphase an nicht mehr zu unterscheiden. In den jungen Spermato- und Oocyten entwickeln sich aus den, anscheinend wenigstens, unregelmäßig im Kernranm verteilten Chromatinkörnchen die 16 dünnen Fadenschleifen, welche eine ähnliche Lagerung im Kern einnehmen wie die Tochterchromosomen am Ende der vorangehenden Teilung. Bis zu diesem Stadium sind auch die beiderlei Geschlechtszellen von ziemlich gleicher Größe. Die Synapsis erfolgt bei beiden durch parweise Vereinigung der 16 dünnen Fadenschleifen. Gemeinsam ist auch, daß die Chromatinfäden auf einigen Entwicklungsstadien aus einzelnen Microsomen zusammengesetzt sind. Aus den Doppelfäden entstehen die definitiven Doppelchromosomen. Die beiden Reifungsteilungen habe ich, wie gesagt, in der Oogenese nicht verfolgt, aber aus der Lage der Doppelchromosomen in der 1. Richtungsspindel und aus der frühzeitig sichtbaren Längsspaltung in den Einzelchromosomen läßt sich mit Sicherheit schließen, daß die Eireifung ebenso wie die Samenreifung nach dem Präreductionsmodus vor sich geht.

In den folgenden Punkten verhalten sich die Spermato- und Oocyten verschieden:

1. Die Doppelfäden sind in den Oocyten erheblich größer als in den Spermatocyten, wie aus einer Vergleichung der Figg. 50 und 17 hervorgeht. Es möchte fast scheinen, als ob auch die Körnchen, aus denen die Fäden zusammengesetzt sind, in den Oocyten größer sind, soweit sich darüber bei ihrer unregelmäßigen Gestalt ein Urteil bilden läßt. 
2. In den spermatocyten bilden sich die Duppelfïden direkt zu den ringfürmigen Chromosomen $1 \mathrm{~m}$. wie oben beschrieben ist. In den Oocyten tremnen sich die Einzelfäden nach der Synapsis zwal anch wieder auf größere Strecken hin, sie rerkiurzen sich aber dabei nicht. um sofort die beiden Ringhälften zu bilden, sondern sie rerlängern sich im Gegenteil sehr stark; dabei verlieren sie die oft erwähnte charakteristische Lagerung, und dadurch kommt bei oberflächlicher Betrachtung ein Bild zustande, als ob sämtliche Chromatinfäden nach der Synapsis wieder zerfallen, so wie das z. B. nach S'HockaERT (1902) in der Oogenese ron Thysonozoon brocchi der Fall sein soll. Eine weitere Eigentiumlichkeit der Oocyten ist die. dali sich ihre Ioppelfäden auf diesem Stadium dicht an die Kernoberfläche anlegen und daß das Kerninnere rollkommen chromatinfrei ist. während etwas derartiges in den Spermatocyten nicht rorkommt.

3. Die definitiven Clromosomen der 1. Reifungsteilung sind in den spermatocyten mehr oder weniger regelmäßige, in der Richtung ler Spindelachse ausgezogene Ringe; in den Oocyten ist die Ringform nur selten deutlich zu sehen, und die Doppelchromosomen sincl hier meistens Doppelstäbchen oder ganz unregelmäßige Gebilde. deren Doppelwertigkeit aber stets durch eine Längsspalte angedeutet ist. In den Einzelchromosomen der Oocyten ist schon seln früh mit großer Dentlichkeit eine Längsspaltung eingetreten. welcht spüter allerdings oft wieder undentlich wird. In den Spermatocyten erfahren die Ringhälften erst damn eine Längsteilung: wemn sie sich hei der Metaphase voneinander getrennt haben. Eine Telgleichung der Größenunterschiede der Chromosomen in den Spermatocyten mit jenen in den Oocyten läßt sich eben infolge ihrer rerschiedenen Form auch nicht annähernd durchführen.

4. Ein weiterer Unterschied ist hinsichtlich des Nucleolus vorhanden. In den Spermatocyten ist el klein, teilt sich eimmal durch mon ist dann kurz nach der Synapsis nicht mehr nachweisbar. In den focyten ist er ganz erheblich gröber. namentlich nach der synapsis: er enthält hier häufig Vacuolen und schnürt mehrmals kleine Körperchen ab. Er bleibt anch viel länger bestehen, schwindet aber dann auch. wenn die ('homosomen sich definitiv ausbilden.

5. Der letzte: wichtigere Cnterschied ist der, dab der Zelleil, der Oucyten ganz erheblich gröber ist als jener der spermatocyten. ein Cinterschied, weleher ja bekannt genug ist. Anf jünger'n stadien ist er, wie schon oben erwiblut, nicht rorhanden oder arering. Dir. 
Größenzunahme, also die „Wachstumsperiode“, der Oocyten fällt in die Zeit der Synapsis und besonders in die Zeit nach dieser.

Wie oben schon hervorgehoben wurde, erfordern die eben aufgezählten Unterschiede in der Ei- und Samenreifung eine Erklärung; denn bei der vollkommenen Gleichwertigkeit, welche die Chromosomen des Eies und des Spermatozoons nach allen bisherigen Erfahrungen besitzen, müßten sie auch denselben Entwicklungsprozeß durchmachen, namentlich da gezeigt werden konnte, daß die Oogonien und Spermatogonien, ja sogar noch die jüngsten Oocyten und Spermatocyten einander zum Verwechseln ähnlich sehen. Man muß also folgern, daß das, was beiden Prozessen gemeinsam ist, das Wesentliche derselben darstellt und daß das Abweichende, was in dem einen oder dem andern Reifungsprozeß zutage tritt, nur der Ausdruck der besondern Funktion der betreffenden Art von Geschlechtszellen ist. Von dem Gemeinsamen zeigt nun die Spermatogenese wenig Abweichungen; das Spezielle der Leistung der männlichen Geschlechtszellen tritt eben erst nach der Reifung auf, bei der Ausbildung der beweglichen Spermatozoen. Dagegen zeigt die Eireifung viele Eigentümlichkeiten; von diesen mögen zunächst besprochen werden die Größe der Doppelfäden, ihr scheinbarer Zerfall nach der Synapsis und die mit diesem scheinbaren Zerfall einhergehende Ansammlung der Doppelfäden an der Kernoberfläche. Nan darf vielleicht annehmen, daß die genannten Eigenheiten in kausaler Beziehung zu einer andern stehen, nämlich zu der stärkern Größenzunahme der Oocyten, welche während der Wachstumsperiode, besonders nach der Synapsis, zu konstatieren war. Ausgehend von der sicher gestützten Vorstellung, daß der Kern einen bestimmenden Einfluß auf die Stoffwechselvorgänge seiner Zelle und damit auf ihr Wachstum ausübt, kommt man zu der Folgerung, daß die nenerliche postsynaptische Ausbreitung des Chromatins und seine Ansammlung direkt an der Grenze zwischen Kernvacuole und Plasma das Chromatin unter die guinstigsten Beziehungen setzt, damit es mit dem Zellplasma in Wechselbeziehung treten kann. Wenn aber die Chromatinschleifen zı einem dichten Knäuel zusammengedrängt sind, so wie es im Synapsisstadium der Fall ist, und außerdem noch im Innern der Kernvacuole liegen, so können sie allem Anschein nach kaum in Beziehung zum Zellplasma treten. Ich möchte also aus dem Vorstehenden folgerm, dab die nur in der Oogenese auftretende postsynaptische Ausbreitung der Chromatinfäden an der Kernoberfläche den Zweck hat, dem Chromatin die Leitung der während der 
Irachstumsperiode natürlich sehr starken Assimilation neuen Materials zn ermöglichen. Ferner möchte ich rermuten, daß die erheblichere frö̈be der Chromatinschleifen in den Oocyten etwas ähnliches belentet: man könnte sich rorstellen, dab sie der Ausdruck einer zeitweiligen Hypertrophie des Chromatins ist während des stärkern Zellwachstums. Denn die fertigen Chromosomen der 1. Reifungsspindel sind in den Spermato- und Oocyten wieder ungefäh gleichgrub. ebenso wie die Spermato- und Oogonien und ferner die jüngsten spermato- und (Jocyten sich hinsichtlich ihres Chromatingehalts nicht merklich unterscheiden. Ein Einwurf läßt sich gegen diese Auffassung machen: Die Oocyten nehmen schon während der Synapsis an tiröle zu. wenn auch nicht so stark wie später; diesem Finwurt kam aber zweierlei entgegengehalten werden: 1. künnte während der Syrupsis blob Material in die Zelle anfgenommen, nicht aber verarbeitet. assimiliert werden, und zu ersterm Prozeß ist die Mitwirkung. des ('hromatins vielleicht nicht nötig; 2. könnte aber auch der Kern schon zu einer frühern Zeit Teilchen an das Zellplasma abgegeben lraben, welche während der Srmapsis zur Leitung des Assimilationsrorgangs ausreichen könnten. Übrigens hebt auch Mnnfrar 1905 hervor, daß im Teleosteerei die Dotterbildung nach ler Srnapsis beginnt. - So lassen sich also in diesem Fall die speziellen Chromatinverhältnisse. d. l. die besondere Entwicklungsweise der l'hromosomen der weiblichen Geschlechtszellen, erklären aus ihrer speziellen physiologischen Aufgabe.

Ton diesem Gesichtspunkt ans ließe sich auch der Lnterschied verstehen. der in den spermatocyten und Gocyten hinsichtlich der Gröbe des Nucleolus besteht. Stellen wir ms auf den Boden der Haw krr'schen 'Theorie (1895), nach welcher der Nucleolus ein Kernsechet rarstellt. so wird die erheblichere Größe des Kernkïrperchens in den rocyten rerständlich, da in den Oocyten die Assimilation. die sirh wohl unter dem binflul.s des C'lromatins vollzieht. infolge der Interbildung stäker ist. Demn einer stäkern T'atigkeit des Kerns miilite anch eine stäliere Secretion, also ein gröberer Nucleolus

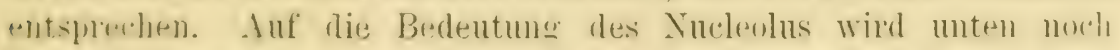
zuriickzukommen sein.

Vicht erkliat ist anch die entwickelte Auffasmag der. Inter-

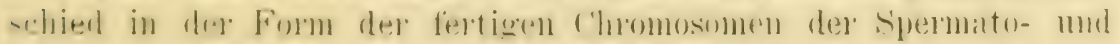

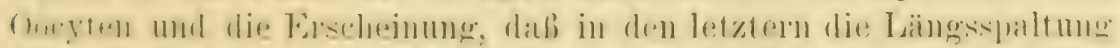

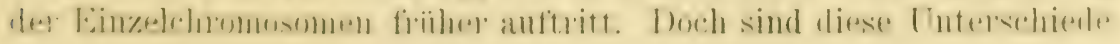


wohl keine wesentlichen, wenigstens spricht nichts dafür, daß die Form der Chromosomen eine besondere Bedeutung besitzt.

\section{Allgemeines.}

Zum Schluß möge noch untersucht werden, ob die in der vorliegenden Arbeit gewonnenen Resultate geeignet sind, einiges zur Beantwortung der in der Einleitung aufgeworfenen Fragen beizutragen.

1. Die Individualitätstheorie. Am SchluB der letzten spermatogonialen und oogonialen Teilung fanden wir die Chromosomen an den Polen zusammengedrängt, die Umbiegungsstellen nach dem entsprechenden Pol, die freien Enden nach dem Äquator der Spindel gerichtet. Später waren die einzelnen Chromosomen nicht mehr erkennbar. Erst im Stadium der dünnen Chromatinschleifen ließen sich wieder, wenigstens mit großer Wahrscheinlichkeit, alle 16 Chromosomen erkennen; sie waren ebenfalls wieder ungefähr $\mathrm{V}$-oder Uförmig, ihre Umbiegungsstellen sahen wieder nach einer Seite, ihre freien Enden nach der entgegengesetzten. Wenn nun also die Tochterchromosomen der Spermato- und Oogonien auch nicht Schritt für Schritt verfolgt werden konnten, bis sie die Chromosomen der Spermato- und Docyten darstellen, so bildet doch die im Vorstehenden hervorgehobene Gleichartigkeit in der Form und Lagerung ein schwerwiegendes Moment für die Annahme, daß die 16 Fadenschleifen der Oocyten und Spermatocyten die Tochterchromosomen der vorhergehenden Generation von Oo- und Spermatogonien sind. Es wäre wenigstens schwer, einen andern Grund sich vorzustellen. warum die 16 Chromatinschleifen diese für die Tochterchromosomen der vorangehenden Teilung charakteristische Lagerung einnehmen, welche später während der Ausbildung der definitiven Chromosomen der 1. Reifungsteilung dann doch aufgegeben wird. Eine weitere Beobachtung unterstiitzt diese Auffassung; Fig. 15 zeigt 2 Kerne im Synapsisstadium. Die Chromatinschleifen derselben, welche allerdings nicht ganz vollständig eingezeichnet werden konnten, sind derartig gelagert, daß die freien Fadenenden in jedem Kern nach dem andern Kern hinsehen. Genau so sind die Tochterchromosomen am Ende der Teilung einer Spermatogonie gelagert, und ich möchte auch aus der Form des Zelleibs der beiden Spermatocyten schließen, daß sie die zueinander gehörigen Tochterzellen einer Spermatogonie sind. Es deckt sich das vollständig mit dem schon eingangs er- 
wähnten Befund ron Rabl (1875), nach welchem in den Epidermiszellen der Larve ron Sulanantia die Chromosomen. welche aus dem ruhenden fierngerüst hervorgehen, annähernd dieselbe Lagerung zeigen. welche die Tochterchromosomen bei der rorhergehenden Teilung ror ihrem Übergang in das Kerngerüst einnahmen. Sicherlich findet aber bei den Planarien kein nachträglicher Zerfall der' 16 'hromatinschleifen oder' der 8 Doppelschleifen nach der Synapsis statt. Wie ron ScHockient 1902) für Thysanozoon brocchi und ron zahlreichen andern Autoren für andere Objekte beschrieben rorden ist. In den spermatocyten und, wie ich in meiner vorangehenden Arbeit gezeigt labe, ebenso in den Oocrten ist davon nichts zu sehen. insbesondere nichts. woraus man eine Auflösung ron Chromatin im Fernsaft oder eine Ausstoßung sichtbarer Teile des Chromatins aus dem Kern in das Plasma erschließen könnte.

Venerdings: hat sich Frck (1905) gegen die Individualitütstheorie ansgesurochen und zwar deshalb, weil die Terschiedenheit der Chromsomenzahl bei nahe rerwandten Tieren und umgekehrt das häufige Vorkommen gleich vieler Chromosomen bei weit entfernt stehenden auber der Unwichtigkeit der Chromosomenzahl anch die Unhaltbarkeit der Individualitïtstheorie beweise. Mir scheint aus der angeführten Tatsache nur das hervorzugehen, da. man aus der Gleichlheit der Chromosomenzahl zweier Tiere nicht auf ihre TerWandtschaft schließen darf: dagegen scheint sie mir die Boreri'sche Ansicht nicht zu widerlegen. nach welcher die Konstanz ler Chromosomenzahl bei einer und der'selben Art einen guten Stützpunkt dei Individualitatstheorie darstellt. Auberdem beweist doch die Konstan\% der Chromusmenzahl bei der gleichen Art unzweifelhaft eine gewisse Wichtigkeit der Zahl, und damit läßt sich die andere Tatsache ohne s.hwierigkeit rereinigen. dab ansnahmsweise auch Arten rorkommen. welche in zwei Varietäten zerfallen, von welchen die eine doppelt so riel C'hromosomen besitzt wie die andere. Ïbrigens diurfe eine vergleichende Zusammenstellumg der chromosomenzahlen imnerhall,

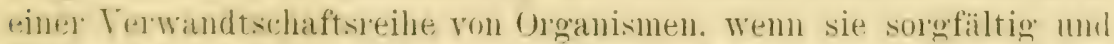
vollstindige genug ausgefiihrt wird, doch vielleicht einen Aufschluti iiber die Bedeutung der Chromosomenzahl ergeben.

II ie schon in der Finleitung angedentet wurde. muli man abes

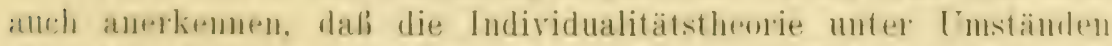

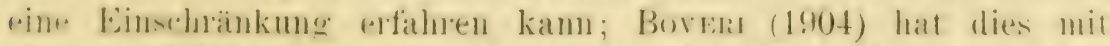
Prozte anf die Protisten ansresprochen. Vor allem scheint mir aber

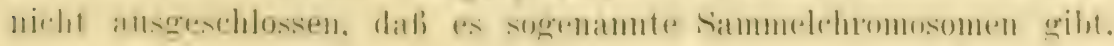


welche aus mehreren niedern, unter sich aber essentiell gleichen Einheiten bestehen und welche in diese Einheiten zerfallen können, die sich dann zu nenen Sammelchromosomen in anderer Weise gruppieren können. Weisuans (1892), welcher aus gewissen Erscheinungen der Vererbung ebenfalls schließt, daß die ganzen Idanten (= Chromosomen) bleibende Gebilde sind, hält es auch nicht für unmöglich, daß Änderungen in der Zusammensetzung der Idanten aus Iden eintreten können. Würde sich das bestätigen, so könnte es nicht ohne Einfluß bleiben auf die Beantwortung der zweiten Frage, zu welcher wir uns jetzt wenden.

2. Qualitative Verschiedenheit der Chromosomen. Für die besonders von Suttox und Boveri vertretene Hypothese, daß die einzelnen Chromosomen einer reifen Geschlechtszelle qualitativ verschieden sind, hat letzterer (1904) zwei Beweise angefïhrt, 1. seine Beobachtungen an dispermen Seeigeleiern und 2. die Größenverschiedenheiten der Chromosomen innerhalb eines Kerns. Was zunächst letztern Punkt anlangt, so haben sich derartige Größenunterschiede der Chromosomen auch bei den Planarien sowohl in der Spermato- wie in der Oogenese leicht feststellen lassen. Es ist aber oben schon hervorgehoben worden, daß gerade das, was für die genannte Theorie von besonderer Wichtigkeit sein wiirde, sich bei den Planarien nicht feststellen ließ: erstens sind die Größenunterschiede nicht konstant in dem Sinn, daß alle oder wenigstens mehrere Chromosomen an ihrer Größe erkennbar wären, und zweitens sind in den Spermato- und Oogonien nicht nachweisbar je 2 Chromosomen gleich groß. Wenn nun auch solche negative Befunde weniger Beweiskraft haben, so kommen noch folgende positive Beobachtungen hinzu, welche für die Auffassung der Bedeutung der Größenunterschiede von Einfluß sind: 1. wechselt die Größe der Chromosomen sehr erheblich nach ihrer Entwicklungsstufe, 2. sind die Chromosomen einer Spermatocyte öfters durchschnittlich deutlich größer als die einer andern, und 3. sind die auf der gleichen Entwicklungsstufe (etwa der Synapsis) stehenden Chromosomen der Oocyten erheblich größer als die der Spermatocyten. Aus dem Gesagten scheint mir nun zu folgen, daß den Größenunterschieden der Chromosomen geringere Bedeutung beizulegen ist als bisher geschehen; mindestens ist $\mathrm{zu}$ schließen, daß verschiedene Größe allein keine verschiedene Qualität anzeigt, denn sonst wären ja die Chromosomen einer Spermatocyte qualitativ verschieden von denen einer andern oder einer Oocyte, was theoretisch nicht denkbar ist. Man könnte vielleicht 
aber ammehmen. dab die rerschiedene Größe eine individuelle Tershiedenheit der Chromosomen bedentet oder dab sie ihren Grund in der rerschieden starken physiologischen Tätigkeit hat, wie oben hinsichtlich der Größendifferenzen der ('hromosomen in den Spermatomul Oocyten vermutungsweise ausgeführt wurde. Auch Fick (1905) hebt hervor. dab dem Umstand bei den bisherigen Untersuchungen iiber die Chromosomenverschiedenheiten noch wenig Rechmung getragen wurde, dab nämlich jedes Chromosom längere Zeit braucht zur rollen Ausbildung seiner typischen Form und daß die Bilder. Welche man rou den Chromosomen erhält, gewissermaßen nur \omentbilder sind. Die große Mehrzahl der Angaben, nach welchen in len jungen Spermato- und Oocyten eine Anzahl an ihrer rerschiedenen Gröbe sicher unterscheidbarer Chromosomenpare vorhanden sein sollen und die beiden g]eichgroßen, in der Symapsis sich rereinigenden Chromosomen väterlichen und mïtterlichen Trsprungs sind. scheint mir zu wenig begründet zu sein. So bilden z. B. A. 11. K. E. Schrenter (1905) in ihren figg. 21-26, tab. T, die Chromosomen der Spermatogonien von Myxine ab; ich kann mich len genannten Antoren wenigstens nach ihren Bildern nicht anschließen. wenn sie annehmen, daß ron den 52 (hromosomen je 2 wleich groß sind und die 26 Paare konstante Größenunterschiede zt:igen: ich glaube. daß dies bei der Kleinheit und der Menge dieser ' 'hromosomen überhaupt nicht festzustellen ist. Nicht einmal das möchte ich den Bildern mit sicherheit entuehmen. daß in jeder vpermatugonie ein Parr gleicher und besonder's grober Chromosomen ron allen andern (hromatinelementen sicher zu unterscheiden ist. In der Suermatugenese ron Brachystola scheint nach Strow (1902, die Konstanz der Gröbenverschiedenheit der Chromosomen ja sicher zu sein: us fehlt aber meines Wissens der Nachweis. daß die ('hromosomen auch in der Oogenese an ihrer Größe wieder zu erkemmen sind.

Die bekannten Beobachtungen von Bovkn (1902) an dispermen Seeigeleiern bilden zweifellos eine wertvolle Stuitze der 'Theorie der () ualitätsverschierlenheit der ('hromosomen. Immerhin ist schon ron verschiedenen Seiten. \%. B. yon Fick (1905), darauf hingewiesen worden. dali die Borkaschen Experimente nicht eindentio sind. und dathes diurfe olne andere unterstïtzende Beweismomente die Theorie dery (gnalitatsverschiedenheit nicht geniigend begrïndet sein.

Es gibt noch ein anderes Gebiet. anf welchem sich intscheiden läbt, ob die C'homosomen qualitativ gleich oder versehioden simb.

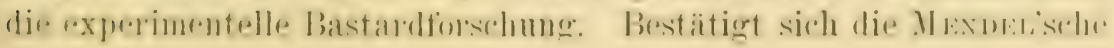


Regel der "Reinheit der Gameten“, so wird man notwendigerweise zu der Ansicht kommen müssen, daß in der reifen Geschlechtszelle nur eine Determinante einer Eigenschaft vorhanden ist, daher würden dann die Chromosomen nicht qualitativ gleich sein können. Die "Reinheit der Gameten" ist aber, wie anch MoRgar (1905) hervorhebt, bisher nichts weniger als bewiesen.

3. Die "Conjugation" der Chromosomen. Das Vorkommen einer mehr oder weniger vollständigen paarweisen Vereinigung der Einzelchromosomen vor den Reifungsteilungen ist, wie schon eingangs erwähnt wurde, ein fast allgemeines. In den allermeisten Fällen soll nach den vorliegenden Angaben die Paarung der Chromosomen derart erfolgen, daß die Einzelchromosomen mit je einem ihrer Enden vereinigt sind; ich führe als Beispiel nur die von Ḧ̈скER (1896-1902) und von RückeRt (1894) studierten Copepoden sowie die zahlreichen Untersuchungen von Mostgomerr über die Reifungsvorgänge bei den Insecten an. Die paarweise Vereinigung der Chromosomen in der Weise, wie sie im Vorstehenden für die Planarien beschrieben wurde, ist bisher erst in wenigen Fällen, auf zoologischem Gebiet, vor allem bei Wirbeltieren, beobachtet worden. Die erste hier zu erwähnende Arbeit ist die ron Winiwarter (1901), welcher die Bildung der Oocyten beim Kaninchen und Menschen untersuchte. Er fand, daß vor dem Synapsisstadium das Chromatin in Form von dünnen Fäden den Kern durchsetzt; diese Fäden verlaufen oft parallel, und Winiwarter hält es für wahrscheinlich, daß je zwei dünne Fäden sich paarweise aneinander legen. Diesen Vorgang faßt Wintwarter als das Wesen der Synapsis auf. Wintwarter konnte aber nicht feststellen, ob die Doppelfäden ein einziges zusammenhängendes Band oder mehrere Schlingen bilden; jedenfalls aber entstehen die Chromosomen dadurch, daß sich das einheitliche Band oder die Schlingen durch Querteilung segmentiert. Ähnliches berichtet Schomsfeld (1901) für die Spermatogenese beim Stier.

A. u. K. E. Schrenner (1905) sind bei Myxine zu folgenden, ganz analogen Resultaten gelangt: Sie fanden in den Spermatogonien etwa 52 Chromosomen. In den jüngsten Spermatocyten sind die Chromosomen als solche nicht mehr zu erkennen, auch hier durchsetzt das Chromatin in Form von feinen Fäden den Kern. Diese Fäden lassen bald deutlich erkennen, daß sie nach einem Pol gerichtet sind; je 2 nehmen einen parallelen Verlauf, und schließlich ist das ganze Chromatin in Doppelfäden angeordnet. Dieselben verlaufen in langen, 
zam Teil gewmulenen schleifen lurch den Kern. so dab die Enden her schlingen gegen die polare Partie des Kerns konvergieren: an lieser stelle hängen mehrere Schlingen zusammen. Die Doppelfäden yeigen antier der durch die parrweise Tereinigung zweier Einzeltiiden entstandenen spalte noch eine solche in den Einzelfäden selbst. Sach den Autoren entspricht die Zahl der Schlingen der der Doppelhromosomen - 26 - nicht. sondern letztere entstehen durch quere regmentierung der Doppelfüden. Die Teilung selbst geschieht in lerselben Teise als Präreductionsteilung wie bei den Planarien. Also rerlänft die Spermatogenese bei Myrine in allen wesentlichen Punkten wie bei unserm objekt, mit der Ausuahme, dab die Zahl ler Chromatinschlingen nicht der Zahl der Chromosomen entspricht. Wäre es aber nicht möglich. dab das in ler Tat der Fall ist und dab die Autoren es wegen der großen Zahl ron Doppelchromusomen 26 gegenüber \& bei den Planarien) nicht feststellen komnten? Ihre tig. 71. tal) 9 läßt die Termutung aufkommen, dal, die beiden (1)jekte auch in diesem Punkt. der für die Frage der Individualität der Chromosomen ron Bedeutung ist, übereinstimmen.

Ganz die gleichen Torgänge mie bei den Planarien fand schlieli-

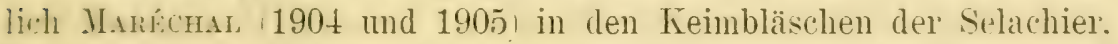
Telensteel und. suweit untersucht. auch in denen ron Amphioxus und ('imu. Tie C̈bereinstimmung ist hier noch vollständiger' als bei den 2 andern Arbeiten, da M.ırích.ı ebenfalls kein zusammenlängendes - firemstadium. sondern stets nur einzelne Fäden fand. Lagerung: faarweise Terklebung der Fäden der Länge nach usw. verlanten genau so, wie in den andern Arbeiten beschrieben ist.

Eine weitere hierher gehörige Arbeit ist die Lntersuchung von Jussoxi 1905) über das Entstehen des Bouquetstadiums in den

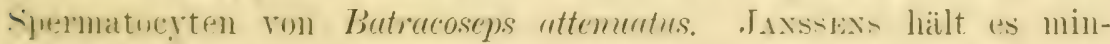
destens fïr sehr wahrscheinlich, dab bei diesem ohjekt die 1르 shleifen des Boupuetstadiums duch parweises Aneinanderlegen

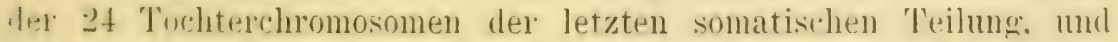
zwar ilner ganzen lä̈nge nach. 'ntstanden sind. Dis, Finzeltiident liergen sich dabei eine Zeitlang so dioht an, dab die dicken sidheifen Hes Bonguetstadiums keine spur ihres Doppeleharakters mehr yeigen. Jerselbe tritt aber später dureh Wiedererseheinen der Längspalta

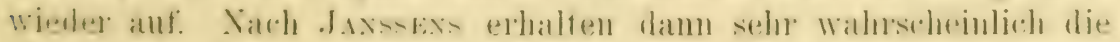

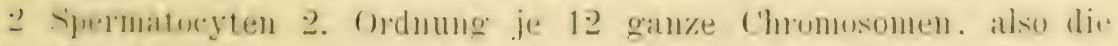

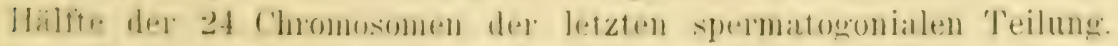
Was die Wirbellosen angeht, so hat Lrin' (1905) bei der 
Spermato- und Oogenese von Cyclons stremus ebenfalls eine parallele Conjugation zweier dünner Fäden gefunden und stellt sich dadurch in Gegensatz zu den frühern Autoren (Ḧ̈скER, Voм Rath und Rückert).

Auf die neuern, ganz gleichlautenden Angaben auf botanischem Gebiet, die von Strasburger (1905) und einer Reihe anderer Autoren stammen, gehe ich nicht ein.

Wenn es nun auch ein Fehler wäre, nach den Befunden bei einigen Objekten die Beobachtungen an andern, weit entfernt stehenden korrigieren und umdeuten zu wollen, möchte ich es doch nicht unterlassen, auf die große Ähnlichkeit hinzuweisen, welche die Figuren der genannten Autoren und meine eignen mit den entsprechenden vieler anderer Arbeiten über Reifungsteilung haben, wobei aber die letztern in ganz anderer Weise gedeutet wurden; auch A. u. K. E. Schreiner (1905) haben darauf aufmerksam gemacht. Man möge vergleichsweise einmal nur einige der Abbildungen (z. B. fig. 20, 21, 43, 44) betrachten, welche Montgomery (1905) in seiner Untersuchung über die Spermatogenese von Syrbula und Lycosa gibt. Ich kann mich ebensowenig wie A. u. K. E. Schreiner durch diese Figuren überzeugen lassen, daß die Schlingen durch Vereinigung zweier Chromosomen mit je einem ihrer Enden entstanden sind. Die Zahl ähnlicher Beispiele ließe sich noch sehr vermehren. Daher muß von jeder Arbeit über die Reifungsvorgänge der Geschlechtszellen in Zukunft der Nachweis verlangt werden, ob in frühen Stadien 2 Chromatinfäden sich der Länge nach vereinigen oder ob ein solcher Vorgang ausgeschlossen ist.

Was aber die innige Aneinanderlegung der Einzelchromosomen bedeutet, ist hente noch weit entfernt davon entschieden zu sein; zweifellos hat auch sie wie jede andere Tetradenbildung zur Folge. daß bei einer der beiden 'Teilungen eine Zahlenreduction der Chromosomen eintritt. $\mathrm{Ob}$ dies aber ihre einzige Bedeutung ist, darüber kann mit Erfolg erst dann diskutiert werden, wenn entschieden ist, ob dieses Vorkommen eine weitere Verbreitung hat.

4. Die Bedeutung des Nucleolus. Von allen Bestandteilen des Kerns sind diejenigen Gebilde, welche mit dem Namen Nucleolen bezeichnet werden, am rätselhaftesten geblieben. In ihrer Deutung stehen sich zwei Ansichten gegenüber. Nach der HäckERschen Auffassung (1895) sind die Nucleolen nichtorganisierte Stoffwechselprodukte, welche im Kern entstehen und denselben als secretartige Stoffe verlassen. Nach der gegenteiligen Ansicht bestehen die Nucleolen ans demselben Chromatin wie die Chromosomen und 
werden auch zum Aufbau der Chromosomen rerwendet. \%wischen beiden Anschaumgen steben eine Anzahl ron rermittelnden Auffasumgen. Bei den Planarien wird sicherlich der Nucleolus in keiner Weise zum Aufbau der ('hromosomen rerwendet, auch nicht in der Weise. wie sie Taxisers (1905, für den Nucleolus der Spermatocyten ron Batracoseps annimmt. Ebensowenig ist etwas zu sehen. Was datïr spricht. daß die Chromosomen in den Nucleolus einwandern. um dort irgend eine Veränderung einzugehen. wie dis zuerst ron (rïxthen (1903) beschrieben wude. Sollte sich die lï̌mufrsche Angabe bestätigen, so wäre es jedenfalls ein Torkommnis vou keinerlei allgemeiner Bedeutung. Die Befunde an den Planarien lassen sich vielmehr, wenn man überhaupt eine Deutung unternehmen will. am ungezwungensten mit der Hïcrer schen Kernsecretthenrie rereinigen. Dafür spricht der schon erwähnte Umstand. dab der Nucleolus in den stärker wachsenden Eiern größer wird und länger bestehen bleibt als in den kleiner bleibenden Spermatocyten. Ferner erinnert die starke Färbbarkeit des Nucleolus mit Eisenliünatoxylin an die Affinität vieler Secretkörner zu diesem Farbstoft. Tnd schlieblich darf man auch aus der Beobachtung: daß Teile des Vucleulus und schlieblich dieser selbst aus dem Kern austritt, ohne daf el in erkennbare Beziehung zu den Chromosomen getreten ist, schlielien. lab er sich wie ein Secret verhält. Wichtig wäre es allerdings. zu wissen. wie der Nucleolus entsteht. Auch eine Beziehung zwischen Nucleolen und Centrosomen ist bei den Planarien nicht festzustellen.

Zum Schluß dieser Arbeit möchte ich Herrn Geheimrat Prof. In. Wersms für die vielen Anregungen, die ich ihm rerdanke. und fïr sein Interesse an meiner Arbeit meinen herzlichsten Dank sagenl.

Freiburg i. Br.. Juni 1906.

\section{Nachtrag.}

Eist narde Alschluli der vorliegenden Arbejt bekam ich die

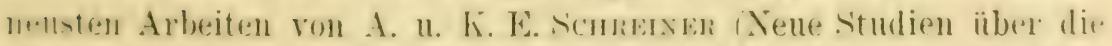

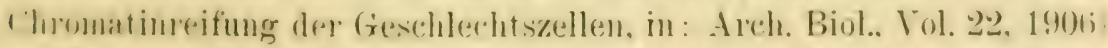

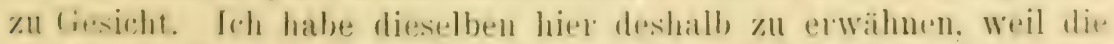

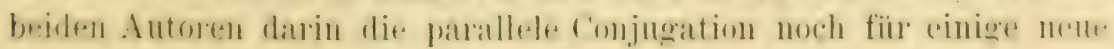


Objekte (einen Ammeliden Tomopteris u. a.) beschreiben. Vor allem muß ich aber hervorheben, daß die beiden Autoren es nun auch für sehr wahrscheinlich halten, daß die dünnen und dicken Fadenschleifen in den Spermatocyten von Myxine jeweils einem Chromosom bzw. einem Doppelchromosom entsprechen; eine Segmentierung der Schleifen nehmen sie also nicht mehr an.

\section{Literaturverzeichnis.}

BergHs, J., 1904, La Formation des chromosomes hétérotypiques dans la sporogénèse végétale, in: Cellule, Vol. 21.

Bonnevie, K., 1905, Das Verhalten des Chromatins in den Keimzellen von Enteroxenos oestergreni, in: Anat. Anz., Vol. 26.

BoyerI, TH., 1887, 1888 und 1890, Zellenstudien I-III. Jena.

—, 1902, Über mehrpolige Mitosen als Mittel zur Analyse des Zellkerns, in: Verh. phys. med. Ges. Würzburg.

—, 1904, Ergebnisse über die Konstitution der chromatischen Substanz des Yellkerns. Jena.

Bresslad, E., 1904, Beiträge zur Entwicklungsgeschichte der Turbellarien. I. Die Entwicklung der Rhabdocoelen und Alloiocoelen, in: Z. wiss. Zool., Vol. 76.

Chicknoff, G. D., 1892, Recherches sur les Dendrocoeles d'eau douce (Triclades), in: Arch. Biol., Vol. 12.

CurTis, W. C., 1902, The life history, the normal fission and the reproductive organs of Planaria maculata, in: Proc. Boston Soc. nat. Hist., Vol. 30.

EIsEn, G., 1900, The spermatogenesis of Batracoseps, in: Journ. Morphol., Vol. 17.

FICK, R., 1905, Betrachtungen über die Chromosomen, ihre Individualität, Reduktion und Vererbung, in: Arch. Anat. Physiol., Anat. Abt., Suppl.

Fоот, K., and E. C. Strobeld, 1905, Prophases and metaphases of the first maturation spindle of Allobophora foetida, in: Amer. J. Anat, Vol. 4.

Fraxcotte, P., 1898, Recherches sur la maturation, la fécondation et la segmentation chez les Polyclades, in: Arch. Zool, expér. (3), Vol. 6. 
GÉrard, O.. 1901, Iiovocyte de premier ordre du Prostheceraeus vittatus, in: Cellule, Tol. 18.

(iolischund, 1905, Eireifung, Befruchtung und Embryonalentwicklung des Zoogonus mirus, in: Zool. Jahrb., Vol. 21, Anat.

Frtrither, K., 1903, Über den Nucleolus im reifenden Echinodermenei und seine Bedeutung, ibid., Vol. 19, Anat.

HAECher, V., 1905, Die Eibildung bei Cyclops und Canthocamptus, ibid., Vol. 5, Anat.

-. 1905̆, Die Vorstadien der Eireifung, zusammenfassende Untersuchungen über die Bildung der Vierergruppen und das Verhalten der Keimbläschen-Nucleolen, in: Arch. mikrosk. Anat., Vol. 45.

-, 1899, Praxis und Theorie der Befruchtungslehre, Jena.

- 1902, Über das Schicksal der elterlichen und großelterlichen Kern. anteile. Morphologische Beitrïge zum Ausbau der Vererbungslehre, in: Jena. Z. Naturwiss., Vol. 37.

Hertwri, O., 1890, Vergleich der Ei- und Samenreifung bei den Nematoden, in: Arch. mikrosk. Anat., Vol. 36.

JAXs:Ex, F. A. 1902, La spermatogénèse chez les Tritons, in: Cellule, Vol. 19.

-, 1905, Spermatogénèse dans les Batraciens. III. Evolution des Auxocytes mâles du Batracoseps attenuatus, ibid., Vol. 22.

IIJIMA, J., 1884, Untersuchungen ïber den Bau und die Entwicklungsgeschichte der Sïßwasser-Dendrocölen (Tricladen), in : Z. wiss. Zool,, Vol. 40).

J゙LIx, Ch, 1893, Ovogénèse, spermatogénèse et fécondation chez Styelopsis etc., in: Bull. sc. France Belg., Vol. 25.

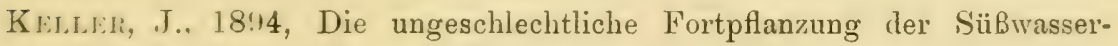
turbellarien, in: Jena. Z. Naturwiss., Vol. 28.

Krx;, H. D., 1901. The maturation and fertilization of the egg of Bufo lentiginosus, in: J. Mlorphol., Vol. 17.

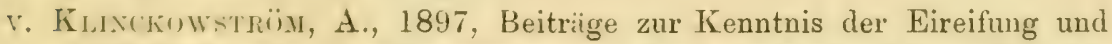
Befruchtung bei Prostheceraeus, in: Arch. mikrosk. Anat., Tol. 48.

Konscint, E.. 1895, Über Kernteilung, Eireifung und Befruchtung bei Ophryotrocha puerilis, in: Z. wiss. Zool., Vol. 60.

Korsthit, E.; und K. Hinen, 1902, Lehrbuch der vergleichenden Entwicklungsgeschichte der wirbellosen Tiere, Jena.

L.1..., A. 1884, Die Polyclarlen des Golfs von Neapel, in: Fauna Flora Neapel, Nonogr. 11.

LEAIT, I'., 1911.5, Les phénomenes de maturation dans l'ovogenèse et lia spermatogenèse du Cyclops strenuus, in: Cellule, Vol. 22.

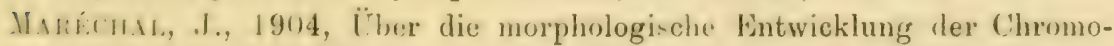
somen im Keimblïschen der Selachier, in: Anat. Anz., Vol. 25.

- 1905, Ciber die morpholorgicelue Entwicklung dex ('hromosomen im Teleostierei, ibir., Vol. 26. 
Mattiesen, E., 1904, Ein Beitrag zur Embryologie der SüBwasserdendrocoelen, in: Z. wiss. Zool., Vol. 77.

Montgomery, TH. H., 1899, Chromatinreduction in Hemiptera, in: Zool. Anz., Vol. 22.

-, 1900, The spermatogenesis of Peripatus balfouri up to the formation of the spermatid, in: Zool. Jahrb., Vol. 14, Anat.

- 1901, A study of the chromosomes of the germcells of metazoa, in: Trans. Amer. phil. Soc., Vol. 20.

-, 1905, The spermatogenesis of Syrbula and Lycosa, with general considerations upon chromosome reduction and the heterochromosomes, in: Proc. Acad. nat. Sc. Philadelphia.

Morgan, T. H., 1905, The assumed purity of the germ cells in Mendelian results, in: Science (N. S.), Vol. 22.

Prantu, H., 1905, Reduktion und Karyogamie bei Infusorien, in: Biol. Ctrbl., Vol. 25.

RABL, C., 1905, Über Zellteilung, in: Morphol. Jahrb., Vol. 10.

RepiachofF, W., 1893, Zur Spermatogenese der Turbellarien, in: Z. wiss. Zool., Vol. 56.

SchleIP, W., 1906, Die Entwicklung der Chromosomen im Ei von Planaria maculata Dug., in: Zool. Jahrb., Vol. 23, Anat.

Schnemoer, K. C., 1902, Lehrbuch der vergleichenden Histologie der Tiere, Jena.

SchockanRT, R., 1901, L'ovogénèse chez le Thysanozoon Brocchi, 1. partie, in: Cellule, Vol. 18.

-, 1902, 2. partie, ibid., Vol. 20.

SchomnfeLd, H., 1901, La spermatogénèse chez le taureau et chez les mammifères en général, in: Arch. Biol., Vol. 18.

SchrenNER, A. und K. E., 1904, Die Reifungsteilungen bei den Wirbeltieren, in: Anat. Anz., Vol. 24.

—, 1905, Über die Entwicklung der männlichen Geschlechtszellen von Myxine glutinosa (L.), in: Arch. Biol., Vol. 21.

Stevens, N. M., 1904, On the germ cells and the embryology of Planaria simplicissima, in: Proc. Acad. nat. Sc. Philadelphia.

Strasburger, E., 1904, Über Reduktionsteilung, in: SB. Akad. Wiss. Berlin, Vol. 18.

-, 1905, Typische und allotypische Kernteilung, in: Jahrb. wiss. Bot., Vol. 42.

SutTon; W. S., 1900, The spermatogonial division in Brachystola magna, in: Bull. Univ. Kansas, Vol. 9.

-, 1902, On the morphology of the chromosome group in Brachystola magna, in: Biol. Bull., Vol. 4.

TretjakofF, D., 1905, Die Bildung der Richtungskörperchen in den Eiern von Ascaris megalocephala, in: Arch. mikrosk. Anat., Vol. 65.

-, 1905, Die Spermatogenese bei Ascaris megalocephala, ibid., Vol. 65. 
Thx den Stricht, O., 1898, La formation des deux globules polaires et l'apparition des spermocentres dans l'oeuf de Thysanozoon, in: Arch. Biol., Vol. 15.

v. WAGXER, F., 1890, Zur Kenntuiss der ungeschlechtlichen Fortpflanzung von Microstoma, in: Zool. Jahrb., Vol. 4, Anat.

WeIsmaxi, A., 1887, Über die Zahl der Richtungskörperchen und über ihre Bedeutung für die Vererbung, Jena.

—, 1892, Das Keimplasma, eine Theorie der Vererbung, Jena.

Winsus, E. B., 1896, The cell in development and inheritance, New York.

ץ. Wiм̌martel, H., 1901, Recherches sur l'ovogénèse et l'organogénèse de l'ovaire des Mammifères, in: Arch. Biol., Vol. 17. 


\section{Erklärumg der Abbildungen.}

Fig. 1-3 sind gezeichnet mit ZEIss Apochr. 1,5 mm, Comp.Okular 4, Tubuslänge $16 \mathrm{~mm}$ mit Hülfe eines ABBÉ'schen Zeichenapparats auf Objekttischböhe; Fig. 4 ebenso nur mit Comp.-Okular 6; alle andern Figuren ebenso, nur mit Comp.-Okular 12.

\section{Tafel 1}

Fig. 1. Hodenfollikel, in Bildung begriffen, vom Parenchym noch nicht abgegrenzt.

Fig. 2. Hodenfollikel, älteres Stadium.

Fig. 3. Teil eines Querschnitts durch einen reifen Hodenfollikel; enthält büschelförmig angeordnete Spermatiden auf verschiedenen Ausbildungsstadien und in verschiedener Richtung vom Schnitt getroffen; ferner Spermatozoen. Links oben Follikelwand an einer Stelle nicht mehr vorhanden.

Fig. 4. Spermatidenbüschel.

Fig. 5. Sogenannte "Stammzelle"; Bordeauxrot, Eisenhämatoxylin.

Fig. 6. Spermatogonie; Äquatorialplatte mit 16 Chromosomen in Polansicht, 3 von den Chromosomen decken sich teilweise. Bordeauxrot, Eisenhämatoxylin.

Fig. 7 und 8. Spätere Teilungsstadien einer Spermatogonie. Bordeauxrot, Eisenhämatoxylin.

Fig. 9. Tochterkern einer Spermatogonie. Hämatoxylin, Pikrokarmin.

Fig. 10. Spermatocyte 1. Ordnung; jüngstes Stadium, Chromosomen nicht erkennbar; Bordeauxrot, Eisenhämatoxylin.

Fig. 11 und 12. Ausbildung des Stadiums der dünnen Chromatin= fäden; Bordeauxrot, Eisenhämatoxylin. 
- 102003

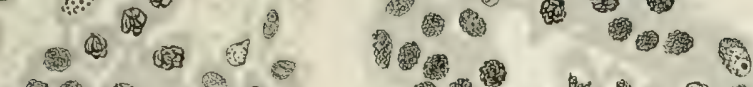

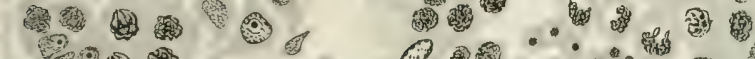
(2)

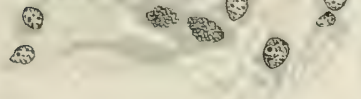

$$
\begin{aligned}
& \text { (ㄱ) } \\
& \text { 4. }
\end{aligned}
$$

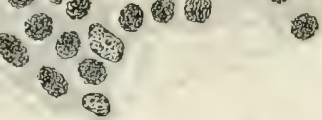
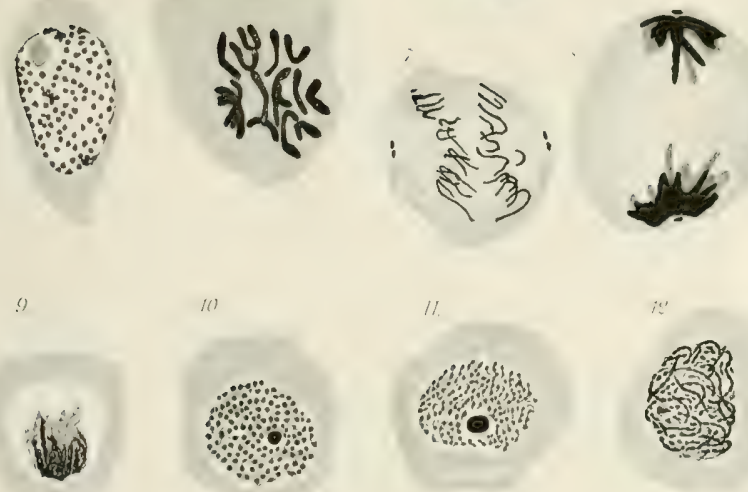

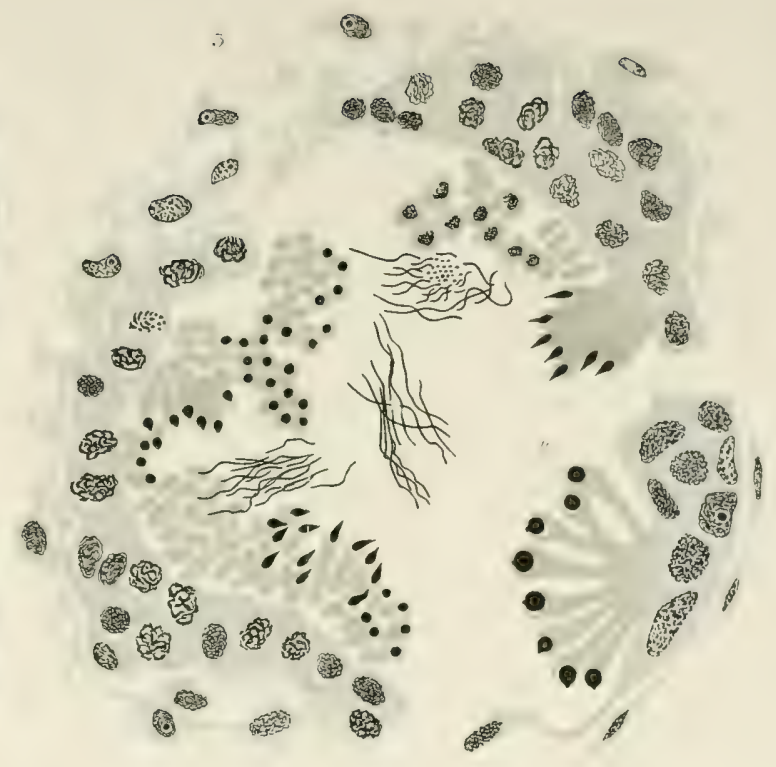

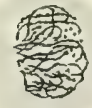
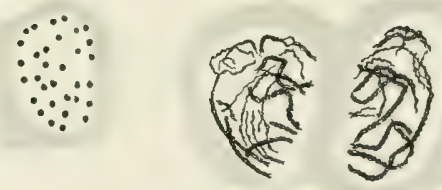

Fig. 13. Stadium der dünuen Chromatinschleifen; Bordeauxrot. Eisenhämatoxylin.

Fig. 14. Das gleiche Stadium, die Schleifenschenkel im Querschnitt gesehen; Bordeauxrot, Eisenhämatoxylin.

Fig. 15. 2 Spermatocyten im Synapsisstadium; dünne Fäden im Begriff sich zu Doppelfäden zusammenzulegen: Bordeauxrot, Eisenhämatoxylin.

\section{Tafel 2.}

Fig. 16. Stadium der dicken (hromatinschleifen, Längsspalte nicht zu sehen; Bordeauxrot, Eisenhämatoxylin.

Fig. 17. Dasselbe Stadium, deutlich 8 Schleifen sichtbar; Lïngsspalte nicht zu sehen; Bordeauxrot, Eisenhämatoxylin.

Fig. 18 und 19. Dasselbe Stadium, in Fig. 184 Schleifen eingezeichnet, in Fig. 19 die andern 4 Schleifen desselben Kerns. Längsspalte sichtbar.

Fig. 20. Dasselbe Stadium; von der Seite gesehen, nach welcher die Schleifenenden konvergieren; 15 freie Enden zu zählen; Hämatoxylin, Pikrokarmin.

Fig. 21 und 22. Dasselbe Stadium, die Schleifen im optischen Querschnitt gesehen. 16j bzw. 17 Fadeuquerschnitte zu zählen; Bordeauxrot. Eisenhämatoxylin.

Fig. 23-25. \%weiteilung des Nucleolus: Bordeauxrot, Eisenhämatoxylin (stark entfärbt).

Fig. 26-28. Einzelfäden trennen sich wieder; nur ein Teil oder Stücke der Doppelfäden eingezeichnet; Fig. 27 mit Hämatoxylin, Pikrokarmin, die andern mit Bordeauxrot, Eisenhämatoxylin gefärbt. karmin.

Fig. 29. C'hromatin dicht zusammengeknïuelt; Hämatoxylin, Pikro-

Figg. 30. Ausbildung der Chromosomen; Hämatoxylin, Pikrokarmin.

Fig. 31. Dasselbe Stadium; Bordeauxrot, Eisenhämatoxylin.

Fig. 32 und 33. 1. Reifungsspindel; Bordeauxrot, Eisenhïmatuxylin (Fig. 33 überfürbt).

Fig. 3. Dasselbe, nur + Ringe eingezeichnet: Hämatoxylin. Pikrokarmin.

Fig. 35. Dasselbe; Bordeauxrot, Eisenhämatoxylin. karmin.

rig. 3fi. Dassellee: Chromatinringe gedehnt; Hämatoxylin. Pikro-

Fig. 37-41. Alle Chromatinringe einiger spermatocyten 1. (1)dunng zur Vergleichung ihrer Größe.

Fig. 42. Metaphate der 1. Rerfungsteilung: in mindestens t von den 15) ichtharen Ringhälften eine Läsgsspaltung angedentet; Haimatoxylin. Pikrokarmin. 
Fig. 43. Spermatocyte 2. Ordnung in Polansicht; Chromosomen längsgespalten; Bordeauxrot, Eisenhämatoxylin.

Fig. 44. Die Chromosomen einer Spermatocyte 2. Ordnung; Bordeauxrot, Eisenhämatoxylin.

Fig. 45 und 46. Spermatiden in Polansicht; Bordeauxrot, Eisenhämatoxylin.

Fig. 47 und 48. Spermatiden in Anaphase; in Fig. 48 ein kleiner Nucleolus sichtbar; Hämatoxylin, Pikrokarmin.

Fig. 49. Späteres Ausbildungsstadium einer Spermatide; Bordeauxrot, Eisenhämatoxylin.

Fig. 50. Oocyte 1. Ordnung im Stadium der dicken Chromatinfäden, bei gleicher Vergrößerung gezeichnet; Bordeauxrot, Eisenhämatoxylin. 


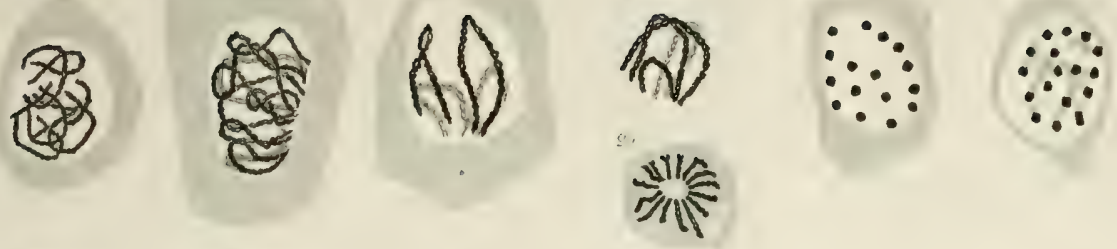

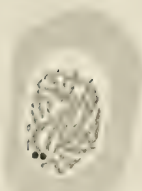

$$
\because \% \quad 27
$$
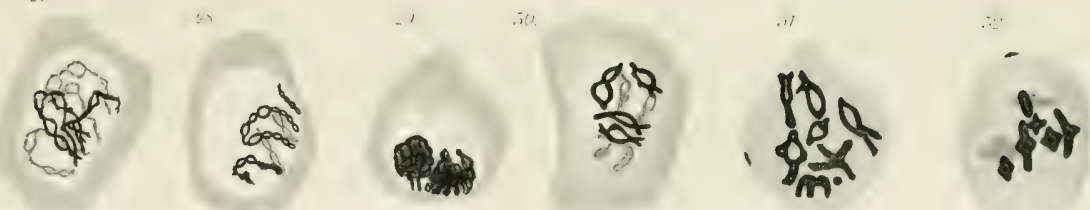

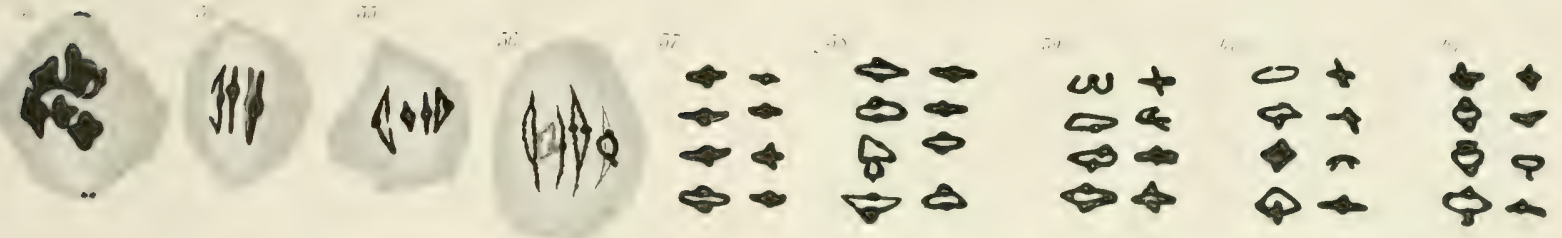

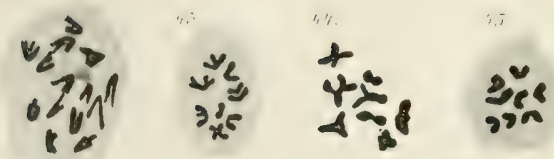

$$
30
$$
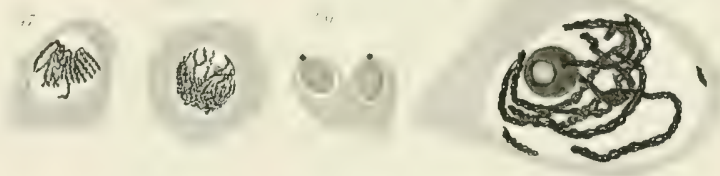



$$
\text { . }
$$



Die

\section{Entwicklung der Chromosomen} im Ei von Planaria gonocephala Dug.

\section{Inaugural-Dissertation}

zur

Erlangung der philosophischen Doktorwürde

der

Hohen philosophischen Fakultät

der

Albert-Ludwigs-Universität zu Freiburg i. Br.

vorgelegt von

\section{Waldemar Schleip,}

Dr. med.

aus Freiburg i. Br.

Naumbury a. S.

I ippert \& Co. (G. Pitz'sche Buchdr.). 
Pall hive:!

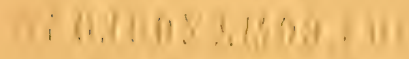

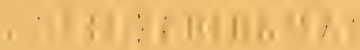




\section{Die \\ Entwicklung der Chromosomen im Ei von Planaria gonocephala Dug.}

\section{Inaugural-Dissertation}

zur

Erlangung der philosophischen Doktorwürde

der

Hohen philosophischen Fakultät

der

Albert-Ludwigs-Universität zu Freiburg i. Br.

vorgelegt von

\section{Waldemar Schleip,}

Dr. med.

aus Freiburg i. Br.

Naumburg a. S.

Lippert of Co. (Gi. Paitz'sche Buchdr.). 


\section{Harvard College Library \\ DEC 111907 \\ From the University \\ his excluzrere}

Gedruckt mit trenehmigung der philosophischen Fakultät der Universität Freiburg i. Br.

Der Dekan:

Prof. Dr. Orituanns.
Der Referent:

Geheimrat Prof. Dr. Whismann.

\footnotetext{
A b it $r u c k$

aus den
}

\%oologischon Jahrbichern. Bd. 23. Heft 2. Abt. f. Anatomie. 1906.

Heransgegeben von Prof. Dr. J. W. Spenget in Gießen.

Verlag von Gustav Fiscume, Jena. 


\title{
Die Entwicklung der Chromosomen im Ei ron Planaria gonocephala Dug.
}

\author{
Von \\ Waldemar Schleip, \\ Assistent am Zoologischen Institut in Freiburg i. Br.
}

Mit Tafel 1-2.

E: sind in der nellen und neuesten zeit eine ganze lieihe von Arbeiten über die Reifung der Keinzellen erschienen, deren Ergebnisse in folgenden Punkt miteinander übereinstimmen: Die ('hromosumen. Welche durch die Teilung der letzten Generation von (logonim bzw. Sipermatogonien zu den ('lnomosomen der oucyten baw. Suermatrcyten 1. Ordung geworden sind, gehen nicht als solche in die 'Homusomen der 1. Reifungsteilung über, somdern das aus ihmen entstandene fhromatingerüst zerfällt vollständig; einige Autoren ge-ben sogar an. liab rin Teil des Chromatins im Kernsaft sich aufliiser oder dabi sichtbare 'teile desselben in das Zellplasma answandern. I)ie definitiven ('hromosomen der 1. Reifungsspindel gehen dann alls einer meln wder weniger vollständigen venordnung des

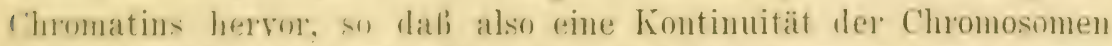
nicht bestïnde. Derartige lingänge sind besmuldrs fon den nemesten

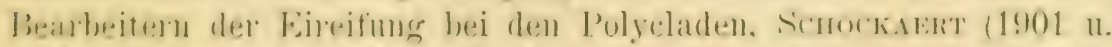

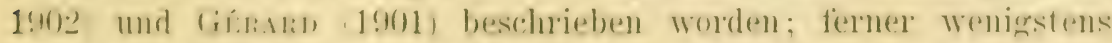

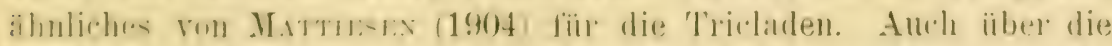
Fireifung andere Tierermpen sind ganz gleiche Angaben gemarh

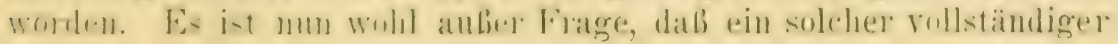


Zerfall der Chromosomen, wenn er sich bewahrheiten sollte, einen großen Einflub auf unsere theoretischen Torstellungen von der Bedeutung der Chromosomen haben müßte, und es dürfte daher nicht wertlos sein, an einem Objekt, für welches ein solcher Zerfall beschrieben ist, die Reifungsvorgänge nachzuprüfen. Es soll daher der Zweck der vorliegenden Arbeit sein, alle Veränderungen des Chromatins von der Oogonie bis zur Ausbildung der 1. Richtungsspindel soweit als möglich zu verfolgen. Auf die beiden Reifeteilungen selbst gehe ich nicht ein, und zwar deshalb, weil es mir aus äußern Gründen während der vergangenen 2 Jahre nicht möglich war, im Herbst zur Zeit der stärksten Eiproduktion die nicht ganz leichte Konservierung der Kokons selbst vorzunehmen; ïberdies diurfte die Art und Weise der Reifeteilungen - ob Reduktion oder Äquation - schon ohne weiteres aus der Form der definitiven Chromosomen hervorgehen. Ferner bin ich auch nicht auf die Ausbildung der achromatischen Figur eingegangen, da ich den Beobachtungen Mattiesen's in dieser Hinsicht wenigstens nichts wesentlich Neues hinzufügen konnte.

\section{Technisches.}

Die zur Untersuchung benutzte Planaria gonocephala DuG. wurde im Lauf der Jahre 1904 und 1905 gesammelt und Tiere zu allen Jahreszeiten fixiert. Als Fixierungsflüssigkeit diente hauptsächlich das von Petrunkewitsch (1901) modifizierte Sublimatgemisch nach Gilson, welches sich am geeignetsten erwies zur Darstellung der chromatischen Substanz; allerdings treten die Spindelfasern dabei nicht deutlich hervor. Zur Färbung wurde die Heidenhain'sche Eisenhämatoxylinmethode nach Vorbehandlung mit Bordeauxrot angewandt, außerdem noch BöHмer'sches Hämatoxylin und Gegenfärbung mit Pikrokarmin, was für viele Stadien bessere Resultate gibt als Eisenhämatoxylin. Ferner wurden Hämatoxylin-Pikrokarmin-Präparate zur Nachprüfung mit Eisenhämatoxylin umgefärbt. Die Schnittdicke betrug meistens 7,5 $\mu$; man kann bei solcher Dicke in den hellen Keimbläschen noch die feinsten Einzelheiten erkennen und lıat dabei den Vorteil, daß ein Keimbläschen in nicht zu viele Schnitte fällt; allerdings habe ich auch unter den jüngern Keimbläschen nur selten ein nicht angeschnittenes gefunden. 
Das Orarium.

Die Bedentung: relche die das Orarium der 'Turhellarien zusammensetzenden Zellen laben. ist in der Literatur schon rielfach erirtert worden. Immu (1884) findet zwischen den Eizellen. welche zurest in der Mitte des Orarimms heranreifen. kleine schlanke und relistelte Zellen. Welche den Eiern gerrissermaben als Lmhïllungsgewebe dienen: er tabt dieselben im Gegensatz zu Mnserser (1st4.

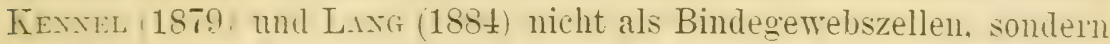
al. Eizellen auf. welche ihr Material an andere abgegeben haben. Wohei sie dam degenerieren. Lasg (1884) findet zwischen den jüngsten Eiern keine Follikelzellen. sondern erst zwischen den ältern: el leitet demnach sowohl die Ei- wie die Follikelzellen ron den das Teimlager bildenden Zellen ab. C'rrts (1900) läßt es mentschieden. ol) die zwischen den Eizellen liegenden kleinern Kerne unentwickelte Fizellen sind oder zu einem Bindegewebe gehören. Bei Plamain mumlata konnte der gleiche Yerfasser 1902) wahrscheinlich machen. dab sowohl die Eizellen wie die zwischen diesen liegenden kleinen Kerne ans den grolien Kernen des Parenchyms, den sog. Bildungszellen. hervorgehen. Mattresex (1904) erwähnt über die rerschiedenen Zellarten des Orariums nichts.

In den jüngsten orarien von Plan. gon., welche im Januar und Februar fixiert sind, findet man folgende Zellarten: 1. Zellen ohne dentlichte Aborenzung des Zellkürpers und mit verhältnismäbig groben Kernen. welche eine stark färbbare Kermmembran. einen mit Kernfarbstoften sich nur schwach färbenden Nucleolus und ein Chromatingeruist liaben. welches wenigstens scheinbar aus zahlreichen im Kernraum rerteilten unregelmäßigen Brocken besteht. Ihre Kerne gleichen vollkmmen den großen im Parenchym des 'Tiers vorkimmenden Kernen. welche die Kerne der von Kextare (1894) so genannten Stammzellen sind. Die Ovarien sind auf diesen Stadien moch nicht abgrenzbar. so dab oft nicht zu entscheiden ist. ob ein solcher Kern im Orarium oder in Parenchym liewt. Man findet auch Teilungstadien dieser herne. typische Mitosen, wie sie gatuz gleich atuh im Parenchym zu sehen sind. Je jünger ein Orar ist. $10 m$ so meln treten die beschriebenten ferne in ihnen hervor. Die ..Stammz:llen" sind alsi in rinklang mit den meisten der obengenamnteri

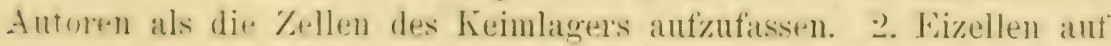
gan\% jungen Futwicklungsstadien. In den ganz reifen Grarien, ans Tieren, dir- inn Herbst fixiert sind, kam man 3 Arten von \%ellem 
unterscheiden: 1. Stammzellen in viel geringerer Zahl, 2. Eizellen auf allen Entwicklungsstadien, 3. sog. Follikelzellen, d. h. Zellen mit kleinen Kernen, zwischen den reifenden Eiern liegend. Alle 3 Arten von Kernen sind aber durch Übergangsstufen miteinander verbunden, und man kann mit Sicherheit schließen, daß sowohl Eizellen wie Follikelzellen aus den Stammzellen entstanden sind. Was die sog. Follikelzellen angeht, so dienen sie wohl in der Hauptsache als Umhüllungsgewebe; doch scheint es mir wahrscheinlich, daß eine oder die andere derselben, wenn gerade an einer Stelle im Ovarium viel Platz frei wird, sich auch wieder zu einer Eizelle entwickeln kann. Wir finden hier also noch keine so starke Spezialisierung der Follikelzellen für ihre besondere Arbeitsleistung. Auf die Bedeutung, die Iтנим ihnen zuspricht (s. o.), werden wir weiter unten noch zu sprechen kommen.

Eimmal habe ich noch eine weitere Zellart im Ovarium gefunden, nämlich Dotterzellen. Innerhalb eines völlig normalen Ovariums, welches Eier mit schon entwickelter 1. Richtungsspindel enthielt, lagen etwa 10-12 verschieden große Zellen, deren dicht mit Chromatin erfüllter Kern sehr dunkel erschien. In ihrem Plasma fanden sich zahlreiche Dotterkugeln, und das Plasma selbst zeigte sich nach der Eisenhämatoxylinfärbung intensiv schwarz granuliert. Die Zellen waren ringsum von Eiern auf verschiedenen Altersstufen umgeben (Fig. 1). Ein Vergleich mit den Zellen der Dotterstränge zeigte, daß die beschriebenen Zellen typische Dotterzellen sind. Da nun in der Nachbarschaft der Ovarien keine Dotterstränge zu sehen sind, so ist nicht anzunehmen, daß diese Dotterzellen etwa durch Wachstumsverschiebungen in das Ovarium hineingelangt sind; sie müssen vielmehr ebenso wie die Eizellen aus den "Stammzellen" entstanden sein, welche das Ovarium ursprïnglich zusammensetzten. Dieser Befund erscheint mir deshalb erwähnenswert, weil ja die Dotterstöcke als ein Teil der weiblichen Keimdrüse aufgefaßt werden, dessen Zellen nur noch Dotter bilden, aber sich nicht mehr zu entwicklungsfähigen Eiern ausbilden. Das oben beschriebene Verhalten, das wohl sicher ein abnormes ist, da ich es nur in einem Ovarium fand, scheint mir ein neuer Beweis für diese Anschaung zu sein.

\section{Oogonien.}

Die „Stammzellen", welche das junge Ovarium zusammensetzen, sind als Oogonien aufzufassen, da ihre Teilung ebenso verläuft wie diejenige der somatischen Zellen und da aus ihnen die Oocyten 
herrorgehen. Im Ruhestadium ist der Kern einer Oogonie ron einer ebenso wie das Chromatin färbbaren Membran umgeben, welcher zahlreiche Chromatinkörnchen angelagert sind. Außerdem sind viele Chromatinkörnchen unregelmäßig im Kernraum rerteilt, ferner liegt darin ein kleiner runder Nucleolus, der sich mit Eisenhämatoxylin intensiv schwärzt, nach Anwendung der übrigen Kernfarbstoffe aber blaß bleibt. Die Kerne der Oogonien sind zu klein, als daß man sicher feststellen könnte, ob das Chromatin wirklich in Form von Körnchen unregelmäßig in der Kernvacuole zerstrent ist oder ob etwa die Körnchen durch ein Liningerüst zu einem oder mehreren Fäden aufgereiht sind. Die Umwandlungen, welche der Teilung einer Oogonie vorangehen, bestehen darin, dab die Kernmembran verschwindet und daß allmählich statt der Chromatinkörnchen ein immer dentlicher werdender Chromatinfaden hervorgeht; doch sind gerade diese Stadien die seltensten. Im Monasterstadium kann man bei Polansicht der Teilungsfigur die Chromosomen genauer erkennen und zählen (Fig. 2). Man sieht hier unregelmäßige Schleifen, deren Zahl in der abgebildeten Zelle 16 beträgt. Bei dieser Ansicht ist in ihnen keine Längsspaltung zu erkennen. Es sind sehr deutliche Größenunterschiede zwischen den Chromosomen einer Zelle vorhanden; da aber bei der relativen Seltenheit der Oogonienteilungen überhaupt die Stadien, in welchen die Chromosomen so gut erkennbar sind, ungemein selten vorkommen, konnte nicht festgestellt werden, ob diese Größenunterschiede konstant sind. Aus der Abbildung kann man ferner auch nicht herausfinden, daß etwa je 2 Chromosomen von gleicher Größe sind. Bei seitlicher Ansicht des Monasters sind die Chromosomen wegen ihrer dichten Lagerung nicht zu zählen, man kann aber feststellen, daß sie eine Längsspaltung erfahren. Der Nucleolus ist auf diesem Stadium schon auf nicht näher erkennbare Teise verschwunden. An den Polen der Spindel sieht man die Centriolen als kleine schwarze Punkte; zuweilen ist eine hellere homogene Zone um sie herum vorhanden.

\section{Oocyten 1. Ordnung.}

Fs fragt sich: Teilen sich die „Stammzellen" oder Oogonien, Trelche das ganze junge Ovarium zusammensetzen, stets ein oder mehrere Male und werden dann erst die Tochterzellen dieser sekundären Oogonien zu Oocyten 1. Ordnung, oder können sie sich direkt olıne Teilung einfach in Oocyten umwandeln? Im letztern Fall wäre natiirlich die Bezeichnung Oogonie falsch und nur auf ihre Mutter- 
zellen anzuwenden. Diese Frage läßt sich nicht mit Sicherheit entscheiden und hat auch mohl keine besondere Bedeutung. Sicher ist, daß einige der Oogonien sich teilen, wie oben beschrieben ist, und daneben ist es sehr gut möglich, daß andere sog. Oogonien sich direkt in Oocyten umwandeln. Vor allem läßt sich die Frage deshalb nicht entscheiden, weil die jüngsten Oocyten sich ebenfalls wie die Oogonien in einem vollständigen Ruhezustand befinden, sie gleichen den Stammzellen des Parenchyms und des jungen Ovariums vollständig mit der Ausnahme, daß die Kernmembran nur von zahlreichen Körnchen dargestellt wird, welche der Kernoberfläche anliegen; gleiche Körnchen liegen zerstreut im Kernraum, und wir dürfen diese vielleicht als die Nicrosomen des spätern Kernfadens ansehen. Ein Liningerüst habe ich nicht feststellen können. Del Nucleolus ist bald vorhanden, bald fehlt er, trotz Anwendung verschiedener Färbemethoden. Der Plasmaleib ist auf diesen Stadien noch nicht abgrenzbar, und im Plasma selbst sind keine chromatophilen Körnchen zı sehen (Fig. 3).

Wir stoßen also hier gleich auf eine Lücke in der Kenntnis der Genese der Oocyten bei unserm Objekt; es fehlen die Stadien der Anaphase, d. h. der Umwandlung der Chromosomen der eben entstandenen Oocyten in das oben beschriebene Kerngerüst. Gerade das Fehlen dieser Stadien, die sonst bei der großen vorhandenen Zahl von jungen Oocyten häufig sein mïßten, spricht meiner Ansicht nach dafür, daß sich die ruhenden Kerne der Stammzellen direkt in die der Oocyten umwandeln können.

Ausbildung der dünnen Chromatinfäden(Fig.4). Auf dem nächsten Stadium hat der Kern erheblich an Größe zugenommen. Eine Membran ist nicht mehr zu erkennen. Das Chromatin ist noch als kleine Körnchen vorhanden, aber die meisten Körnchen sind zu kürzern oder längern Fädchen aneinander gereiht; dabei erscheinen jetat die Körnchen (= Microsomen) viel kleiner als in der Fig. 3. Ein Liningerïst ist, soweit erkennbar, nicht vorlıanden. Anfangs zeigen die Fädchen keine besondere Anordnung, doch bald, selbst dann wenn sie noch kurz sind, kann man doch erkennen, daß wenigstens viele von ihnen nach einem Punkt der Kernoberfläche gerichtet sind. In diesem Ausbildungszustand ist der Nucleolus sehr deutlich geworden; er ist größer und verhält sich bezüglich seiner Färbbarkeit wie der Nucleolus der Oogonien. Auffallend ist, dab man auf diesem Stadium zuweilen 2 Kernkörperchen findet, ein auf spätern und frïhern Stadien nie 
beobachtes Torkommen. Die weitern Lmwandlungen bestehen darin, daf allmählich statt der kürzern Fädchen längere hervortreten, die vorläufig noch mehr oder weniger deutlich eine Zusammensetzung aus Jricrosomen zeigen (Fig. 5). Durch die Sammlung des Chromatins in zusammenhängende Fäden wird die Kernvacnole, die unterdessen oft noch weiter an Größe zugenommen hat, heller. Schließlich ist folgendes Stadium erreicht (Fig. 6 u. 7): Das Chromatin ist in Form von Fäden angeordnet, welche eine glatte Begrenzung haben und demgemäß ihre Zusammensetzung aus Vicrosomen nicht mehr erkennen lassen. Die Dicke der Fäden ist schätzungsweise dieselbe wie die der Tochterchromosomen einer Oogonie während der Metaphase. Die Chromatinfäden zeigen eine sehr charakteristische Anordnung; sie bestehen aus einer Anzahl von Schleifen, deren Umbiegungsstellen in die helle Kernvacuole hineinsehen. während die freien Enden nach einem Punkt der Wand des ellipsoidischen Kerns gerichtet sind. Dieser Punkt kann sowohl an einem der Pole des Ellipsoids wie an einer beliebigen Stelle dazwischen liegen. Daß der Kernfaden nicht einheitlich ist, sondern, wie schon erwähnt, aus einer Anzahl von Schleifen besteht, kann man bei dieser Ansicht allerdings meistens nur schwer feststellen da die Fadenenden an der Stelle, nach welcher sie konvergieren, sehr zusammengedräng't sind. Die Fäden zeigen keine Spur einer Längsspaltung. Der große Nucleolus enthält meist 1 oder 2 verschieden große Vacuolen. Sehr charakteristisch ist seine Lage: er befindet sich immer in der Nähe der Stelle der Kernwandung, nach welcher die Fäden konvergieren. Stets ist er von letztern rings umgeben, ohne daß sie ihn aber berühren. Im Plasma findet man $\mathrm{ab}$ und zu einige unregelmäßige Körnchen, die sich mit Eisenhämatoxylin intensiv schwärzen. Die Centriolen habe ich hier noch nicht finden können. Die Chromatinschleifen sind, wie aus der Fig.6 u. 7 hervorgeht, von verschiedener Länge. Die Keimbläschen sind jetzt schon so groß, daß sie nie in einen einzigen Schnitt fallen, daher ist die Bestimmung der Zahl der Schleifen so gut wie unmöglich. Sieht man eine derartige Oocyte von der Seite des Kerns aus, nach welcher die Chromatinschleifen konvergieren (Fig. 8), so kann man zunächst feststellen, daß die Schleifen wirklich freie Enden haben. Die freien Schenkel erscheinen zum Teil nur als Punkte, nämlich dann, wenn sie im Querschnitt gesehen werden. Es sind mongähr 25-30 solcher freier Schenkel vorhanden, doch läbt sich ilıre Zahl nicht mit Sicherheit bestimmen. Faßt man die Faden- 
schleifen als die Chromosomen auf, welche durch die letzte Teilung einer Oogonie in die Oocyte 1. Ordnung übergegangen sind - und dazu berechtigt uns ihr weiteres Verhalten -, so müßte man 16 Fadenschleifen finden und demgemäß 32 freie Enden. Da aber nicht alle freie Fadenenden den Punkt erreichen, nach welchem sie konvergieren, so wird man öfters weniger als 32 freie Enden zählen. Andrerseits kann oft ein Schleifenschenkel infolge unregelmäßiger Kriummung doppelt gezählt werden. Alle freien Fadenenden scheinen bei dieser Ansicht gegen den Nucleolus zu konvergieren, ohne ihn aber zu berühren. Solche Oocyten können natürlich außer in den 2 beschriebenen Stellungen noch in den verschiedensten andern gesehen werden, und dann scheinen die Chromatinschleifen mehr oder weniger unregelmäßig zu verlaufen (Fig. 9).

Stadium der dicken Chromatinfäden: Die nächsten Stufen in der Ausbildung der Oocyten wollen wir vorläufig übergehen und zunächst folgendes sehr charakteristische Stadium betrachten: Das Chromatin ist wiederum in Form von Schleifen angeordnet, die sehr verschiedene Länge haben. Es ist auch hier bei seitlicher Ansicht (Fig. 13) meistens nicht möglich, mit Sicherheit zu entscheiden, ob die Schleifen ein zusammenhängendes Spirem bilden oder ob sie freie Enden haben. Sie zeigen genau dieselbe Anordnung wie auf vorigem Stadium. Es sind aber folgende wichtige Unterschiede vorhanden: 1. Die Zahl der Chromatinschleifen beträgt weit weniger als 16 , sie läßt sich aber nicht mit Sicherheit bestimmen, da die Kerne stets in 2 Schnitte fallen und die einzelnen Schlingen daher selbst durchschnitten sind; immerhin ist es nicht unwahrscheinlich, daß es 8 sind. 2. Die Fäden sind bedentend dicker als vorher, ziemlich genau doppelt so dick. 3. Die Fäden sind längsgespalten; diese Spaltung ist bald sehr deutlich, bald nicht, so daß sie oft im Bild nicht ohne Übertreibung wiedergegeben werden kann. Die Fäden zeigen ferner deutlich eine Zusammensetzung aus Microsomen, die viel größer sind als die Microsomen der dünnen Schleifen; und die Spaltung beruht darauf, daß diese Nicrosomen in der Längsrichtung des Fadens geteilt sind. Der Nucleolus hat seine schon oben erwähnte Lage beibehalten und noch weiter an Größe zugenommen; die Vacuolen in ihm sind auch entsprechend größer geworden. Chromatophile Granula sind fast immer im Plasma zu finden. Sie liegen häufig in der Nähe der Stelle, nach welcher die Schleifen konvergieren, also auch in der Nähe des Nucleolus. Der Zellkörper ist etwas, aber nicht viel größer ge- 
worden. Iie Fermracunle, die auf trühern Stadien hell war. ist jetzt ron einer fïdio-netzfirmig angeordneten Substanz erfüllt. zeigt also ganz die greiche struktur wie das Plasma. nur ist sie immer noch heller. Auch im stalium der dicken Chromatinschleifen kann man bei Ansicht ron der stelle aus, nach welcher die Fäden konvergieren. feststellen. dab hein einheitlicher Kernfaden rorhanden ist, sondern einzrhe schleifen (Fig. 14). Die Zahl der freien Enden erreicht 16 nie. in der abgebildeten \%elle sind sogar nur 9 zu sehen; der Grund. Trarum man die theoretisch zu erwartende Zahl 16 nie findet. sondern immer eine kleinele. ist derselbe. der schon oben für die entsprechende Erscheinung im stadium des diumen Spirems angeführt wurle. Der Fernfaden erscheint ferner in unregelmäBiger Ansicht, wenn man den Fern in einer andern als den beiden eben geschilderten Stellungen zu selen bekommt, Fig. 15\%. Stets ist es aber auffallend. dafi bedentend weniger Windungen als im stadium der dimnen Chromatinfäden zu sehen sind.

Entstehung der dicken Chromatinfäden aus den dünnen. - Synapsis.

Ls gibt filgende Möglichlieiten für die Entstehung der eben reschilderten dicken längsgespaltenen Chromatinschleifen aus den dünnen Fäden: 1. Entreder die eine Hältte der diumen Schleifen ist auf irond eine Teise verschwunden, und die übrigen haben sich verdickt mu der Länge nach gespalten. 2. Oder je 2 der dïnnen Schleifen sind mit je einem Ende miteinander verwachsen: durch starke Kontraktion des nun langen Fadens ist derselbe etwa doppelt so dick geworden, und dam ist die Längsspaltung aufgetreten. 3. Fs: könntell sich auch alle Schleifen zu einem kontinuierliehen spirem vereiniet haben. das sich dam ebenfalls durch hontraktion verlickte und damn in die halbe Zahl längsgespaltener richleifen zerlegte. 4. oder schlieflich: Es haben sich je 2 der diimen Fïden der. Länge nach ancinander gelegt zu einem dicken Faden. und die Längspalte in letzterm bedentet die noch sichtbare Tremungshinie seiner brilen fomponenten. Welche Anhaltspunkte finden wir num zur Entoheidung der lrage? Es sind keinerlei zaichen rorhanden.

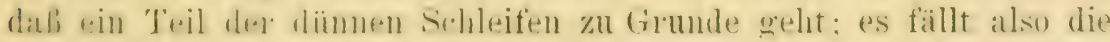
zurrat genante Mäglichkeit hinweg. Ferner finden wir stets freit.

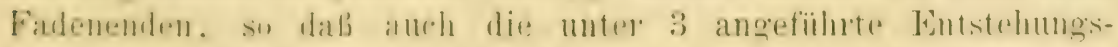

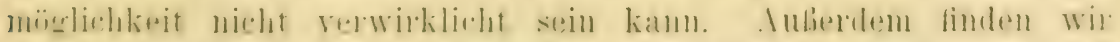

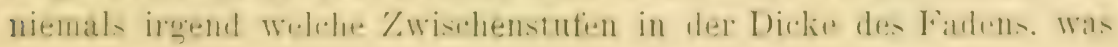


in gleicher Weise gegen die 3 ersten Entstehmosweisen spricht; immer sind entweder dümne oder dicke Fadenschleifen zu sehen. Wir haben also bisher keine Tatsache gefunden, welche gegen die zuletzt genannte Entstehungsmöglichkeit spricht; dagegen sind nun aber mehrere vorhanden, welche sehr entschieden für sie sprechen. Erstens findet man ab und zu Kerne im Stadium der dünnen Schleifen, in welchen je 2 der letztern wenigstens eine Strecke weit parallel und nahe nebeneimander verlaufen. In Fig. 10 sind, um das Bild nicht zu verwirren, nur einige Schleifen bzw. Teile von solchen eingezeichnet. Ferner sind solche Kerne verhältnismäßig häufig, in welchen neben den dicken, mehr oder weniger dentlich längsgespaltenen Schleifen noch dünne, halb so dicke wie jene, vorkommen, und man kann dann erkennen, daß mindestens sehr häufig in diesen Kernen immer 2 der dünnen Schleifen einander benachbart und auch schätzungsweise gleich lang sind (Fig. 11). Manchmal kann man auch dicke Schleifenschenkel finden, die sich an einer Stelle plötzlich in 2 dünne Fäden fortsetzen. Kerne dieser Zwischenstadien, welche man von der Seite aus sieht, nach welcher die Schleifenschenkel konvergieren, zeigen folgendes Verhalten (Fig. 12): Man sieht in ihnen einige dünne Fäden scheinbar nach dem Nucleolus konvergieren, die zum Teil wenigstens paarweise benachbart verlaufen; außerdem sind ungefähr doppelt so dicke freie Enden in Längsansicht oder im Querschnitt zu sehen, von denen einige sehr dentlich noch eine Längsspalte in der Mitte zeigen. Nun ist es ausgeschlossen, etwa anzunehmen, daß aus den dicken Chromatinschleifen durch Längsspaltung doppelt so viele dünne entstehen, da wir in diesem Fall von größern Keimbläschen und größern Eiern zı kleinern gelangen würden. Daher muß mit der Sicherheit, wie sie eben bei nicht direkter Beobachtung einer Umwandlung möglich ist, geschlossen werden, daß durch paarweises Aneinanderlegen der (wahrscheinlich 16) dünnen Chromatinschleifen die (wahrscheinlich in der 8-Zahl vorhandenen) dicken Schleifen entstehen.

Tit dem Namen Synapsis bezeichnete man früher und auch noch vielfach jetzt jenes Stadium, in welchem das Chromatin einseitig im Kel'n zu einem dichten Knäuel zusammengedrängt ist; ein derartiges Stadium ist in der Oogenese von Plan. gonoc. nicht vorhanden. Neuerdings bezeichnet man ziemlich allgemein mit Synapsis nur den Vorgang der "Konjugation zweier Chromosomen", und wir werden deshalb die eben beschriebenen Stadien auch als Synapsis bezeichmen dïrfen. Die oben erwähnte einseitige Zusammendrängung 
de- (hromitins sheint hei vielen objekten eine Begleiterscheinmg' del farrweisen Zusammenlegung der chromusomen zu sein.

Das scheinbare postsynatische Kerngerïst. Unmittellar nathdem die dümen Füden sich patrweise zu den dicken releinigt haben, ist die Terklebmg so dicht, dab der Doppelcharakter der schleifen nur undentlich erkembar ist (Fig. 13-15. Während der folgenden Terändermngen gelit dann die charakteristische. nach eine:m Punkt der Kermmembran gerichtete Lage der schleifenschenkel rerloren. Wenigstens ist sie zunichst nicht erkembar (Fig. 16-19. Gleichzeitig beginnt die Längsspaltung wieder dentlicher zu werden. Nie beruht darauf, dab die verhältnismäligg großen Microsomen. Welche die dicken Fäden zusammensetzen, in der Längsrichtung des Fadens gespalten erscheinen: zwischen den Microsumen ist die sualtung nicht zu sehen (Fig. 16 u. 17). Dadurch kommt das Bild zustande. als ob die dicken Fäden ans zahlreichen sehr kleinen Ringen oder Kettengliedern zusammengesetzt seien (Fig. 16 и. 17. Yun haben wir gesehen, dal.) die Chromatinschleifen durch pantweises Anemanderlegen ron dïmnen Schleifen entstanden sind, mul wir werden daher auch amehmen müssen, daß die rerhältnismälbig grofien Microsomen, welche die dicken Schleifen zusammenzusetzen scheinen, solanget letztere die Längsspaltumg undentlich zeigen. in Wirklichkeit aus 2 aneinandergelegten kleinen Microsomen bestehen. wie sie in den dümnen Fäden zu erkennen тaren. Der spalt in den gräbern Microsomen bedeutet dam die Trennungslinie zwischen den beiden kleinern, die die erstern zusammensetzen. Inlem sich die beiden Hälften eines Dounelfadens allmählich auf wröhere strecken hin roneinander lösen. geht die geschilderte Kettenform dam wiedter verloren; gleichzeitig strecken sich die EinzelIaiden wieder etwas. und man sieht sie daher wieder ans den kleinen Tricusunen zosiummengeset\%. Es mag hier erwähnt werden, dali die: Mierosomen ïberhant weder alle eine gleichmäbige Gröbe noch eine regelmälige Form haben; aber es ist wohl keine mwahrscheinliche: Annahme, wenn man rermutet. dab das an den lebenden Mirmsinen ander's ist als an den fixierten, geschrumpten und mit Farbstoff' imprägnierten.

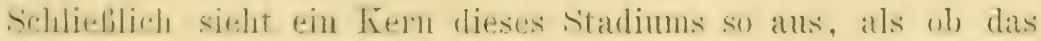

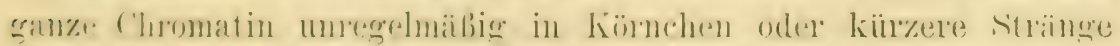

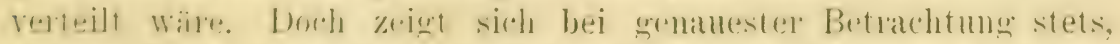

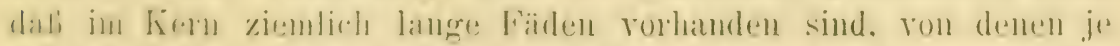

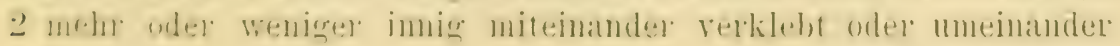


herumgewunden sind, und daß ferner alles Chromatin zu dem einen oder dem andern dieser Fadenpaare gehört. Fig. 19 zeigt einen solchen Kern; in demselben konnten aber nur einzelne Chromatinkörnchen am Rande als nicht zu einem Faden gehörig erkannt werden, und zwar deswegen, weil ihre Fortsetzung durch den Schnitt abgetrennt war. Die Fäden dehnen sich auf diesem und auch auf den folgenden Stadien so weit aus, daß sie an einzelnen Stellen sehr düm sind und ihre Microsomen weit auseinander liegen; dann erscheint namentlich nach Eisenhämatoxylinfärbung ein Faden manchmal unterbrochen, während in Präparaten, die mit BöHмER'schem Hämatoxylin gefärbt sind, stets noch ein Zusammenhang erkennbar ist.

Fine weitere sehr charakteristische Veränderung auf diesem Stadium ist folgende: Alle Chromatinfäden rïcken an die Oberfläche des Kerns und legen sich ihr dicht an (eine Kernmembran ist zulweilen schwach angedeutet sichtbar), während das Kerninnere gar kein Chromatin mehr enthält. Auf einem Schnitt mitten durch ein solches Keimbläschen (Fig. 20) besteht dann scheinbar das Chromatin nur aus einigen Körnchen an der Peripherie. Fig. 21 zeigt ein gleiches Keimbläschen bei verschiedener Einstellung; bei a ist es nach einem Schnitt ungefähr durch die Kernmitte gezeichnet; bei $b$ ist die Hälfte der kugligen Kernoberfläche auf eine Ebene projiziert, und da sieht man die Doppelfäden recht deutlich.

Während dieser Veränderungen hat das Keimbläschen an Größe zugenommen; ebenso der Nucleolus, dessen Vacuolen sehr deutlich hervortreten. Besonders ist aber der Zelleib gewachsen, wie aus einem Vergleich zwischen den verschiedenen Abbildungen hervorgeht. Es muß auch eine Veränderung in dem Plasma vor sich gegangen sein, indem sein Netzwerk grobmaschiger ist (in den Figuren nicht genügend hervorgehoben) und häufig mehrere Vacuolen einschließt. Auch hier findet man häufig Körnchen, die sich mit Eisenhämatoxylin intensiv schwärzen. Es fragt sich, woher dieselben stammen. Ich habe niemals etwas gefunden, was dafür spricht, daß Chromatinpartikelchen aus dem Kern ins Plasma übertreten, doch kann man eine andere Quelle ihrer Entstehung finden. Oft sieht man, wie der Nucleolus kleine mit Eisenhämatoxylin schwärzbare Körperchen abschnürt. Diese treten aus dem Kern aus und sind im Plasma an ihrer Gestalt leicht wieder zu erkennen; außerdem färben sie sich mit BöHMER'schem Hämatoxylin wie der Nucleolus blaß. Durch spätere Deformierung entstehen dann die mehr un- 
regelmäbig geformten Granula. Diese Abschnïrungsvorgänge am Tucleolus sind auf spätern Stadien noch häufiger (Fig: 26).

A usbildung der definitiven Chromosomen der 1. Richtungsspindel. Tachdem die chromatinfäden eine Zeitlang in der oben beschriebenen Treise der Kernoberfläche angelegen und so scheinbar ein zweites. postsynaptisches Spirem gebildet hatten, tritt allmählich wieder eine Kontraktion der Fäden ein. Dadurch werden sie etwas dicker. ferner decken sie sich nicht mehr so häufig, so dal. das ganze Bild über'sichtlicher wird (Fig. 23-27). Man findet dann in jedem Kern 8 Fadenpaare von sehr verschiedener Länğe: die beiden Fäden jedes Paars sind an einzelnen Stellen miteinander rerklebt oder sie sind umeinander hermmgewickelt. Dadurch nehmen die Doppeltäden wiederum das Aussehen einer Kette an. Wobei die Kettenglieder aber gröber sind als bei der frühern Kettenform und nicht so regelmäßig. Die Enden der Einzelfäden sind miteinander rerklebt oder frei. Die Microsomen sind gut erkelmbar. Leider ist es nicht möglich, anf diesem Stadium alle Doppelfäden mit dem Zeichenapparat zu zeichnen, um eine Tergleichung ihrer Größe rorzunehmen; denn die Keimbläschen fallen infolge ilner Grölie meistens in 3 Schnitte, und dabei werden die Dolpelfäden auch mit durchschnitten; außerdem sieht man einige der letztern stets in Terkürzung. In den Einzelfäden tritt nun während ihrer Dickenzunahme eine Längsspaltung auf, die aber fast immer selır undeutlich bleibt; am besten ist sie noch an den freien Fadenenden zu erkennen, namentlich dann, wenn die Enden der Einzelfäden miteinander rerklebt sind; an diesen Stellen weichen die Längshältten oft stark anseinander (Fig. 28). Während der Verkürzung bilden sich die Doppelfäden zu mehr regelmäbigen Figuren um, wie sie in Fig. 27 u. 28 abgebildet sind, zu den bekamnten Fingen. Achtern usw. Oft scheint die Anordnung, welche die dïnnen und die dicken Färlen eines riel frühern Staliums zeigten, auch hier noch erhalten zu sein, wie ans Fig. 22 u. 24 hervorgeht.

Wenn die Eier sich anschicken, die 1. Richtungsspindel anszubilden, dam gehen die Doppelchromosomen anscheinend zirmlich rasch eine anfiallende Veränderung ein; dem man findet nur selten Zwischenstufien. In den Figg. 29-31 sind alle: 8 Doppelehomosomen in Polansialıt abgebildet, nur in Fig. 29 fehlt eins, das im niachsten Schnitt liegt. Sie stellen in virlen fiallen muregelmäbige. meist etwas gectreckte ('hromatinbrocken dar, die nur dis Gemeinsame luaben, dali sie stets ihre bopuehatur durch eine in ilner Längs- 
richtung verlaufende Spaltung zu erkennen geben. In andern Fällen bestehen sie deutlich aus 2 nebeneinander liegenden Stäbchen. Nư selten findet man noch deutliche Ringe, wenigstens bei Polansicht (Fig. 29). In einigen der Doppelchromosomen kann man anch jetzt noch mit Sicherheit die Längsspaltung der Einzelchromosomen feststellen (Fig. 31). Einige Zwischenformen zwischen diesen ausgebildeten Doppelchromosomen und den Ketten der Figg. 26 u. 27 sind in Fig. 28 dargestellt. Die Chromosomen haben also eine sehr starke Verkürzung erfahren, wobei gleichzeitig ihre Zusammensetzung aus Microsomen verloren gegangen ist. Es fragt sich, ob die oben geschilderten unregelmäßigen Doppelchromosomen abnorm oder Kunstprodukte sind; und ich glaube, daß sie in vielen Fällen infolge der Fixierung ihre normale Form von Ringen verloren haben; wahrscheinlich sind sie gerade in diesem Stadium weich und daher durch äußere Einflüsse leicht deformierbar. Bei seitlicher Ansicht der 1. Richtungsspindel (Fig. 32) sieht man öfters die Ringform sehr deutlich und kann feststellen, daß die eine Ringhälfte dem einen und die andere dem gegenïberliegenden Spindelpol zugewandt ist. Sehr gut sind jetzt noch die Größenunterschiede der Doppelchromosomen erkennbar, doch ist es meiner Ansicht nach nicht möglich, konstante Größendifferenzen festzustellen.

Der Nucleolus ist auf diesen Stadien verschwunden; ganz sicher bin ich über sein Schicksal nicht geworden, doch scheint er allmählich immer mehr oder größere Vacuolen in sich zu bilden, bis er sich schließlich ganz auflöst. Manchmal ist er von einer großen Vacuole ganz ausgefüllt bis auf eine dünne, dieselbe umgebende Membran. Im Plasma sind zu dieser Zeit auch alle mit Eisenhämatoxylin färbbaren Granula verschwunden. Eigentümlich ist, daß in manchen Eiern ein Teil des Plasmas, und zwar ein peripher gelegener, sich dunkler färbt als das ïbrige (Fig. 29 u. 31). Es könnte das vielleicht mit der Auflösung der Kernvacuole und dem Eindringen des Kernsafts in das Plasma zusammenhängen, es kann aber ebensogut ein Kunstprodukt sein.

Degeneration von Oocyten.

In jedem Ovarium ist eine sehr große Anzahl von Eiern vorhanden. Selbst wenn ein Tier eine Menge von Eikokons produziert, so können bei der geringen Zahl von Eizellen in einem Kokon doch nur ein Teil aller vorhandenen Eier zur Entwicklung gelangen. Wir sehen daher in jedem Ovarium bald mehr, bald weniger Ei- 
zellen einem Degenerationsprozeb anheimfallen. Dieses Schichsal kamn die Oocyten sowohl auf einem sehr jungen wie auf einem weit rorgeschittenen stadium treffen: letzteres scheint das häufigere zu sein. Ilie Degeneration beginnt im Kern, während das Plasma anfancs noch normal bleibt. Das Chromatin rerliert seine Anordnung. in Färlen und klumpt sich mehr und mehr zusammen; der Nucleolus zerfällt in mehrere stïcke (Fig. 34 a r. b). Dann nimmt auch der' Zelleib an (irïße ab und tärbt sich dunkler, nobei die Kernvacuole immer deutlich sichtbar bleibt, wenn auch in geschrumpftem Zustand (Fig. 3ว̃a). In einigen sehr rorgeschrittenen Fällen ron Degeneration findet man neben den Resten des Nucleolus kein Chromatin mehr. dafïr aber in dem dunklen Plasma zahlreiche. nadelförmige, mit Eisenhämatoxylin geschwärzte Gebilde, deren chemische Natur nicht festoestellt wurle (Fig. 35b). Fig. 33 zeigt schlieblich noch eine Oocyte. deren Plasmaleib noch ganz normal ist, während das Chromatin zu einem mit Tacuolen durchsetzten Klumpen zusammengeballt ist. Im Kiern wie im Plasma sind mehrere Kugeln vorhanden. die sich mit BüH»Er schem Hämatoxylin blaß gefärbt haben; in Eisenhämatoxylinpräparaten findet man ganz ähnliche, dunkel gefïrbte Gebilde: man mu daher wohl annehmen, daß sie ron dem färberisch sich ganz gleich rerhaltenden Nucleolus abstammen. Zuweilen findet man Oocyten mit zusammengeklumptem Chromatin, welche 3 Centrosomen mit Strahlung enthalten. Die Degeneration diurfte wohl durch lokalen Tahrungsmangel bedingt sein. manchmal vielleicht auch durch zu langes Terweilen der Oocyten mit ausgebildeter 1. Richtung:spindel im Ovarium.

Man wird wohl nicht fehlgehen, wemn man amnimmt, dab das bei der Terkleinerung einer Eizelle freiwerdende Mraterial ron giinstiger gestellten benachbarten Fizellen als Nahrung verwertet wird; es muli dies in rerflüssigtem Zustand geschehen, da man eine direkte Aufnahme von degenerierten Eizellen in normale nicht beobachten kann. Die heranwachsenden Embryonen bzw. Fier' der 'Tricladen werden also nicht nur von Dotter\%ellen, d.h. ron spezialisierten bizellen

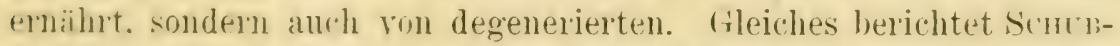

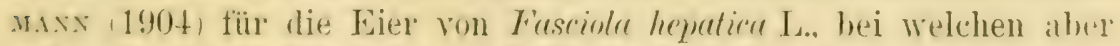
auber den zwei schon genannten Ernährungsformen noch ein sog. Wistiel vorhanden ist und für Zufuhr von Xahrungsmilterial sorgt. In.m.s (1884) nimmt, wie schon oben erwähnt, an, dab die kleinen srhlanken \%ellen in ovarium (Follikeladlen anderer Autoren) degenerierte Eizellen seien, welche ihr Plasma als Xährmaterial an 
andere Eiel abgegeben haben; doch wird diese Auffassung nicht haltbar sein, da die sog. Follikelzellen dann doch auch in ihrem Kern Zeichen von Rückbildung oder Auflösung zeigen mïßten, was nicht der Fall ist.

\section{Zusammenfassung und Deutung der Befunde.}

1. Die Oogonien, welche sich von den im Parenchym des Tiers liegenden großkernigen sog. Stammzellen ableiten, enthalten 16 Chromosomen von verschiedener Größe, ohne daß aber nachweisbar is daß je 2 derselben gleich groß sind. Ihre Chromosomen teilen s: . durch Längsteilung.

2. Die Umwandlung der Tochterchromosomen der letzten Teilung, welche der Bildung der Oocyten vorangeht, in das ruhende Kerngerüst der jüngsten Oocyten konnte nicht verfolgt werden. Ebenso konnten in diesem ruhenden Kerngerüst die einzelnen Chromosomen nich† mehr gesondert erkannt werden. Es sind also in diesem Stadiun die Chromosomen entweder wirklich in einzelne Körnchen zerfallen, oder sie scheinen es nur zu sein, weil der Zusammenhang der letztern nicht nachweisbar ist. Über diese Frage hoffe ich bei der Untersuchung der Spermatogenese des gleichen Objekts Klarheit zu erhalten. Jedenfalls hat diese Chromatinverteilung mit dem auf viel späterm Stadium nach Angabe mehrerer Autoren vorkommenden postsynaptischen Zerfall der Chromosomen nichts zu tun.

3. Aus dem ruhenden Kerngerüst entwickeln sich eine größere Anzahl (wahrscheinlich 16) verschieden lange, dünne Schleifen, deren Schenkel nach einem Punkt konvergieren. Durch paarweises Zusammenlegen von je 2 dünnen Fäden entstehen (wahrscheinlich 8) dicke längsgeteilte Schleifen (Synapsis). Die 16 dünnen Schleifen entsprechen den 16 Chromosomen der Oogonien; die dicken Schleifen sind also Doppelchromosomen.

4. Es legen sich nicht nur die Chromosomen als Ganzes aneinander, sondern es scheint, als ob auch je 2 Microsomen sich aneinanderlegen.

5. Die paarweise verbundenen Fäden entfernen sich dann wieder mehr voneinander; gleichzeitig strecken sie sich und legen sich der Kernoberfläche dicht an, wobei die Anordnung des Chromatins in 8 Doppelfäden undentlicher wird. Es entsteht also, aber nur scheinbar, ein postsynaptischer Zerfall der Doppelchromosomen. Tatsächlich aber bleiben die Chromosomen erhalten. Es spricht nichts. 
dafïr. dab ein Teil des Chromatins sich antlïst oder in das Plasma ausgestolien wird.

i. Ans den Doprelfäden entstehen durch Verkiirzung die s meln wler weniger deutlich ringtürmigen Doppelchromosomen der 1. Rirhtungspindel. In jedem Einzelchromosom tritt eine muleutliche Längspaltmo auf. In der 1 . Richtmosspindel sind die Doppel-hromosumens so orientiert, dab ihre beiden verschiedenen Ringhälffen nach den beiden verschiedenen Polen sehen.

7. Lie Ringe sind den sogen. Tetraden duchats rergleichbar: ?a sir 2 Tremungslinien enthalten, ron denen die eine ganze inomosumen scheilet. die andere lagegen Lüngshälften eines funzelchromosms. Turaussichtlich ist die 1. Teilung eine Reduktionstrilung, indem sie die in der synapsis rereinigten Einzelchromo-

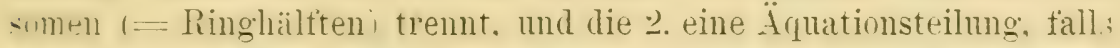
in ihr die schon vorher angedeutete Iä̈nsspaltung der Finzelchromosomen durchgefuhrt wird.

$\therefore$ Der Yucleulus zeigt eine typische Lagerung in Beziehmo. anf lie Chromosumen; sunst aber steht er in keiner erkembaren liezifhug zu dem Chromatin. Die Abschnïrung der rundlichen, in das Ei answandernden Körper kann als ein secretionsprozeb angesehen werden.

Vergleichmit den frïhern Beschreibungen der Eireifung bei den 'Turbellarien.

Bei den Tricladen hat wie oben erwähnt kürzlich erst Matruss 1904, die (1ogenese untersucht mol ist auch auf die Ansbildung del (lnumusumen näher eingegangen. D)ie großen Verschiedenheiten, welche zwishen seinen Ergebnissen - er studierte die Eireifung

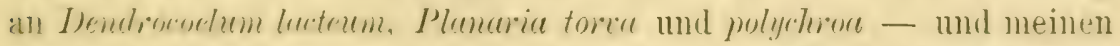
eichrn herrortreten, machen es rrforderlich. austülndicher ant seine, Ii-sultate einzugehen, da wir doch bei der nahen Verwandtschaft all.p. Innorir-Arten einen wenigstens in den Hanptziigen gleichen

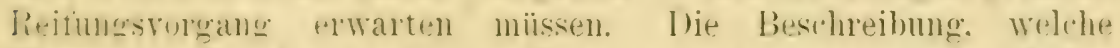
Matrn:-s: fün die das jüngste (Jarim zusammensetzenden Zellen criht. stimmt in der Hauptsache mit meinen Befunden ïberein, wemn anh he unere Ibhildungen etwas rersehieden sind. Er sagt ïbrigens ul.hts dariuber, wh anch typische mitutische Teilungen (der Oogronien)

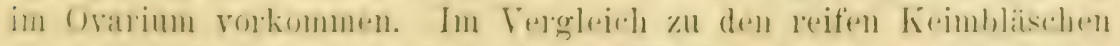

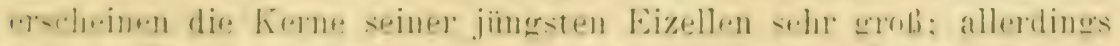
ist es fast unmöglich, einen solchen Vergleich anzustellen, da 
Mattiesen die verschiedenen Figuren, wie er selbst erwähnt, bei verschiedenen V'ergrößerungen gezeichnet hat und diese nicht angibt. Die Eireifung beginnt nun nach MATTIEsen damit, daß sich das Chromatin um den Nucleolus zu einem kompakten Knäuel zusammenballt und sich dabei zu einem oder mehreren sehr langen Fäden vereinigt. Während dieses Stadiums soll der Nucleolus verschwinden, um später wieder zu erscheinen. Dieses Stadium sieht Mattresen als Synapsis an, welche wohl "sozusagen ein Umgießen des Chromatins in neue Formen" bezwecke. Das beschriebene Stadium ist nun, wie aus der weitern Beschreibung hervorgeht, meinem Stadium der dicken Chromatinschleifen homolog und stellt also auch wirklich in Übereinstimmung mit meinen Befunden die Synapsis dar. Es ist nun sehr gut möglich, daß sich bei den von Mattiesen untersuchten Arten die dicken Chromatinschleifen zu einem kompakten Kinäuel zusammendrängen; allerdings habe ich davon bei Dendrococlum lacteum, welches ich nebenbei anch mit untersucht habe, nichts gesehen. Es ist aber auch möglich, daß die beschriebenen kompakten Knäuel Degenerationsprozesse oder Kunstprodukte sind, und Matтiesen hält dieses selbst ja bei einigen Zellen, die 2 solche Knäuel enthalten, nicht für ausgeschlossen. Jedenfalls aber müssen wir in der sogen. Synapsis einen andern Vorgang suchen als eine Umgießung des Chromatins in neue Formen. Alle frühern Stadien der Eireifung bei Plan. gon., z. B. das der dünnen Schleifen, welches ich auch bei Dendrocoelum lacteum fand, beschreibt Matriesex nicht.

Der weitere Reifungsprozeß soll nun darin bestehen, daß der Chromatinknänel sich wieder lockert und zu einem typischen Spiremstadium überleitet. Darauf soll eine Längsspaltung des Fadens auftreten und zwar so, daß sie in bestimmten Abständen unterbleibt, so daß eine Kette entsteht. Die Kettenglieder, deren Zahl meistens um 16 herum betragen soll, lösen sich damn voneinander und bilden sich zu einzeln liegenden Vierergruppen um, während andere solcher Vierergruppen zu langgestreckten Gruppen vereinigt bleiben. Diese Beschreibung paßt ziemlich genau auf die postsynaptischen Stadien der Eireifung bei Plan. gon. mit den Ausnahmen, daß hier erstens kein typisches Spirem entsteht, sondern die Schleifen gesondert bleiben, daß zweitens die Kettenglieder sich nicht voneinander lösen, sondern die Doppelfäden erhalten bleiben, und daß drittens die Kettenglieder sich weder zu 'Tetraden umbilden noch überhaupt jemals irgendwie in konstanter Zahl auftreten. Die beschriebenen Tetraden sollen nun aber nach MatTiesen den Vierergruppen im gewöhnlichen Sinne 
nicht entiprechen. sondern es sollen aus allen diesen scheinbaren Tetraden. suwohl den zu Gruppen rereinigten wie den einzeln liegenden.

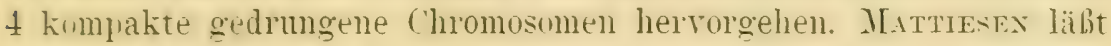
unaufgeklärt. Was die Tetradenbildung bedeuten solle. Zu erwähnen ist. dab er ebensowenig wie ich den Austritt ron ('hromatin aus dem Kern oder die Auflösung ron chromatin im Kernsaft beobachtet hat. Während der Bildung der 1. Äquatorialplatte sollen nun die definitiven Chromosomen, deren es wie bei meinem Objekt \& sind. durch Querteilung aus den rorher rorhaudenen 4 hervorgehen: doch beruht die Angabe nur anf der Beobachtung. dab die ('hromosomen während ihrer Termehrung ron 4 anf \& rerschiedene Länge haben. Bei Plan. gon. ist gar nichts zu selten. Was diesen Torgängen ähnelt: wir haben daselbst ron rornherein 8 Iroppelfäden, die sich zu den \& Ringen der 1. Richtungsspindel umwandeln. Wan darf daher wohl annehmen, dab Mat'Tesex sich durch eine entfernte Ähnlichkeit einzelner Kettenglieder mit Tetraden und durch Kunstprodukte hat täuschen lassen. Auf die ebenfalls einzein dastehende Art und Teise der beiden Reifeteilungen selbst. Welche Matmisex beschreibt. kann hier nicht eingegangen werden. da ich sie in der rorliegenden Arbeit nicht nachgeprïft habe.

Das. was N. M. Stevexs (1904, über die Eireifung ron Planaria simplirissima bringt. ist nur wenig; sie findet eine 2malige Lïngsteilung der 'hromosomen und auftallenderweise bald 6 . bald 3 chromosonnen oder anch Mittelzahlen. Über die frühern Stadien der Eireifung elwähnt Stevexs nichts.

Die Rrifungsworänge bei den Polycladen dürfen wir natülich nicht ohne weiteres mit denen der Tricladen vergleichen. denn es ist nirht ansqeschlusen, dab sie bei den beiden Abteilungen der Jendroülen etwas verschieden verliuft. I)a wir aber in den Arbeiten verschiedener Autoren Figuren finden, welche sehr ähnlich. denen bei Plon. gom. sind. so diurfte es doch angebuacht sein. zu nutersuchen, wh die ringangs uwilnte Verschiedenheit zwischen ihen und moinen eignen fiesultaten violleicht nioht daraut

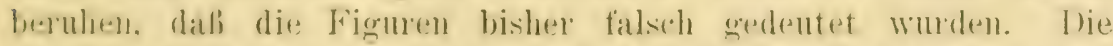
friilarn Barbeiter der Eireifumg bei den Polycladen Vix wan

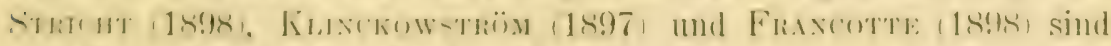
and die vorbereitenden stadien der bireitung so gut wir nirht rin-

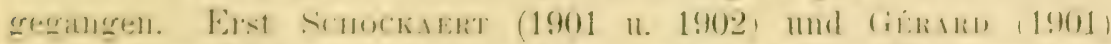

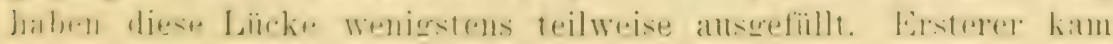


zul folgenden Ergebnissen: Er beobachtete in den jüngsten Oocyten eine Anzahl (wahrscheinlich 9) Kernschlingen, welche aus einer Doppelreihe von Granula bestehen und nach einem Pol des Kerns gerichtet sind. Wir haben hier also fast genau dasselbe Bild wie bei Plan. gon., Sсноckafrt deutet die Schlingen aber ganz ander's. Nach seiner Ansicht sind die 9 Schlingen direkt aus den 18 Tochterchromosomen der letzten oogonialen Teilung hervorgegangen und zwar dadurch, daß sich je 2 'Tochterchromosomen mit je einem Ende rereinigt haben. Die Zusammensetzung der 9 Schleifen aus einer Doppelreihe von Granula sei das Resultat einer Längsspaltung: Nun hat Schockaert die Teilung der Oogonien nicht beobachtet, und deshalb ist seine Deutmng der eben beschriebenen Zellen als jüngste Oocyten nicht genügend begründet. Ich halte es demnach nicht für ausgeschlossen, daß SchockaERT die wirklich jüngsten Stadien der Oocyten nicht gefunden hat, besonders also das Stadium der dünnen Chromatinschleifen und die Synapsis. Nun beschreibt Schockaert weiter, daß die 9 längsgespaltenen Chromatinschleifen vollkommen zerfallen, so daß zwischen ihnen und dem spätern Kernfaden keinerlei morphologischer Zusammenhang bestehe. Der spätere Kernfaden bilde sich vielmehr dadurch heraus, daß eine Anzahl Granula sich zu einem Faden aneinanderreihen, während andere Körnchen isoliert bleiben. Von dem neuentstandenen Faden zerfallen wiederum einige Stiicke, andere bleiben erhalten, wachsen heran und teilen sich der Länge nach; diese Längsteilung verschwindet später zwar wieder, kamn aber vielleicht der Torläufer der Längsteilung der Chromosomen während der 2. Reifungsteilung sein. Die Befunde einer frühen Längsteilung stimmen also mit meinen eignen überein, nicht aber der Zerfall, und sogar ein zweimaliger 7erfall des Chromatins. Bei Planaria gonocephala ist nichts derartiges zu beobachten. Vorausgesetzt also, daß der Reifungsprozeß bei den Polycladen und den Tricladen wenigstens ähnlich verläuft, muß man annehmen, daß Schockaent übersehen hat, daß alle die scheinbar einzeln liegenden Körnchen doch tatsächlich zu einem Faden vereinigt bleiben. Es mag dies mit daran liegen, daß Schockaent fast ausschließlich mit Eisenhämatoxylin gefärbt hat; und nach meinen Erfahrungen werden bei der Reduktion der Färbung mit Eisensalzlösung oft kleinste Partikelchen, welche den Zusammenhang mit den gröBern darstellen, entfärbt und daher unsichtbar. Nun findet aber Schockanrt auch Doppelchromosomen, deren Komponenten sich bei der 1 . Reifungsteilung voneinander trennen. Diese 
sollen aber dadurch entstehen. dab der einfache Faden sich wie ein doppelt genommener Bindfaden doppelt legt und daher ans 2 schenkeln besteht. die sich aneinanderlegen und umeinanderwickeln und sich damn segmentieren rgl. sein schema. Ich mu gestehen. dab anch ich lange Zeit dieses bei Plan. yon. für verwirklicht gehalten habe. bis niir die jüngsten stadien der Oocyten auffielen und bis ich erkannte. dab die Schenkel des Doppelfadens durch Auseinanderweichen der Lïngshälften der dicken Schleifen entstanden sind.

Grindin , 1901, hat bei Prostheccrucus vittutus, Stylochus und Leptoplenir im wesentlichen dasselbe gefunden wie Schocksert bei seinem Objekt. und es ist daher nicht nötig; näher auf seine Beschreibung. einzugehen. Auffallend ist, clab er die polare Anordnung der Kernschleifen. die S'носканiт selı gut zeichnet, nicht gefunden hat.

Über den Reifungsprozel in den Eiern der Rhabdocölen besitzen wir nur eine ganz kurze Angabe ron Bressust (190t); (lerselbe fiand in der 2. Richtungsspindel des Lies von Mesostomm chirmbergi 10 Chromosomen ron etwa Vförmiger Gestalt. 5 ron diesen sullen in der Eizelle verbleiben, die andern in das 2. Richtungslörperchen eintreten. Danach wiirde also der Reifungsmodus in den Eiern der Rhabdocölen wesentlich ron dem bei unserm Objekt rerschieden sein: doch diurfte erst die ron Bressuau in Aussicht gestellte ansführlichere Arbeit abzuwarten sein.

E: ist hier nicht meine Aufgabe, eingehender die Literatur über Feductionsteilung zu besprechen; es sei aber kurz herrorgehoben. dal die Torgänge der Eireifung bei Plan.gon. nicht allein dastehen. sonder'n dal. :ilnnlirhes schon mehrfach gefunden wurde. Tm nur eins herauszunceifen. möchte ich anf die große Ähnlichkeit meiner Befunde mit den Reifungsvorgängen bei Dy,rine und Spinax hinweistr. die A. u. K. F. Scminam (1904) beschrieben haben.

Zun sichlul. s.i mir gestattet. Hern Geheimat Prof. I)r. Wrssmax: meinen her\%lihen Dank dafür ausansprechen, dab er. seitdem ich in spintem Institut weile, in mir das Interesse für die kernthenwtischen Fragen erweckt und wachgehalten und meine Arbeit mit Interesse verfolgt hat. 


\section{Literaturverzeichnis.}

Bresstau, E., 1904, Beiträge zur Entwicklungsgeschichte der Turbellarien, I. Die Entwicklung der Rhabdocölen und Alloiocölen, in: Z. wiss. Zool., Vol. 76.

Curtis, W. C., 1900, On the reproductive system of Planaria simplicissima, a new species, in: Zool. Jahrb., Vol. 14, Anat.

-, 1902, The life history, the normal fission and the reproductive organs of Planaria maculata, in: Proc. Boston Soc. nat. Hist., Vol. 30, No. 7 .

Fraxcotte, P., 1898, Recherches sur la maturation, la fécondation et la segmentation chez les Polyclades, in: Arch. Zool. expér. (3), Vol. 6.

Gérard, O., 1901, L'ovocyte de premier ordre du Prostheceraeus vittatus, in: Cellule, Vol. 18.

JiJniA, J., 1884, Untersuchungen über den Bau und die Entwicklungsgeschichte der Süsswasser-Dendrocoelen (Tricladen), in: Z. wiss. Zool., Vol. 40.

Keltier, J., 1894, Die ungeschlechtliche Fortpflanzung der Süsswasserturbellarien, in: Jena. Z. Naturw., Vol. 28.

Kenned, J., 1879, Die in Deutschland gefundenen Landplanarien Rhynchodesmus terrestris O. F. MÜLL. und Geodesmus bilineatus MEtschn., in: Arb. zool. Inst. Würzburg, Vol. 5.

LANG, A., 1884, Die Polycladen des Golfes von Neapel, in: Fauna Flora Golf Neapel, Monogr. 11.

Mrattiesen, E., 1904, Die Eireifung und Befruchtung der Süsswasserdendrocoelen, in: Zool. Anz., Vol. 27.

-, 1904, Ein Beitrag zur Embryologie der Süsswasserdendrocoelen, in: Z. wiss. Zool., Vol. 77.

Moseley, H. W., 1874, On the anatomy and histology of the Landplanarians of Ceylon, with some accounts of their habits etc., in: Phil. Trans. Roy. Soc. London.

Petrunkewitsch, A., 1901, Die Richtungskörper und ihr Schicksal im befruchteten und unbefruchteten Bienenei, in: Zool. Jahrb., Vol. 14, Anat.

Schockaert, R., 1900, Nouvelles recherches sur la maturation de l'ovocyte de premier ordre de Thysanozoon Brocchi, in: Anat. Anz., Vol. 18.

_, 1901, L'ovogénèse chez le Thysanozoon Brocchi, I. Partie, in: Cellule, Vol. 18.

—, 1901, L'ovogénèse chez le Thysanozoon Brocchi, II. Partie, ibid., Vol. 20. 
Schrester, A. und K. E., 1904, Die Reifungsteilungen bei den Wirbeltieren, in: Anat. Anz., Tol. 24.

Stritis, X. M., 1904, On the germ cells and the embryology of Planaria simplicissima, in: Proc. Acad. nat. Sc. Philadelphia.

Thx IIEli Stricht, 1898. La formation des deux globules polaires et l'apparition des spermocentres dans l'oeuf de Thysanozoon, in: Arch. Biol., Tol. 15.

\section{Erkliirung der Abbildungen.}

Alle Figuren sind mit dem ABBÉ'schen Zeichenapparat auf Objekt. tischhöhe entworfen bei" einer Tubuslänge von $160 \mathrm{~mm}$. Bei Fig. 1 wurde ZEIs: Apochrom. Immers. 1,5 und Comp. Osular 2 angewandt, bei allen andern Zerss Apochrom. Immers. 1,5 und Comp. Ocular 6.

$$
\text { Tafel } 1 \text {. }
$$

Fig. 1. Schnitt durch Ovarium. Zwischen den verschieden alten Eizellen 6 dunkel gefärbte Dotterzellen.

Fig. 2. Oogonie, Monaster in Polansicht; 16 Chromosomen.

Fig. 3. Jüngste Oocyte. Kern im Ruhezustand.

Fig. 4. Anordnung der Microsomen zu Fädchen.

Fig. 5. Dasselbe in vorgeschrittnerm Stadium.

Fig. 6 und 7. Stadium der dünnen Chromatinschleifen, von der Seite gesehen.

Fig. 8. Dasselbe von unten gesehen, $d$, $h$, von der Seite, nach welcher die Schleifenschenkel konvergieren.

Fig. 9. Dasselle: Schleifen anscheinend unregelmälig angeordnet; schräge Ansicht.

Fig. 10. Einigre dünue Chromatinfäden verlaufen paarweise parallel. Es sinrl nur einige Schleifen hzw. T'eile von solchen eingezeichnet.

Fig. 11. Kern mit dünnen und mit dicken Chromatinschleifen.

Fig. 12. Dasselbe, von der Seite gesehen, nach welcher die śchleifenschenkel konvergieren. Die dicken Fäden zeigen Andeutung einer Lä̈ngs spaltung, die dünnen verlaufen paarweise parallel.

Fig. 13. Stadium der dicken Chromatinfirlen; von der Seite gesehen.

Fig. 14. Dasselbe, schräg gesehen.

Fï. 15. Dasselthe, von der Seite gesehen, nach welcher die Schleifenschenkel konvergieren. Isingsspaltung schwer sichtbar.

Fig. 16 u. 17. Wiederauftreten der Lainesspaltung in den dicken Füden, welche dadurch das Aussehen einer Kette mit kleinen Ketten- 
gliedern annehmen. Es sind nur Teile der jetzt mehr unregelmäßig angeordneten Fäden gezeichnet.

Fig. 18. Weitere Trennung der Einzelfäden.

Fig. 19. Dasselbe, weiter vorgeschrittenes Stadium; scheinbarer Zerfall der Fäden.

Fig. 20. Durchschnitt durch den Kernmittelpunkt. Chromatin peripher angeordnet; Nucleolus mit Vacuolen.

Fig. 21. Ein Kern bei verschiedener Einstellung: a Schnitt durch die Kernmitte, b die eine Hälfte der Kernoberfläche auf eine Ebene projiziert.

Fig. 22. Kernoberfläche eingestellt (wie Fig. 23-26). Fäden zeigen noch eine ähnliche Anordnung wie in Fig. 15.

Fig. 23. Doppelfäden, sehr lang und dünn.

Fig. 24. Doppelfäden, etwas kontrahiert.

\section{Tafel 2.}

Fig. 25. Doppelfäden in Form von unregelmäBigen Ketten, Ringen usw. Größenunterschiede.

Fig. 26. Dasselbe; Nucleolus schnürt einen kugligen Körper ab.

Fig. 27. Doppelfäden bilden mehr regelmäßige Figuren (Ketten, Ringe, Achter).

Fig. 28. 3 einzelne stark kontrahierte Doppelchromosomen. Längsspaltung in den Einzelchromosomen sichtbar.

Fig. 29-31. Äquatorialplatte der 1. Richtungsspindel. In Fig. 29 fehlt ein Doppelchromosom, das im Nachbarschnitt liegt. Chromosomen stark verkleinert.

Fig. 32. 1. Richtungsspindel in Seitenansicht; 3 Doppelchromosomen sichtbar. Die achromatische Figur wegen Färbung mit BöHıIER'schem Hämatoxylin nur teilweise sichtbar.

Fig. 33. Chromatin zusammengeklumpt; Nucleolus zerfallen. Degenerationsstadium.

Fig. 34. Degenerierende Kerne.

Fig. 35. Degenerierte und stark verkleinerte Oocyten. In $b$ nadelförmige Gebilde. 


\section{Lebenslauf.}

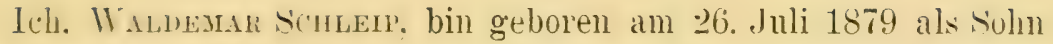
des I'rivatmamns ('anl Schleip zu Freiburg' i. Br., besuchte daselbst ron Ostern 188ว̃-1888 die Tolksschule, sodam 9 Jahre hindurch das Gymnasium. Welches ich 1898 mit dem Reifezengnis verlieb. Meine Studienzeit verbrachte ich in Freiburg i. Br. und in München. Im .Tahr 1903 bestand ich das medizinische Staatsexamen, und im folgenden .Tahre erlangte ich das medizinische Doktordiplom. Seit Frïhjahr 1903 bin ich Assistent am Zoologischen Institut der Lniversität Freiburg i, Bl: 




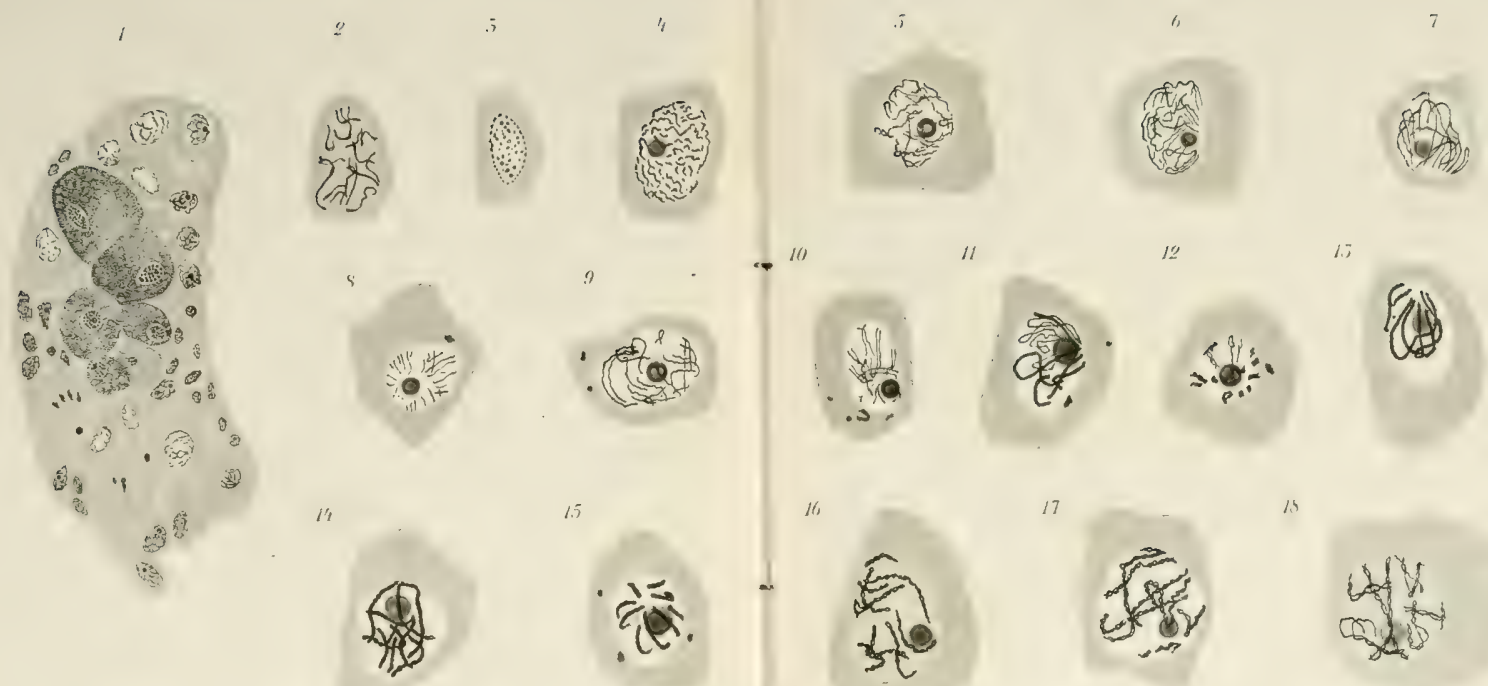

(2)

1.5

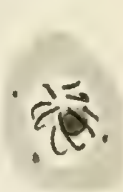

16.

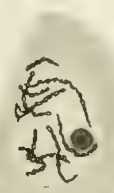

17

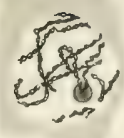

cof
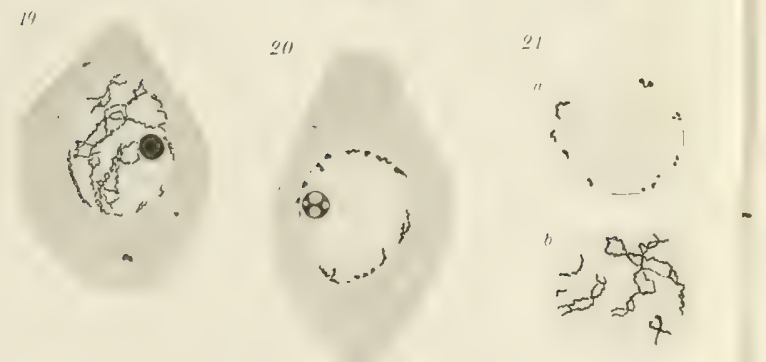

22

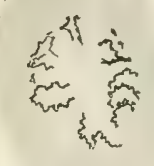
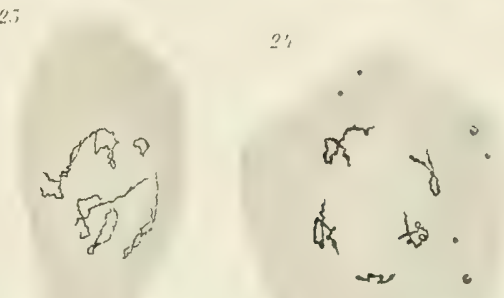


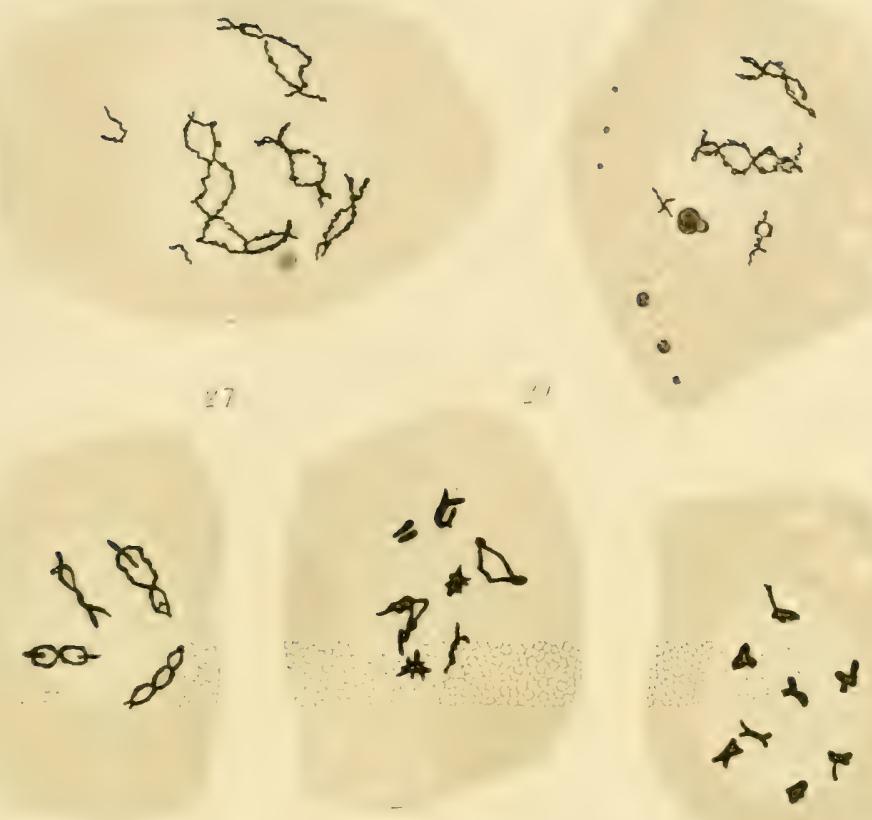

$\phi \varnothing$

$x^{x}+x^{x}$

it

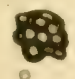

.

(1)

ฮั

-

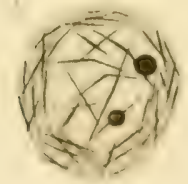









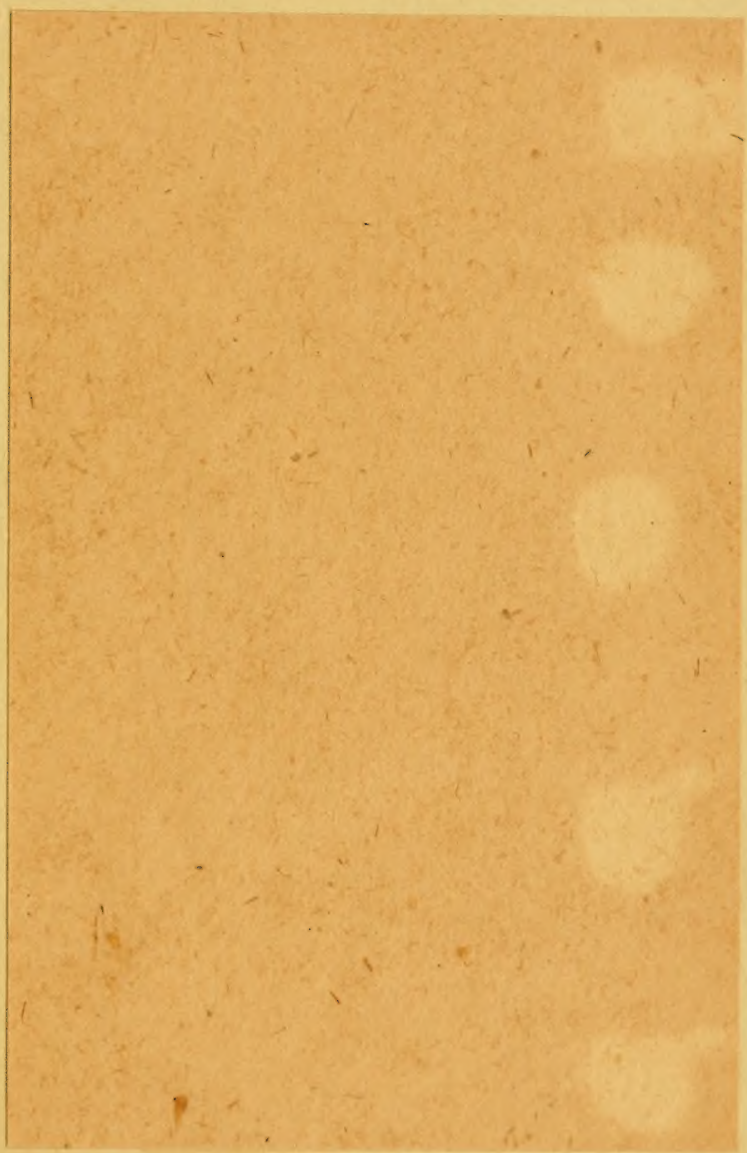




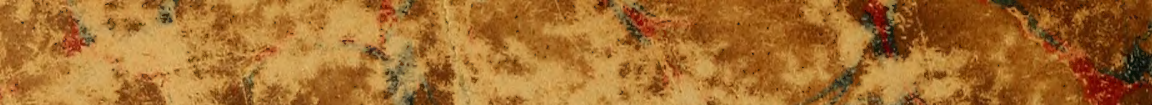
$2.0304=340$

$2+3 x^{2}-4 y^{2}-2 x+3$

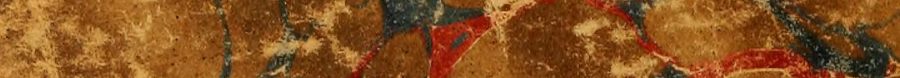

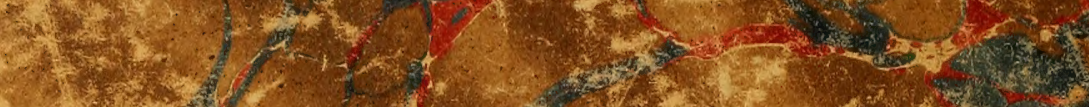

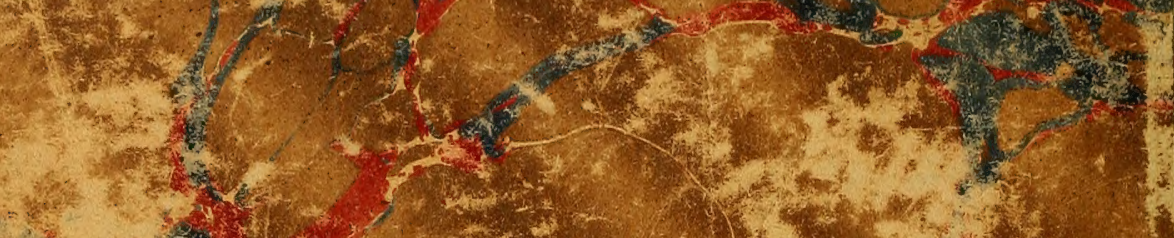
$4 x+2=x^{2}=4$

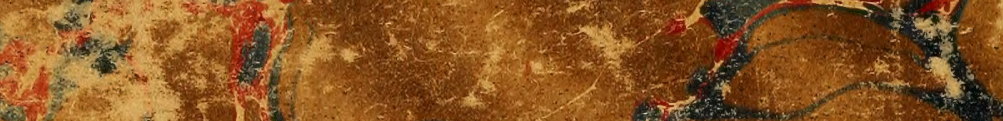
( 381

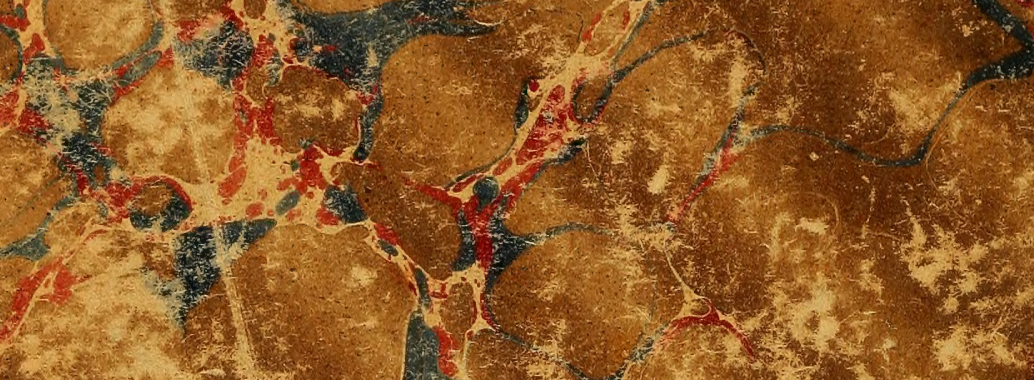

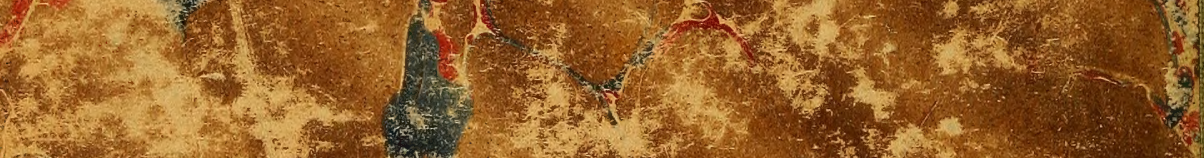

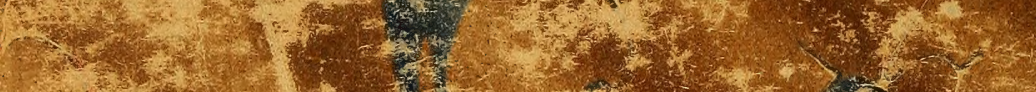

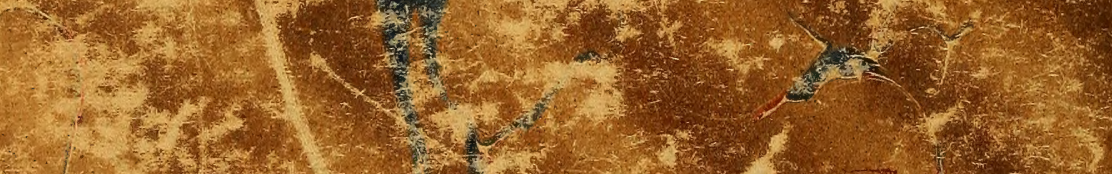

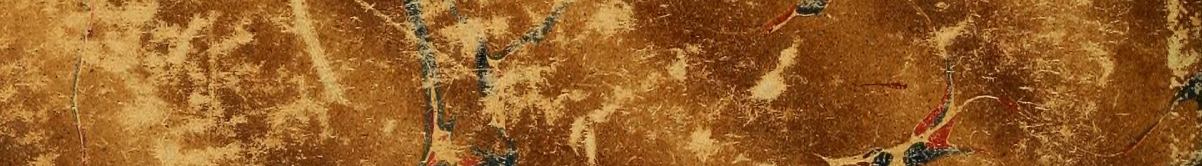

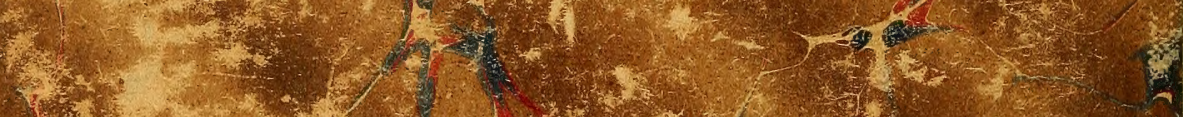

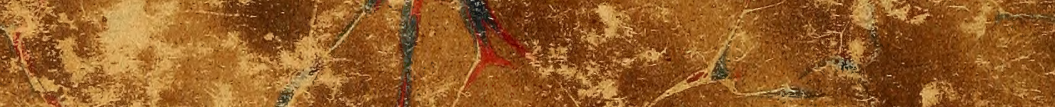

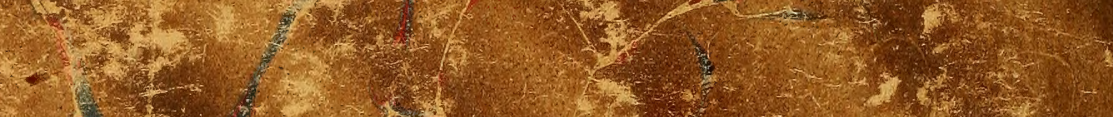

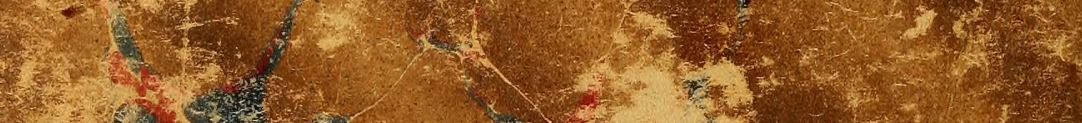

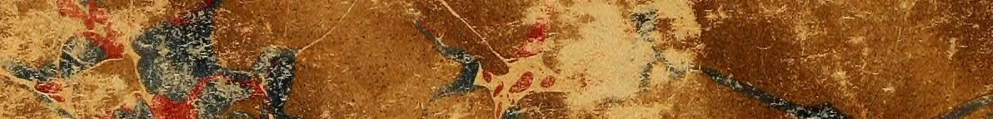

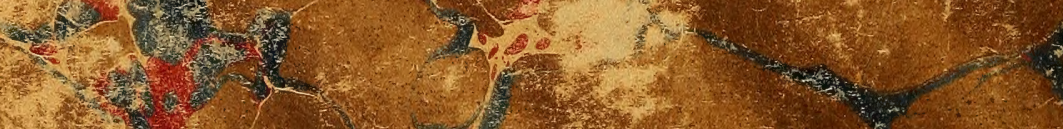
4.

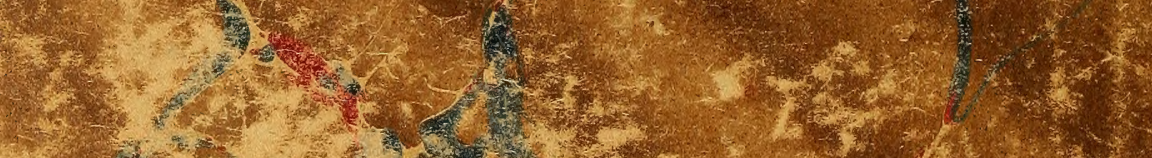
$x^{2} y=3 y-30$

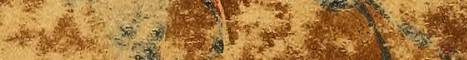

